\title{
Ninth Annual Meeting of the Czechoslovak Society for Microbiology
}

\author{
Starý Smokovec - Vysoké Tatry, May 5-7, 1971
}

\section{Abstracts of Communications}

\author{
GENERAL SECTION
}

The Direct Conversion of Germinating Spores of Bacillus cereus to Non-growing Semirefractile Cellular Types by Combined Starvation and Shift-up Treatments. J. ŠTASTNÁ, J. CÁsLAVSKá, V. VINTER, Institute of Microbiology, Czechoslovak Academy of Sciences, Prague.

Two main types of cytodifferentiation of sporeformers after spore germination have usually been studied: (1) Sporogenesis after a few divisions in complete nutrient media (macrocycle sporogenesis) and (2) Sporogenesis after a few postgerminative changes only without an intervening cell division (microcycle sporogenesis). This latter shortened developmental cycle may be induced: (a) by a limitation of some components in a nutrient medium, or (b) by the shift-down treatment in the early elongation stage of postgerminative spore development. Both above-mentioned processes leading to the spore formation include the sporangial stage of development. A new cellular type has been found recently: semi- or fully refractile cells with thick cell walls. They are formed directly from the germinated spore without typical vegetative and/or sporangial stages. The formation of these forms could be induced by a sequence of three basic treatments: first, the germination of spores in the presence of germination stimulants only (L-alanine, glucose and adenosine), second, short or long-termed (1-3 hours) exposure of germinated spores to starvation in this medium, and third, resuming the level of complex nutrients. During the third treatment the resulting cellular type was determined by the aeration rate, pH value and the qualitative composition of the medium. Further details will be discussed concerning the biochemical, physiological and morphological properties of this non-spore type of sporeformers.

The Energetics of Growing and Non-growing Microbial Cells. L. KovÁ, E. BöHMEROVÁ, Institute of Biochemistry, Komenský University, Bratislava.

Yeast Saccharomyces cerevisiae was used as a model organism for the study of the energetics of the microbial cell. The following data indicate that catabolic and anabolic processes are effec. tively coupled in growing. cells: (a) Molar growth yield was 13 times higher aerobically than anaerobically, reflecting the formation of 2 moles of ATP and 28 moles ATP per mole of glucose under aerobic and anaerobic conditions, respectively. (b) Approximately $10.5 \mathrm{~g}$ dry weight cells were formed per 1 mole ATP produced by catabolism corresponding to the Elsden constant found universally with other microorganisms. On the other hand, the following data indicate that the coupling process is looser in non-growing cells: (a) Catabolism of glucose is high in resting ceils and is only doubled in the presence of uncoupling agents. (b) On blocking oxidative phosphorylation with oligomycin, respiration is inhibited by only $60 \%$. (a) The extent of the Pasteur effect reflects a relatively inefficient aerobic phosphorylation. (d) Only a small portion of energy liberated by glucose catabolism is used for the synthesis of cellular polysaccharides. The loose coupling in non-growing cells may be due to (a) Intrinsically higher proton permeability of yeast mitochondria; (b) formation of endogenous uncoupling agents in non-growing cells; (c) activation of endogenous ATPases; (d) cyclic ion transport across cellular membranes. 
Non-specific Control in the Induced Synthesis of Respiratory Nitrate Reductase and Tetrathionate Reductase in Non-growing and Growing Bacteria. F. Kaprálex, J. Doležal, I. Drahoñovská, Department of Microbiology, Faculty of Sciences, Charles University, Prague.

It is known that respiratory nitrate reductase and tetrathionate reductase, two terminal enzymes of two anaerobic respiratory chains are induced by their own substrates, nitrate and tetrathionate, respectively. The synthesis of both is repressed by oxygen and oxygen also inhibits their activity. It was found that the synthesis of both enzymes is moreover governed by another rather non-specific regulatory pattern. Citrobacter was grown in a complex medium containing lactose as a carbon source and without an inducer. The cells from the stationary phase of growth were harvested, washed and resuspended in a buffer solution containing pyruvate as a source of electrons, tetrathionate or nitrate serving as inducers. During anaerobic incubation of these non-growing cells the synthesis of the respective enzyme occurred. When the same procedure was applied to cells pregrown on glucose the induction did not take place at all or was considerably lower. The assay of enzyme activities in cell-free extracts of both kinds of cells verified the above results. Thus, the glucose grown cells were partially blocked in the realization of induction. The phenomen differed from catabolite repression as similar results were obtained when glucose supplanted pyruvate during the induction, i.e. glucose itself did not prevent the induction. Moreover, both kinds of resting cells were able to synthesize $\beta$-galactosidase to the same extent. The rate of tetrathionate and nitrate reduction by bacterial cells growing anaerobically on lactose or glucose in the presence of the inducer was determined in further experiments. The specific metabolic rate of tetrathionate and nitrate reduction was two-fold in cells growing on lactose as compared with that in cells growing on glucose. The activity of both reductases was also determined in cell-free extracts of these cells and plotted as a differential rate of the enzyme synthesis. Both activities were significantly lower in cells growing on glucose.

The Effect of Tetrathionate Respiration on the Biosynthesis of some Oxidation-reduction Enzymes in Growing Bacteria. M. PoLÁČková, F. KaPRÁLEK, Department of Microbiology, Faculty of Sciences Charles University, Prague.

Many facultative anaerobic bacteria reduce tetrathionate to thiosulphate enzymically under anaerobic conditions. This inducible activity is physiologically analogous with the reduction of nitrate to nitrite in anaerobic nitrate respiration.
It was the aim of the present work to establish whether the tetrathionate respiration changes the intracellular level of some oxidation-reduction enzymes as in the case of oxygen and nitrate respiration. Citrobacter was grown in a liquid complex medium with fructose under four experimental conditions: (a) anaerobically without an external elextron acceptor; (b) anaerobically with tetrathionate; (c) anaerobically with nitrate; (d) aerobically. The cells were harvested from the exponential phase of growth, washed and disrupted by ultrasonic oscillation. Specific activities of five enzymes were determined in crude cell-free extracts. (1) Hydrogenase showed the following relative specific activities under the four experimental conditions used (A:B : C : D) $100: 34: 5: 1$. (2) Hydrogenylase specific activities were 100 : $0: 0: 0$. (3) Formate dehydrogenase specific activities equaled $15: 46: 60: 100$. (4) Formate oxidase system had a relative activity of $20: 40$ : $20: 100$. (5) $\mathrm{NADH}_{2}$ oxidase activities were $24: 30: 31: 100$. It follows that the tetrathionate respiration resembles the oxygen respiration in the ability to repress the synthesis of some typical anaerobic enzymes (hydrogenase, hydrogenylase) but cannot induce the synthesis of aerobic enzyme systems (formate oxidase, $\mathrm{NADH}_{2}$ oxidase).

Some Physiological and Metabolic Changes in Cells of Escherichia coli during their Exposure to Nongrowth Conditions. D. TóTH, Institute of Experimental Hygiene, Slovak Academy of Sciences, Bratislava.

Cells of Escherichia coli B taken from the loga: rithmic phase of growth on MPB or a synthetic medium SyB (ammonium sulphate, glucose and minerals) retained their reproductive capacity for more than 30 days when cultivated statically in the $\mathrm{SyB} \mathrm{N}^{-} \mathrm{C}^{-}$(i.e. $\mathrm{C}$ - and $\mathrm{N}$-free medium) at 25 C. A decrease to $50 \%$ occurred only after 46 days. The number of cells capable of reproduction did not change over 20 days when the cells were cultivated at $37 \mathrm{C}(50 \%$ on the 25 th day). In the SyB $\mathrm{N}^{-}$medium the cells retained their reproductive capacity for a longer time, i.e. glucose had a positive effect. The number of cells capable of reproduction was determined by the MPB agar plate technique in both cases. The restoration of growth of thus maintained cells on the liquid SyB medium was preceded by adaptation indicated by a lag period, the interval of which was proportional to the time of the previous cultivation under nongrowth conditions when practically all cells still retained their reproductive capacity. The transhydrogenation capacity (the reduction activity in the presence of glucose or glutamate and without these substrates as detected with TTC) decreased considerably during the initial period of this interval. The observed decrease of the respiration 
activity was slower and stabilized at $10-30 \%$ of the initial intensity. This held both for endogenous respiration and respiration in the $\mathrm{SyB} \mathrm{N}^{-}$or $\mathrm{SyB}$ media $\left(Q_{{ }_{2}}\right.$ values calculated from the oxygen consumption during the first hour of the measure. ment). A further decrease of the respiration intensity was found to be correlated with a decrease in the number of cells capable of reproduction. Considerable differences in numbers of cells capable in reproduction after spraying on MPB and SyB agar plates were observed (much lower values were obtained in the latter case). Glutamic acid was found to have a positive effect when added to the SyB medium.

Changes in the Content of Sulphhydryl Groups in Relation to the Course of Cell Division in Escherichia coli. J. Moravová, L. Homolka, V. Greplová, Department of Microbiology, Faculty of Sciences, Charles University, Prague.

The division cycle of bacteria terminates by the so-called cytokinesis, the most important feature of which is the preparation and formation of the transverse septum (physiological division) facilitating the separation proper of daughter cells of the cell division was induced by low concen tration of penicillin (PNC); the inhibition $\mathbf{w a}_{\mathrm{s}}^{-}$ reversed by adding penicillinase.

Concentration Changes of SH.groups in Bacteria after Treatment with Various Metabolic Inhibitors. O. Ondrejučková, M. Miko, L. Drobnica, Faculty of Chemistry, Slovak Polytechnic University, Bratislava.

The concentration of protein and non-protein sulphhydryl groups (P-SH and NP-SH) was determined in resting and growing cells of Escherichia coli B and Bacillus subtilis treated with different types of antibacterial substances with a more or less known mechanism of action. The effect of compounds mainly inhibiting processes of carbonenergy metabolism, compounds affecting more selectively protein synthesis, synthesis of nucleic acids and substances damaging the cytoplasmic membrane was investigated. Compounds directly blocking P-SH as well as NP-SH groups, e.g. monoiodacetate, phenyl-mercuriacetate and various natural and synthetic isothiocyanates were included in the first group of inhibitors. The concentration of SH-groups was determined after centrifugation and ultrasonic disintegration of cells using the reaction with 5,5-dithio-bis-(2-nitro-

$$
\begin{gathered}
\text { Log. } \\
\text { phase }
\end{gathered}
$$
Stationary phase

PNC filaments

Reversion of division

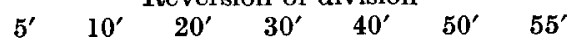

nmol SH

per mg protein
263

135
365
368
354
305
260
239

The inhibition of the cell division resulted in an increase in the content of SH-groups, whereas the reversion was accompanied by a decrease. The reversion of the division of filamentous forms was observed 60 min after adding penicillinase.

(physical division) at a time when its growth is finished. In addition, in Gram-negative bacteria cytokinesis includes constrietion of the cell at the site of separation. A sudden change in the orientation of growth of the eytoplasmic membrane in the centripetal direction signalizing the beginning of cytokinesis and the constriction accompanying the division of Gram-negative bacteria led to the assumption that a contractile protein present in two alternating states, contraction and relaxation, is responsible for this process. Therefore the function of SH-groups, the role of which is apparent in the structure of protein molecules, was studied and their amount related to individual stages of cell division. The assay of SH-groups was based on the reaction with fluorescein-mercuriacetate. A fraction obtained by centrifugation of a cell-free homogenate at $10,000 \times g$ (supernatant) was used for the determination. Considerable changes in the content of SH-groups in cells from different phases of growth and division were found. The inhibition benzoic acid). Analogous experiments were performed with the Ehrlich Ascites Carcinoma cells (EAC). The cells were exposed in a Krebs-Ringer phosphate solution containing glucose and ascitis serum. A considerable decrease in the concentration of P-SH was found after the incubation of the cells with the compounds directly reacting with SH-groups and with the compounds damaging the cytoplasmic membrane. Polymyxin B causing more than $50 \%$ decrease of the P.SH concentration in Escherichia coli $B$ cultivated for only $5 \mathrm{~min}$ with a concentration as low as $2.5 \mu \mathrm{g} / \mathrm{ml}$ was found to be particularly effective among the compounds damaging the cytoplasmic membrane. However, the above decrease resulted from a release of intracellular components (including proteins) into the incubation medium. The observed effect of the individual compounds is discussed from the point of view of the mechanism of their action and a degree of the metabolic damage caused in bacteria and EAC cells. 
The Effect of Glucose-starvation on Cells of Escherichia coli $15 T^{-} U^{-h i s}$ in the Preirradiation Phase on their UV Resistance and DNA Melting Point. V. Slezáriková, M. Sedliaková, Biological Institute, Slovak Academy of Sciences, Bratislava.

Changes of the resistance of Escherichia coli $15 \mathrm{~T}^{-} \mathrm{U}^{-}$his $^{-}$to ultraviolet radiation and changes of the melting point of DNA caused by irradiation after a preirradiation starvation for the energy source - glucose - were investigated. The resistance of cells to $\mathrm{UV}$ radiation increased proportionally with increasing time of starvation. A dose of $500 \mathrm{erg} / \mathrm{mm}^{2}$ decreased the melting point of DNA isolated from an exponentially growing culture by $3 \mathrm{C}$. The same dose did not influence the DNA melting point in cells starving for glucose for $60 \mathrm{~min}$ prior to the irradiation. It appears that the completion of replication cycles of DNA results in stabilization of the DNA molecule, thus favouring repair processes after the irradiation.

Escherichia coli 15 TAU Cell Division after Stop of DNA Synthesis as Dependent on Growth Conditions before and during Inhibition. M. OpEKaroVÁ, B. JANDERová, V. VondreJs, Department of Biophysics, Faculty of Sciences, Charles University, Prague.

(1) The cell number of Escherichia coli 15 TAU increased in a thymine-free medium, where DNA synthesis is completely inhibited. (2) The increase of cell number in a medium with thymine continues for about $20-30 \mathrm{~min}$. After cessation of DNA synthesis only a fraction of the cells divided and each of those only once. (3) The number of cells dividing in a medium wi.hout thymine depends on the growth conditions before inhibition and is dependent on the rate of increase in turbidity during the inhibition. (4) More cells in the fraction of the culture containing a higher percentage of large cells divided than in the fraction containing smaller cells (fractionated using centrifugation in sucrose gradient). (5) When the culture before the inhibition grew exponentially with a generation time of $32,42,56$ and $136 \mathrm{~min}$, then in the thymine-free medium, regardless of the earbon source, about $66,45,33$ and $33 \%$ of the cells divided, respectively. These values are in very good agreement with the theoretical fractions of cells with completed replication cycles calculated on the brsis of the age distribution function (Yoshikawa \& Sueoka, 1965) and on the basis of the assumption that the replication cycle is completed $23 \mathrm{~min}$ before cell division if the generation time is shorter than $60 \mathrm{~min}$.

DNA Synthesis in Escherichia coli 15 TAU bar after Thymine Starvation. M. OPHkarova, V. VoNDREJs, Department of Biophysics, Faculty of Sciences, Charles University, Prague.
Replication cycles of Escherichia coli TAU bar were synchronized by uracil and amino acid star. vation. DNA synthesis in complete or synchroniz. ation media was studied by measuring $\mathrm{H}^{3}$-thymine incorporation after different periods of continual or pulse-interrupted thymine starvation. With a prolonged period of continual starvation both the rate of DNA synthesis after thymine addition and total amount of DNA synthesized in the synchronization medium decreased. When starvation was interrupted each $20 \mathrm{~min}$ by a $5 \cdot \mathrm{min}$ pulse of thymine, then both rate and total amount of DNA syntkesis increased with the total length of the starvation period. Similar relationships were observed with Escherichia coli 15 TAU (Hirsch \& Vondrejs, 1969), however, some remarkable differences were found between the two strains. In both cases defective phage is present in cells but only Escherichia coli 15 TAU. lyses. Only in the case of Escherichia coli 15 TAU does a thymine pulse induce an extra increase in the turbidity of a thymine-starved culture. The rate of DNA synthesis and total amount of synthesized DNA increase after a prolonged pulse-interrupted starvation of Escherichia coli 15 TAU bar only to some extent and then stop. It follows from this comparison that the prevention of lysis by short pulses of thvmine is not the cause of increase of DNA synthesis after the interrupted starvation; more likely short pulses prevent the expression of some early function of the defective phage which would cause a decrease in total cellular DNA synthesis after starvation. The faster limiting increase of DNA synthesis in Escherichia coli $15 \mathrm{TAU}$ bar after interrupted starvation is in agreement with the hypothesis of Donachie (1968) that the initiation of replication occurs only when the size of the cell reaches some distinct value.

Some Metabolic and Physiological Consequences of Starvation of Mycobacterium fortuitum for Carbon and Nitrogen Sources. V. MAJTÁN, The Research Institute of Epidemiology and Microbiology, Bratislava

Cells of Mycobacterium fortuitum grown in a liquid Youmans medium (glyeerol, asparagine, albumin, citrate and mineral components) were subjected to starvation in $0.85 \% \mathrm{NaCl}$ with or without $1 \%$ glycerol and with 0.1 Tween 80 , i.e. to nitrogen or to nitrogen plus carbon starvation for 71 days. The number of cells capable of reproduction on a solidified Youmans medium and on a solidified Davis medium (minimal medium with a mineral nitrogen source), the dynamics of growth in liquid media, the intensity of respiration and the reduction activity of cells in the presence of different substrates, the virulence in mice as well as the sensitivity to tuberculostatics were investigated. It was found that the number of cells capable of 
reproduction in the suspension starving for a nitrogen source for 60 days in the glycerol containing medium decreased to $1 \%$ of the initial value. On the other hand, a high number of cells starving for $\mathrm{C}$ and $\mathrm{N}$ retained their reproductive capacity during the whole time of starvation. Correspondingly, the proportion of metabolically active and virulent cells was also high. Metabolic parameters, above all the respiration intensity on several substrates as well as the endogenous respiration were found to be suitable indicators of the physiological state of cells or of the number of cells capable of reproduction. The starvation for $\mathrm{N}$ and $\mathrm{C}$ sources did not increase the sensitivity to tuberculostatics.

The Synchronization of Cell Division in Certain Strains of Mycobacterium phlei. J. KoNtCEk, Institute of Microbiology, Czechoslovak Acadermy of Sciences, Prague.

Three synchronization methods based on temperature change, centrifugation and starvation as well as their combinations were elaborated in order to achieve the synchronized division in $M y c o$. bacterium phlei. It was found that a cold shock combined with centrifugation was most suitable. The optimum conditions were as follows: original inoculum from the beginning of the logarithmic phase of growth $\left(2.0 \times 10^{5}-8.5 \times 10^{5}\right.$ cells $\left./ \mathrm{ml}\right)$, time of centrifugation -90 sec at $1,900 \mathrm{rpm}$, time of the cold shock - $60 \mathrm{~min}$ at $6 \mathrm{C}$; concentration of Tween 80 in a liquid Dubos medium was increased to $0.6 \%$. A threefold synchronized cell division took place under these conditions. It was found that the time of cooling, composition of the cultivation medium and the initial cell number significantly influenced the synchronized cell growth and the length of the lag phase. The synchronization of growth was less successful when using a more gentle centrifugation method and the results were not easily reproducible. Cell division was followed by determining viable cell numbers. The synchronously dividing culture was also stud. jed microscopically using phase contrast.

Escherichia coli CRT 115 Division-promoting Activity in Crude Extracts of Different Bacterial Strains. V. JrRk U, Department of Microbiology, Faculty of Sciences, Charles University, Prague.

Thermosensitive cells of Escherichia coli CRT 115 dividing at $30 \mathrm{C}$ stop septum formation at $42 \mathrm{C}$ while growth, synthesis of RNA, DNA and pro. teins and chromosome segregation are not affected (Hirota et al., 1968). The reversion to septum fornation at $42 \mathrm{C}$ was observed when crude extracts prepared from stationary-phase cells of Escherichia coli K 12, Escherichia coli B, Bacillus subtilis, Pseudomonas aeruginosa and Escherichia coli
CRT 115 cultivated at $30 \mathrm{C}$ were added to the culture of Escherichia coli CRT 115. The extracts from exponentially-growing cells and from Escherichia coli CRT 115 cultivated at $42 \mathrm{C}$ were inactive. Cell number increased only about twice independently of the time of cultivation at $42 \mathrm{C}$ when the extract was added to the culture. A new burst of division induced by extract re-addition was not observed. If the extract was added to the culture $30 \mathrm{~min}$ before the shift to $42 \mathrm{C}$, at which cultivation continued for no longer than $60 \mathrm{~min}$ and cells were then transferred to $30 \mathrm{C}$, the rate of division was not affected, whereas in the absence of the extract a remarkable decrease of the divi. sion rate occurred already after 30 min cultivation. It may be assumed on the basis of the results obtained that the division promoting activity (a) does not arise at nonpermisive temperatures in Escherichia coli CRT 115; (b) is not inactivated at $42 \mathrm{C}$; (c) is accumulated only in stationary-phase cells; (d) requires for expression a special cell acceptor state which is not thermosensitive but which does not arise at $42 \mathrm{C}$.

The Characteristics of a Factor Inducing Cell Division of Escherichia coli CRT 115 at Non-permissive Temperatures. V. JiRKư, Department of Microbiology, Faculty of Sciences, Charles University, Prague.

The division of filamentous cells of Escherichio coli CRT 115 at non-permissive temperatures was proved to be induced by crude extracts of different bacterial cells (Jirkú, these abstracts). It was observed that the active, non-dialysable component loses its activity when the extract is treated with pronase, trypsin, chymotryptin, papaine, urea, deoxycholate, nalidixic acid or when sonicated or exposed to higher temperatures. The temperature sensitivity increased when the extract was prepared from cells cultivated in a medium containing $p$-fluorophenylalanine. The activity of the extract prepared from the nalidixic acid-resistant strain was not affected by nalidixic acid. The divisionpromoting activity was not sensitive to lipase, DNase, RNase, lysozyme or ether. It co-sedimented with pieces of the membrane. It is assumed on the basis of the above results that the division-promoting activity is carried by a protein, probably of particulate character. The interaction of this activity and the cell was found to be prevented in the presence of lysine, omithine, spermidine and/or putrescin and when the cells were exposed to shearing forces which strip off the pili before the addition of the extract. The division did not proceed to a full extent either when lysine was added or when the culture was washed earlier than about $25 \mathrm{~min}$ after the extract addition. The same was true when the cells were exposed to shearing forces until about $10 \mathrm{~min}$ after the extract addition. 
The Uptake of Histone by the Cells of Escherichia coli. E. Pavlasová, S. Štrbáx̌ová-Ně̌rinová, E. Stejskalová, Institute of Microbiology, Czechoalovak Academy of Sciences, Prague.

Previous studies of this laboratory were concerned with the effect of externally added histone on protein synthesis in Escherichia coli. It has not yet been determined whether histone enters the cell or whether it remains adsorbed on its surface. This study presents data supporting the former possibility. In most experiments the effect of histone on the synthesis of $\beta$-galactosidase provided indirect proof of its presence in the cells. (1) The effect of histone on protein synthesis was not interrupted even after the removal of histone from the medium by washing the cells. The intensity of its effect was found to depend on the preincubation period. (2) The indirect evidence that histone enters the cell probal ly by active transport was based on the comparison of preincubation of the cells with histone at $0 \mathrm{C}$ and $37 \mathrm{C}$. In the cells preineubated at $0 \mathrm{C}$ the effect of histone dissappeared after washing, whereas in the cells preincubated at $37 \mathrm{C}$ the histone effect continued. (3) Transport experiments with spermine, which exerts an opposite effect to histone on the synthesis of $\beta$-galactosidase and even antagonizes it showed that both compounds probably enter the cell by the same mechanism. ${ }^{3} \mathrm{H}$-spermine preaccumulated in cells of Escherichia coli could be completely displaced by the subsequent addition of histone to the medium. (4) It was found that dinitrophenol inhibits the accumulation of both spermine and histone in the cells. This fact may be considered as other evidence of the active transport of the compounds in question.

The Effect of Theophylline on the Induced Synthesis of B-galactosidase in Escherichia coli. J. SCHLAMMaDinger, G. Szabo, Biological Institute, Medical University, Debrecen.

In mammalian cells Butcher and Sutherland (1962) reported a competitive antagonism among methylxanthines, especially between theophylline and cyclic adenosine- $3^{\prime}, 5^{\prime}$-monophosphate (cyclic AMP). This cyclic nucleotide plays an important role in the transcription of the lac operon in Esche. richia coli. Therefore, it was of interest to study the effect of theophylline on the induced synthesis of $\beta$-galactosidase in Escherichia coli. Escherichia coli $\mathrm{K} 12$ was used throughout. It was found that theophylline at $3 \times 10^{-3} M$ and higher concentrations inhibits the synthesis of $\beta$-galactosidase induced by methyl - thio- $\beta \cdot D$-galactopyranoside (TMG). The growth of the microorganism was decreased as well but the differential rate of the synthesis of $\beta$-galactosidase showed a specific inhibitory effect on the synthesis of the enzyme in question thus resembling the glucose effect on the induced enzyme synthesis. This latter was found to consist in decreasing the intracellular cyclic AMP concentration (Perlman et al., 1969). In contrast to the findings of Butcher and Sutherland obtained in the mammalian system, theophylline did not inhibit cyclic AMP phosphodiesterase activity in Escherichia coli and did not increase the synthesis of $\beta$-galactosidase when present at low $\left(5 \times 10^{-4} \mathrm{M}\right.$ and $\left.10^{-4} \mathrm{M}\right)$ concentrations. These findings are in agreement with the data of Pastan and Perlman (1970). Theophylline appears to influence the induced synthesis of $\beta$-galactosidase at the level of transcription as shown by the method of Jacquet and Kepes (1969). It may be assumed on the basis of the results obtained that theophylline might be a competitive antagonist of cyclic AMP, hence inhibiting the induced synthesis of $\beta$-galactosidase in Escherichia coli.

Substances of Plant Origin Affecting the Synthesis of $\beta$-galactosidase in Escherichia coli $K$ 12. J. ERDEI, J. Schlammadinger, G. Szabó, Biological Institute, Medical University, Debrecen.

Szabó, Bekesi and Vitalis (1967) isolated an extract from a submerged culture of a mutant strain of Streptomyces griseus influencing cytodifferentiation in certain strains of Streptomyces griseus. The isolated and partially purified substance was tested with Streptomyces griseus, Bacillus subtilis and Escherichia coli. It was found that the factor $C$ in the presence of actinomycin $D$ increased the amount of ${ }^{14} \mathrm{C}$-uracil incorporated into cold 5\% TCA precipitate. Subsequently, Schlam. madinger and Szabó (1970) showed that the $\mathrm{C}$ factor containing preparation reversed the glucose repression of the inducible synthesis of $\beta$-galactosidase in Escherichia coli. After further purification of the extract, fractions exhibiting morphogenetic effects were separated from those reverting the glucose repression. The substance responsible for the above reversion effect was detected in one of the components of the culture medium. Data concerning the isolation and characterization of the substance and the results obtained when studying the mode of its action are presented in this communication. It was found that the extract shortened the doubling time (measured by following the optical density) of Escherichia coli $\mathrm{K} 12 .{ }^{14} \mathrm{C}$-Leucine incorporation was also enhanced by the extract. The induced synthesis of $\beta$-galactosidase was higher in the presence of the extract even when the enzyme activity was related with the optical density. This enhancement of the induced synthesis of $\beta$-galactosidase brought about by the extract was antagonized by increasing concentrations of glucose. Glucose repression of the induced synthesis of $\beta$-galactosidase could be reversed both by the above extract and cyclic $3^{\prime}, 5^{\prime}$ adenosine monophosphate. The effect of the two substances was found to be additive. 
The Cooperative Kinetics of Galactose Transport by Methylgalactoside Permease from Escherichia coli $\mathrm{K}^{-}$. J. Vořtštek, A. KEPEs, Institute of Microbiology, Crechoslovak Academy of Sciences, Prague, and Institut de Biologie Moléculaire de la Faculté des Sciences, Paris.

The affinity of MP for the substrate is very high $\left(K_{\mathrm{M}}-=0.5 \mu \mathrm{M}-\mathrm{V}\right.$. Boos, J. Biochem $10: 66$, 1969), therefore, extremely dilute suspensions of bacteria were used to study the galactose transport in Escherichia coli. It was found that the double reciprocal plot of the initial velocity of the galactose entry versus the substrate concentration formed a parabolic curve. Therefore, the $K_{\mathrm{M}-}$ value could not be specified exactly. Sub sequently, the cells sustained osmotic shock and the released proteins were concentrated. The binding specificity of this preparation for several hexoses and pentoses was tested by equilibrium dialysis. It was also found that the binding affinity of the protein preparation for galactose was of a sigmoid character. This finding confirms the general role of the isolated galactose binding protein in the transport of galactose by the investigated system.

Have Colicins E1, E2 and E3 a Common Receptor? J. SMARDA, J. ADLER, Institute of Biology, Medical School, J. E. Purkyně University, Brno.

The problem of a common receptor for all three colicins of the $\mathrm{E}$ group was investigated by analyzing the kinetics of the effect of their mixtures and of individual substances. Colicins E1, E2, E3 and $K$ are adsorbed and exert their inhibitory effects at different states at the same multiplicity. E2 effect is fastest, the rate of the $\mathrm{El}(\mathrm{K})$ effect is lower and the effect of E3 is the slowest; the degree of the inhibitory activity decreases in the same order. Differences in the inhibitory effect of the above colicins may be used to analyze their effect in the mixture of two colicins with a ratio of lethal units 1 : 1. It was found that colicins E2 and E3 show an intermediary curve as compared with those of colicins $\mathrm{E} 2$ and $\mathrm{E} 3$ alone. Colicins E2 and $\mathrm{E} 1$ or $\mathrm{E2}$ and $\mathrm{K}$ give a curve identical with a curve of colicin E2 alone. The intermediary curve could be obtained in the E2 + E1 mixture only at a ratio of $\mathrm{E} 1: \mathrm{E} 2=5: 1$. Also the degree of degradation of DNA in sensitive cells by mixtures of colicins $\mathrm{E} 2+\mathrm{E} 1 \quad(1: 1)$ was almost identical with that of the colicin $\mathrm{K} 2$ alone. When receptors were saturated with colicin E3, the effect of the subsequently added colicin E2 was hardly detected, whereas the effect of secondarily added E2 was fully manifested when saturating receptors with colicins E1 or K. The results presented show clearly that the E1 colicin receptor, as well as the $K$ colicin receptor differ from the common receptor for E2 and E3.
Thermosensitive Mutants of Escherichia coli $K 12$. E. A. Adefbera, B. Magee, B. Liška*, Department of Microbiology, School of Medicine, Yale University, New Haven and *Institute of Biophysics, Czechoslovak Academy of Sciences, Brno.

Thermosensitive mutants of Escherichia coli K 12, able to form colonies at $30 \mathrm{C}$ but not at $42 \mathrm{C}$, were isolated after treatment of the parent culture with ethylmethanesulfonate. In some experiments the yield of mutants was increased by penicillin selection at $42 \mathrm{C}$. Forty-eight mutants were compared for growth rate, morphology changes, and viability at $30 \mathrm{C}$ and at $42 \mathrm{C}$. The mutants varied from types which stopped growth immediately when shifted to $42 \mathrm{C}$, to types which continued normal growth over the eight-hour observation period. A number of mutants underwent profound morphological changes during incubation at $42 \mathrm{C}$. One strain lysed at $42 \mathrm{C}$; all others remained viable at this temperature. Twenty strains were examined for their ability to incorporate radioactive precursors of macromolecules at 42 C. Extracts made from eighteen of the strains exhibiting primary defects in protein synthesis, were assayed for all twenty amino-acyl t-RNA synthetases. Thermo-sensitive enzymes were found as follows: valine -4 strains, alanine -3 strains, glycine -2 strains, glutamine -1 strain. The remaining "protein mutants' are currently being tested for thermosensitivity in other components of the protein-synthesis machinery (ribosomes, initiation factors and elongation factors). The genetic map positions of some of the mutations were determined.

The Attempt to Transfer Episome to Mycobacterium phlei. M. KonÍčKOVÁ-RADOCHOVÁ, Institute of Microbiology, Czechoslovak Academy of Sciences, Prague.

The possibility of transfering episome from $\boldsymbol{E} \boldsymbol{s}$ cherichia coli to Mycobacterium phlei was investigated. The acid-fast, adenine ${ }^{-}$, STMr Mycobacterium phlei PA was used as acceptor, Escherichia coli $\mathrm{F}^{\prime} \mathrm{OR}$ Fl, adenine ${ }^{+}$, lactose ${ }^{+}$, proline ${ }^{+}$served as donor. Cultures of both strains taken from the logarithmic phase of growth were mixed 1:1 in a liquid conjugation medium. The conjugation method of Fulton in which the mixed culture of both strains is stabilized by means of membrane filters was then applied. Colonies of Mycobacterium phlei PA, adenine+, STMr were selected on a solid selection medium. The frequency of spontaneous mutants of Mycobacterium phlei PA, adenine ${ }^{+}$,

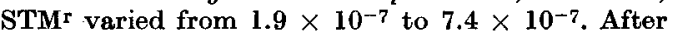
the incubation of the mixed culture the frequency of the adenine ${ }^{+}$, STMr phenotype varied from $2.9 \times 10^{-4}$ to $1.6 \times 10^{-5}$. On the basis of the above results the possibility of cross nutrition as a first step of control was investigated in more detail. 
The DNA-inactivating Activity of the Competence Factor from the Surface and Sterile Filtrate of the Transformable Strain and Non-transformable Mutants Cells of Pneumococcus. M. KоHоUTOVÁ, V. RYTfř, H. Braná, Institute of Microbiology, Czechoslovak Academy of Sciences, Prague.

It was found that the DNA-inactivating activity is probably an integral component of the active compound inducing competence (CF) in noncompetent cells of pneumoeocei. When the sample was eluted from a Sephadex G-25 column with HCl gradient (after previous elution with water when practically the whole protein exhibition of the DNase activity which is probably not associated with the active compound was separated) of the IF activity was detected in fractions in which the active compound was eluted at $\mathrm{pH} 3.0-3.5$. This activity by its behaviour towards both native and denatured DNA (Lipavská et al., these abstracts) resembled that described in studies of the hyperchromicity effeot (Kohoutové et al., 1970) taking place after the incubation of the active compound with DNA. The active compound which during fractionation on a Sephadex G-25 column behaved similarly to the $\mathrm{CF}$ isolated from streptococci was degraded after $3 \mathrm{~min}$ incubation with pronase $(7 \mu \mathrm{g} / \mathrm{ml})$ at $37 \mathrm{C}$ and was found to be relatively thermoresistant. A similar IF activity was detected in the active compound extracted from the surface of competent cells of pneumococci. The activity inducing competence was found to be strictly specific. In spite of the fact that physico-chemical properties of the CF from streptococei and that from pneumococci appear to be comparable, the competence could not be induced by a heterologous CF. In order to obtain more information concerning the importance of both activities in the penetration of DNA a series of spontaneously non-transformable mutants with different or non-detectable IF activity is being investigated.

Nuclease Activity Accompanying the Competence Factor Isolated from a Transformable Strain of Diplococcus pneumoniae. H. LIPAVSKÁ, V.VOND REJS, M. КоноuTová, Institute of Mierobiology, Czechoslovak Academy of Sciences and Biophysics Department, Faculty of Sciences, Charles University, Prague.

Cells of Diplococcus pneumoniae which have passed the maximum of competence, release into the medium a substance called the competence factor (CF) which is capable of inducing a competent state when added to a non-competent culture. The ammonium sulphate precipitate of the filtrate of the culture was fractionated on Sephadex G 100 and the fraction with maximal concentration of CF (Sample 1) was purified on Sephadex G 25. CF was released from the column at pH 3 (Sample 2) by a pH gradient. Samples 1,2 and Sample 1 treated with pH 3 (Sample 3) were tested for nuclease activity using centrifugation in a sucrose gradient. In all three cases the dominant activity wes endonuclease activity introducing single-strand breaks. The activity in Sample 1 was found to break both single-stranded and double-stranded DNA. In Sample 2 single-stranded DNA was preferred as substrate. Double-stranded DNA was gradually degraded in such a way that a portion of the DNA moved as native double-stranded DNA in neutral sucrose gradient, the next maximum was in the position of denatured DNA and the third portion of radioactivity was shifted to the position of more slowly sedimenting degradation products. A similar situation occurred when the DNA was digested with Sample 3. However, the amount of smaller degradation products was much larger. A possible explanation of this type of degradation pattern would be a two-step process, including the formation of denatured DNA, probably by unwindase, and a break-down of single-stranded DNA. This explanation is in agreement with earlier experiments in which the hyperchromic effect after the incubation of native DNA and denatured DNA with CF was studied (Kohoutová et al., 1970).

The Effect of UV-Radiation on Molecular Weight of DNA in Escherichia coli. J. BUGAN, M. SEDLIAKová, Institute of Biology, Slovak Academy of Sciences, Bratislava.

Changes in the moleeular weight of single DNA strands after the treatment with different doses of UV-radiation as well as the repair rate in the logarithmically growing culture in which the resistanee to UV-rays was increased by preirradiation amino acid starvation were investigated. Molecular weight was determined in an alkaline sucrose gradient. It had been shown previously that the increase in the resistance after the $\mathbf{A A}^{-}$starvation is associated with a more pronounced release of UV-photoproducts and not with a considerable repair synthesis. It was found in the recent experiments that there are no differences in molecular weights of the UV-irradiated DNA isolated from logarithmically growing and $\mathbf{A A}^{-}$prestarved cells. This finding indicates that the last step in the excision repair, the re-association of terminal ends of single DNA strands by means of ligase, is not stimulated by AA- prestarvation.

The Effect of Ribosides on the Synthesis of $D N A$ in

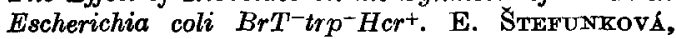
L. Bernátová, M. Sedliaková, Institute of Biology, Slovak Academy of Sciences.

The effect of ribosides on growth, viability and DNA synthesis in logarithmically growing E\&cherichia coli $\mathrm{BrT}^{-} \operatorname{trp}^{-} \mathrm{Hcr}^{+}$was investigated. It 
was found that purine ribosides (ado, guo) are practically without any effect, whereas pyrimidine ribosides (cyd, urd) support growth of the cells with a simulteneous decrease in their viability and the inhibition of DNA synthesis. The inhibition was shown to be proportional to the concentration of the added riboside. In further experiments it was found that cyd $(200 \mu \mathrm{g} / \mathrm{ml})$ inhibits the DNA synthesis completely and irreversibly. A lower cyd concentration (50 $\mathrm{kg} / \mathrm{ml}$ ) brought about an in. stantaneous but reversible inhibition. It is known that similar phenomena are observed during thymine-less starvation in thymine-requiring mutants of Escherichia coli. This analogy between the thymine-less starvation and the effect of ribosides will be subject to further studies in combination with UV-radiation.

The Causes of a High Sensitivity of Mycoplasma Laidlawii to Ionizing Radiation. V. DRÁs̆L, J. HUŤKovA, B. LIŠkA, Institute of Biophysics, Czechoslovak Academy of Sciences, Brno.

Survival curves of Mycoplasma Laidlawii A after irradiation with $\mathrm{X}$-rays showed that this organism is relatively very sensitive. $D_{0}$ varied around $5,000 \mathrm{rad}$ when irradiating in the presence of $\mathrm{O}_{2}$. The removal of oxygen from the suspension resulted in an increase of $D_{0}$ to $12,000 \mathrm{rad}$. As the genome size of this organism is only $8 \times 10^{8}$ daltons, it appears likely that the primary effect of the. radiation on DNA is not the only cause of death of these cells after the irradiation. The above assumption was verified by following irradiated cells. It was found that their DNA is very rapidly degraded during further incubation. After irradiation with $8,000 \mathrm{rad}$ in the presence of $\mathrm{O}_{2}$ the cells lost up to $70 \%$ of their own DNA in the form of acid-soluble material in $60 \mathrm{~min}$. The losses were less considerable when the cells were irradiated in the absence of oxygen. In this latter case DRF reached values roughly comparable with the ratio of respective $D_{0}$ values, i.e. 2.4. The degradation of DNA was found to be of enzymic nature. It could be prevented by adding EDTA to the medium. Enzymes responsible for this process are probably bound to the cell wall under normal conditions. After irradiation they combine with DNA and hence increase the primary effect of the radiation.

The Mutagenic Effect of Antibiotics. L. EBRINGER, P. Foutŕnová. Department of Microbiology, Komenský University, Bratislava.

It was originally assumed that the hereditary conversion of autotrophic cells of Euglena gracilis to heterotrophy could be induced only by streptomycin. However, 37 other antibiotics and a high number of synthetic derivatives of 5 -nitrofurane were later found to exhibit a similar mutagenic effect. The frequency of obtained heterotrophs is high as most antibiotics induce up to $100 \%$ heterotrophic mutants. It was found that all antibiotics exhibiting the "bleaching effect" induce heterotrophic mutants by a similar mechanism. Chloroplasts disappear only under conditions when normal cell reproduction is possible. Antibiotics with the "bleaching effect" inhibit the replication of plastids so that chloroplasts are gradually diluted out during active cellular division. With most antibiotics about 5 cellular divisions are required for the complete elimination of chloroplasts. The average number of chloroplasts is reduced to one-half after each generation time. It was shown that all the so-called bleaching antibiotics induce the loss of chloroplasts only when added to actively growing cells. When the antibiotics is added to a stationary culture of Euglena gracilis the cells retain chlorophyll and also chloroplasts. A similar depigmentation cannot be directly observed when high concentrations of antibiotics also preventing the cell replication are applied. As all tested inhibitors of the synthesis of DNA (rubiflavin, sarkomycin, anthramycin, porphyromycin, streptonigrin, nalidixic acid, novobiocin, myxin and others) exhibit a strong "bleaching effect", it may be assumed that the replication of chloroplasts is stopped due to the intervention with the synthesis of chloroplast DNA.

The role of Streptomycin in Strains of Streptomyces griseus and Their Transamidinase Activity. G. BARaBÁs, G. Szabó, F. Szeszak, Institute of Biology, University Medical School, Debrecen, Hungary.

It was found previously (Szabó et al., 1965; Barakás et al., 1970) that streptidine, a component of streptomycin is a constituent of the cell wall of strains of Streptomyces griseus. Streptidine was identified and isolated from the purified walls of both SM-producing (No. 52-1) and SM-non-producing (No. 45) strains of Streptomyces griseus. According to Walker et al. (1964) the transamidinase (TA-ase) activity was detected only in SM-producing strains of Streptomyces, and in viomycin producers (Raczynska-Bojanowska et al., 1969). The authors could not detect the TA-ase activity in SM-nonproducing and viomycin-non-producing strains. In the experiments deseribed here the TA-ase ac. tivity was detected not only in the SM-producing Streptomyces griseus used (No. 52-1) but also in the SM-non-producin strain (No. 45). However, the level of the TA-ase enzyme was much lower in the latter strain. The occurrence of the TA-ase enzyme in dependence of the life cycle, the possible localization of this enzyme and the effect of different substrates were investigated and compared in the SM-producing (No. 52-1) and SM-nonproducing (No. 45) strains. 
Models for the Investigation of the Structure-activity $\boldsymbol{R}$ elationship in a Series of Antimicrobial Compounds. L. Drobnica, P. Nemec, J. Augustín, Department of Microbiology and Biochemistry, Slovak Polytechnical University, Bratislava.

Studies concerning relationships between the structure and antimicrobial activity in a series of compounds require a sensitive test for toxicity and a knowledge of certain chemical properties. Molar concentrations (c) of compounds required for a standard biological response (ED 50 or $\mathbf{E D}_{100}$, similar values $L D$, ID) are used when evaluating the compound's toxicity. The lipophility of compounds is most important among physico-chemical characteristics. When a complex of multistage adsorption and separation processes precedes the effect proper of certain types of compounds (their reaction with respective "receptors"), distribution coefficients $(P)$ determined for different systems and also molar solubilities $(S)$ in water or other solvents, represent important data in determining the biological activity. An important new possibility is the use of empirical $\pi$ substituents $(\pi=$ $=\log P$ substituents in the molecule $-\log P$ basis of the molecule) as there exist mathematically formulated relationships between values $S$ and $P$ or $S$ and $\pi$. Examples of several series of compounds, substituted benzyl, $\beta$-phenylethyl and phenylisothiocyanates, the antimierobial activity of which is determined by the equation (I) are presented. The equation relates differences in the lipophility of the compounds to the properties responsible for their activity. Values $\tau_{i}$ and $\tau_{r}$ represent effective molar concentrations $(C)$ of the $i^{\text {th }}$ up to $r^{\text {th }}$ member of the series, $\alpha$ is the proportionality constant for a given biological system and $\beta$ is the constant characterizing lipophility $(\log P, \log S)$ or the effect of the substituent $\pi$.

$$
\begin{aligned}
\log \left(\tau_{i} / \tau_{r}\right)= & \alpha \beta \\
\log \left(\tau_{i} / \tau_{r}\right)= & \rho \sigma \\
\log (1 / y)= & k_{1} \mathrm{x}+k_{2} \\
\log (1 / \mathrm{c})= & k(\log P)^{2}+k^{\prime} \log P+k^{\prime \prime} \\
\log (1 / \mathrm{c})= & -k(\log P)^{2}=k^{\prime} \log P+\rho \sigma+ \\
& +k^{\prime \prime} \\
\log (1 / \mathrm{c})= & k_{1} \log P+\rho \sigma+k_{2}
\end{aligned}
$$

Another simple example is the finding that the biological activity can be correlated with data characterizing reactivity of the functional group of derivatives of a given basic molecule. Logarithms of rate constants $k$ of model reactions, in certain cases Hammett constants of substituents $\sigma$ and $\sigma_{n}$, Taft constant $\sigma^{*}$, in special cases polarographic half-wave potentials shifts of characteristic absorption maxima in ultraviolet and infrared ranges, $p K$ values etc. may serve as measures of the correlation. The above values substitute the value in the so-called modified Hammett equation
(II). The equation (III) is the generalized expression of the equations (I) and (II). The excession of the optimum lipophility is demonstrated in the equation (IV). Examples when differences in the biological activity of a series of compounds are determined both by differences in their lipophility and by differences in their reactivity are illustrated by equations (V) and (VI) formulated by Lien $e t$ al. (1968) who verified their usefulness also for correlations in a series of arylisothiocyanates. Mathematical models also representing the sterical arrangement of molecules are more complex.

Morphological Changes in Botrytis cinerea Induced by Macrolide Antibiotics from Moulds. V. Betina, D. Mičeková, Department of Microbiology and Biochemistry, Slovak Polytechnical University, Bratislava.

Inhibitory effect of cytochalasin A, monorden and zygosporin A on Botrytis cinerea were observed in studies of antimicrobial properties of macrolide antibiotics from moulds. The antifungal activities of cytochalasin $\mathbf{A}$ and zygosporin $\mathbf{A}$ have not yet been described in the literature. All antibiotics tested brought about typical morphological changes of growing hyphae of Botrytis cinerea. Cyanein had a similar branching effect to those, in experiments described previously (Betina $e$, al., 1966). Monorden induced growth of large numbers of short lateral branches perpendicular to main hyphae. Dichotomous ramification of the side branches occurred after prolonged incubation. Bulging of hyphal tips of lateral branches and the main filaments was also observed. Cytochalasin $\mathbf{A}$ and zygosporin $\mathbf{A}$ exhibited similar effects. The latter caused leakage of the cytoplasm. The relationships between the the observed morphological effects and the mechanisms of action of the antibiotics tested are discussed.

Effects of Citrinin on Nucleic Acid and Protein Synthesis in Saccharomyces cerevisiae. V. BETINA, Z. Baráth, Department of Microbiology and Biochemistry, Slovak Polytechnical University, Bratislava, and Biological Institute, Slovak Academy of Sciences, Bratislava.

Citrinin is a fungal metabolite known since 1931 and first described as an antibecterial antibiotic in 1941. Robinson and Park (1966) observed its inhibitory effects on filamentous fungi. Growth inhibition of yeasts and yeast-like organisms has been described recently (Betina \& Rúčková, in press). The effects of this antibiotic on energy metabolism, function of cell membranes and synthesis of macromolecules in Saccharomyces cerevisiae Sherry V3 were studied. Respiration and glycolysis were very little affected when glucose 
was used as substrate. Practically no leakage of cell constituents absorbing at 260 and $280 \mathrm{~nm}$ was observed. Citrinin, at concentrations causing a partial inhibition of growth, completely inhibited the incorporation of ${ }^{14} \mathrm{C}$-adenine into the cold TCA insoluble fraction Saccharomyces cerevisiae. Incorporation of radioactivity from ${ }^{14} \mathrm{C}$-adenine into DNA and RNA was inhibited to the same extent. Five-fold concentrations of citrinin were required for complete inhibition of ${ }^{14} \mathrm{C}$-leucine ineorporation into cold and hot TCA insoluble materials. The possible mode of action of citrinin on Saccharomyces cerevisiae is discussed.

The Effect of Cis-dichlorodiaminoplatinum (II) on the Growth, Division and Respiration of Escherichia coli. J. Dronnfk, S. Rešzová, V. Šnejdar, Biophysics Department, Faculty of Sciences, Charles University, Prague, and Biophysics Department, Michigan State University, East Lansing.

Division was found to be more sensitive than growth to cis-dichlorodiaminoplatinum (II) in both $B$ and $B / \mathbf{r}$ strains of Escherichia coli. The addition of the complex resulted in filamentous growth. The division process was more inhibited in the former strain, whereas growth was equally sensitive in both. The effect of the drug always occurred after a lag period lasting roughly for one generation time. Cultures grown on glycerol, lactose or pyruvate were more sensitive to the growth inhibition than cultures grown on glucose. The culture grown on glueose under anaerobic conditions was less affected. Respiration on glucose or glycerol was nct altered in the presence of $100 \mu \mathrm{M}$ cis-Pt (II). However, cells (filaments) grown in the presence of the drug exhibited lower respiration rates, particularly when grown on glucose. Nevertheless, the "adjustment" of the filaments to glycerol was not impaired. Glyeerol-grown filaments showed a slight suppression of respiration on glucose and a substantial suppression of respiration on glycerol. Thus the effect of cis-Pt (II) on the respiration is indirect. An effect on the metabolic regulation is assumed.

The Effect of Cis-dichlorodiaminoplatinum II on the Induction of B-galactosidase in Escherichia coli $B$. V. Snejdar, S. Rešlová, J. Drobnft, Division of Biophysics, Faculty of Sciences, Charles University, Prague, and Biophysies Department, Michigan State University, East Lansing.

The effect of cis-dichlorodiaminoplatinum (II) on the enzyme induction in Escherichia coli B was studied with $\beta$-galactosidase; the induction period (inducer present) and the synthetic period (after dilution of the inducer) were studied separately. A little effect of $100 \mu \mathrm{M}$ Cis-dichlorodiamino- platinum (II) was observed when the compound was present only during the induction period, whereas a lower enzyme activity resulted when the complex was added after the dilution of the inducer. However, an increase of enzymic activity was detected when the complex was present during both the induction and the synthetic periods. It is assumed that $C i s-\mathrm{Pt}$ (II) prevents the inhibition of translation of lac-mRNA caused by catabolite repression. A very low effect of Cis-Pt (II) on the enzyme induction was found with filaments obtained by cultivating the cells in the presence of the platinum complex. Therefore, changes of the induction ability of the culture during flament formation in the presence of the platinum complex and during their fragmentation after its removal were investigated. The inducibility inereased for one hour after the addition of the complex and decreased later remaining below control values for even three hours after the removal of the complex from the medium. A tendency to recover was observed after 4 hours. Reversible and irreversible changes in the regulatory mechanisms are suggested.

The role of Fil, Her and Exr Markers in the Sensitivity of Escherichia coli $B$ to Cis-platinum II Diaminodichloride. J. DroBnf́k, M. KRÁtKÁ, Biophysica Department, Faculty of Sciences, Charles. University, Prague.

The effect of Fil, $\mathrm{HCr}$ and $\mathrm{Exr}$ markers in $\boldsymbol{E} \boldsymbol{E}$ cherichia coli B on growth and survival in the presence of cis- $\mathrm{Pt}$ (II) was studied. The frequency of revertants and suppressor mutations of the strain WP 2 was also followed. The colony-forming ability (c.f.a.) of the strain $B / r$ did not decrease. The c.f.a. of the $B$ strain was only slightly decreased by $50 \mu \mathrm{M}$ cis-Pt (II). On the other hand, the c.f.a. of the strains $B_{S-1}$ and $B_{S-1}$ decreased exponentially by more than six orders of magnitude after 240 and $150 \mathrm{~min}$, respectively, in the presence of $20 \mu \mathrm{M}$ cis-Pt (II). As the culture turbidity and the direct cell count of the above two sensitive cultures increased normally, it was concluded that $B_{8-2}$ and $B_{\mathrm{s}-1}$ cells can undergo several divisions but are not able to form colonies. Washed suspensions of the strains $B$ and $B / r$ (WP 2) showed similar, almost exponential inactivation curves in the presence of $500 \mu \mathrm{M}$ cis.Pt (II). The inactivation constant was $4.8 \mathrm{sec}^{-1} \mathrm{~mol}^{-1}$. Complex curves were obtained with the strains $B_{\mathrm{s}-1}$ and $B_{8-2}$ which were much more sensitive already to $50 \mu \mathrm{ar}$ cis-Pt (II). Five min contact of $\mathrm{B}_{\mathrm{s}-1}$ cells with $600 \mu \mathrm{M}$ cis.Pt (II) resulted in a decrease in the c.f.a. by three orders of magnitude. The frequency of revertants of the Try- auxotroph of the B/r (WP 2) increased 7.5-fold after two hours growth in the presence of $50 \mu \mathrm{M}$ cis-Pt (II), whereas the suppressor mutation frequency doubled. An 
independent mutation of nuclei in multi-nucleated filaments was observed. The role of the Exr marker is discussed.

The Study of the Ultrastructure and Function of Penetration Organelles in Toxoplasma and Sarcosporidia. J. LuDví, Institute of Microbiology, Czechoslovak Academy of Sciences, Prague.

The substructure of pole organelles, conoids, functioning as penetration organelles during the penetration of Toxoplasma and Sareosporidium cells into host tissue cells was demonstrated under the electron microscope using a modified method of negative staining. An extending spiral movement of conoids serving to perforate cytoplasmic membranes of attacked cells was observed. The movement was found to be caused by subpelicular microtubuli radially diverging from the double pole ring. Other structural details of microtubuli i.e. longitudinal subfibrillae and spiral substructure could be observed at a high magnification and high resolution of the electron microscope.

The Electronoptic Study of Strains of Mycobacterium phlei. J. ĆásLavská, M. KovfČKová-RADOCHová, J. KoníČ̈K, I. MáLEK, Institute of Microbiology, Czechoslovak Academy of Sciences, Prague.

The acid-fast PA strain and the non-acid-fast PN strain of Mycobacterium phlei differing in such important features as acid-fastness have been studied previously and their morphological and cultivation characteristics, chemical composition, biochemical and serological properties compared. In addition, the content of DNA bases was determined, the cellular pigment isolated and both strains were compared genetically by studying mutagenesis. In spite of the observed differences the basis of the change of the acid-fastness was not clarified. In further experiments the two strains from different phases of growth were studied under the electron microscope. It was found that the size of cells of both the PA and PN strains of Myco. bacterium phlei equals $0.5 \mu \times 4-6 \mu$. A thin mucous layer could often be observed on the surface of cells. Most significant differences were found in the thickness of the cell wall and in the shape of mesosomes. The studied strains differed also in the number of inclusions formed by reserve substances. It was found that the non-acid-fast strain hus a thicker cell wall and larger intracellular membranous system. Fewer inclusions were observed as compared with the acid-fast PA strain. The relationship between the above differences and the change of the acid-fastness could not yet be clarified.
The Ultrastructure of the Genus Pediococcus and Aerococcus. M. Sovadina, T. Martinec, M. Kocur, O. NEČs, Czechoslovak Collection of Microorganisms and Department of Biology, J. E. Purkyne University, Brno.

The taxonomic classification of the genera Pediococcus and Aerococcus is still under discussion. As the two genera are closely related some authors recommend their classification in a single genus, others support the present taxonomy. The ultrastructure of cells of Pediococcus cerevisiae and Aerococcus viridans was compared in the present work. It was the aim of the study to establish similarities between the two microorganisms. The structure of cells was studied by means of ultrathin sections and by freeze-etching. Cells treated by freeze-etching had a similar structure to those observed on ultrm-thin sections. Both species differed in the size and configuration of cells, however, the structure of the wall and inner cellular structures were similar.

I-arginine-deaminase (EC 3.5.3.6) in Streptococcus lactis and its Peripheral Localization in the Cell. F. Smékal, R. Bícová, Research Institute of Antibiotics and Biotransformations, Roztoky near Prague, and Institute of Epidemiology and Microbiology, Prague.

L-arginine-deaminase was detected in a strain of Streptococcus lactis. It was found that intact cells deaminate L-arginine to L-citruline with the simultaneous production of $\mathrm{NH}_{4}^{+}$ions. L-citrulline was detected by chromatography. The highest activity of L-arginine-deaminase was found in cells from the end of the logarithmic phase of growth and in stationary-phase cells. The enzyme activity in a cell-free preparation was comparable with that in intact cells of streptococci; the enzyme activity was low in the fraction of cell walls. Conversion of cells of Streptococcus lactis to spheroplasts with egg-white lysozymo at $\mathrm{pH} 8.5$ resulted in a release of $60-84 \%$ enzyme into the medium; L-argininedeaminase activity was low in the spheroplast fraction. On the basis of the results obtained it can be assumed that L-arginine-deaminase is localized between the cell wall and the cytoplasmic membrane.

Alkaline Phosphatase Production and Localization in Cells of Pathogenic and Non-pathogenic Streptococci. R. Bf́cová, F. SmÉkal, Institute of Epidemiology and Microbiology, Prague, and Research Institute of Antibiotics and Biotransformations, Roztoky near Prague.

Alkaline phosphatase was studied in cells of pathogenic and non-pathogenic species of stroptococci. Sodium glycerolphosphate was used as sub- 
strate and the amount of liberated orthophosphate determined by the colorimetric method. The enzyme production was low in the representatives of both types, being two-fold in Streptococcus pyogenes, Blackmore strain (group A) as compared with the Streptococcus lactis (group N) strain employed. The localization of alkaline phosphatase was studied in some experiments. For this purpose the cell wall was hydrolyzed; egg-white lysozyme was used to convert cells to osmotically fragile spheroplasts. The cell wall was lyzed in $0.03 \mathrm{M}$ Tris-HCl buffer $\mathrm{pH} 8.4$ containing $0.6 \mathrm{M}$ sucrose as a stabilizer. Microscopic observation revealed a loss of Gram-positivity; the content of amino sugars in cell walls decreased and alkaline phossphatase was released into the medium. Only $20 \%$ of the original activity remained bound in the cells showing that the enzyme is localized outside the cytoplasmic membrane. As a result of the osmotic shock the density of spheroplasts decreased by $80 \%$. Penicillin failed to induce the formation of spheroplasts; the loss of Gram-positivity was observed but the enzyme was not released into the medium.

Localization and Production of EC.2 L-asparaginase in Certain Strains of Gram-negative Bacteria. J. VRÁNOVÁ, F. SMÉkaL, Institute of Epidemiology and Microbiology, Prague, and Research Institute of Antibiotics and Biotransformations, Roztoky near Prague.

In Escherichia coli EC-2 L-asparaginase (EC 3.5.1.1.) is localized in the periplasmic region of the cell, between the cell wall and the cytoplasmic mombrane. The localization of the enzyme wes studied in further strains of Gram-negative bacteria by preparing lysozyme spheroplasts and following the EC-2 x-asparaginase activity in supernatant and sediment fractions of spheroplasts (the enzyme activity in intact cells served as control). A high enzyme activity was found in the super. natant of spheroplasts in the Escherichia coli strains tested (more than $60 \%$ of the aetivity released after the conversion of cells); Iow enzyme activities were detected in spheroplasts (about $20 \%$ of the total enzyme activity). On the other hand, in strains of Serratia marcescens and Salmonella typhimurium activities were found in the spheroplast fraction, whereas only low activities could be de. tected in the supernatant after the conversion of cells. Of the strains tested the highest enzymo activities were found in Escherichia coli 11787 (3.4 IU/mg dry weight) and Erwinia carotovora CCM 1008 (2.8 IU/mg dry weight).

Characteristics of the Allosteric Enzyme Aspartate. transcarbamylase in Bacillus megaterium and Halobacterium rubrum. V. LIEBL, H. SAJdLOVA, P.
SaJdL, Institute of Microbiology, Czechoslovak Academy of Seiences, and Department of Biochemistry, Charles University, Prague.

Aspartate-transcarbamylase (ATCase) was stud. led in Bacillus megaterium growing in the presence of low concentrations of salts and in an extremely halophilic Halobacterium cutirubrum requiring high concentrations of $\mathrm{NaCl}(3-6 \mathrm{M})$. Cells of the latter microorganism lyzed in the presence of lower $\mathrm{NaCl}$ concentrations and accumulated $\mathrm{KCl}$ inside the cells practically to saturation $(4-5 \mathrm{M})$. The activity and the regulation of ATCase were studied in homogenates of bacteria after their disintegration by ultrasonication. The regulating capacity of the enzyme was decreased on purification. ATCase catalyzes the formation of carbamylas. partata from earbamyl-phosphate and aspartic acid. It thus starts the biosynthesis of the pyrimidine ring, simultaneously controlling by feed-back inhibition concentrations of final low-molecular metabolites, cytidine-triphosphate (CTP) and uridine-triphosphate (UTP), serving as starting products for the biosynthesis of nucleic acids. The control by means of the above-mentioned "feedback" mechanism, i.e. retroinhibition of ATCase molecule is exerted by CTP (or eventually UTP) already at a concentration of $10^{-4} \mathrm{M}$. It was found that ATCaso from the extremely halophilic microorganism has a maximum activity in $4 \mathrm{M} \mathrm{KCl}$ and is denatured at a low ionic strength. ATCase from Bacillus megaterium has good activity in the absence of salts and negligible activity in $1 \mathrm{M} \mathrm{KCl}$. Both enzymes exhibit optimum activity and opti. mum retroinhibition at $\mathrm{pH} 8$. The activity was found to be more sensitive to a pH change than the retroinhibition. The retroinhibition of the halophilie ATCase by CTP $\left(10^{-3} \mathrm{~m}\right)$ and UTP $\left(10^{-3} \mathrm{M}\right)$ was up to $90-95 \%$ and $40-60 \%$, respectively. It was found in kineties experiments that the above effectors compete allosterically with aspartic acid but not with carbamyl-phosphate. The retroinhibition of ATCase from Bacillus megaterium by CTP was lower, reaching a maximum of $50-60 \%$. Temperature optima of the retroinhibition of the halophilic enzyme and the non-halophilic enzyme were $25 \mathrm{C}$ and $15 \mathrm{C}$, respectively. CTP was most effective in the regulation of both enzymes. The effect of UTP was less pronounced, CDP was only slightly effective. ATP slightly activated or decreased the retroinhibition. A lower activity and a lower retroinhibition were found when substituting $\mathrm{KCl}$ by chlorides of $\mathrm{Rb}, \mathrm{Cs}, \mathrm{NH}_{4}, \mathrm{Na}$, Li $(3-4 \mathrm{M})$. Both the activity and retroinhibition were low in the presence of divalent cations. It may be concluded that the halophilic ATCase is comparable to the non-halophilic enzyme as far as its enzymological properties are concerned, however, it is a typical halophilic protein which is most active in concentrated $\mathrm{KCl}$ corresponding to physiological conditions in cells of extreme halophiles. 
The Production of Sulphite from Cystine in Der matophyta and its Role in the Decomposition of Keratin. J. KUNERT, Department of Biology, Medical School, Palacký University, Olomouc.

The dermatophyt Microsporum gypseum was cultivated in different media containing $0.1 \%$ cystine. Sulphate excreted into the medium was a final product of the cystine metabolism in all media tested. In addition, cysteine and sulphite (at concentrations up to $0.2 \mathrm{mg} / \mathrm{ml}$ ) were detected in media where the microorganism grew only slowly. In an alkaline medium $\mathrm{SO}_{3}^{--}$ions degrade disulphides according to the equation

$\mathbf{R}-\mathrm{S}-\mathrm{S}-\mathrm{R}+\mathrm{SO}_{3}^{--} \rightarrow \mathrm{R}-\mathrm{SH}+\mathrm{R}-\mathrm{S}-\mathrm{SO}_{3} \mathrm{H}$

to thiol and thiosulphate-ester (S-sulphonate). It is hence assumed that cysteine in the cultivation medium did not originate by reduction but by this "sulphitolysis". The production of sulphite was demonstrated also in other species of dermatophyta. It was the aim of further experiments to investigate, whether organic sulphur is partially oxidized to sulphite during growth on the so-called hard keratin (containing $10-18 \%$ cystine). Free sulphite could not be detected and only trace quantities of thiols were present. However, a high amount of strongly acid groups yielding positive results in reactions specific for thiosulphate-esters $(\mathrm{R}-S-$ $-\mathrm{SO}_{3} \mathrm{H}$ ) could be demonstrated by means of topochemical methods. It follows that partially digested parts of the substrate contain the groups originating by sulphitolysis of disulphides. It is hence very likely that the degradation of cystine bridges of keratin by sulphite is the so far unknown reaction by which the fungus denatures the resistant substrate and renders it sensitive to proteolysis.

Trehalose as a Metabolite in the Yeast Rhodotorula glutinis. S. J JNDA, Institute of Microbiology, Czechoslovak Academy of Sciences, Prague.

It was found that $D$-xylose, which is transported into Rhodotorula glutinis against a concentration gradient, is mostly transformed by this strictly aerobic yeast into another compound before undergoing appreciable oxidation to $\mathrm{CO}_{2}$. The compound was isolated and its identity with trehalose was demonstrated by determining its physical and chemical properties. D-Glucose was found to be converted into trehalose much like $\mathrm{D}$-xylose although by different metabolic pathways. Metabolic products of other sugars in Rhadotorula glutinis were tested to examine the possibility of trehalose sormation. The role of trehalose as a storage subftance in Rhodotorula glutinis is discussed.
Double Effect of a Metabolic Suppressor in Sac. charomyces cerevisiae. L. ŠrtHÁNKová, Department of Biochemistry and Microbiology, College of Chemical Technology, Prague.

A suppression of the expression of three nonlinked rough genes was found in rough mutants obtained by the UV-treatment of two prototrophic haploid strains of Saccharomyces cerevisiae. The suppression was found to be strongly influenced by the genetic background, the presence of certain components of the genome of both strains being necessary for its performance. The suppression of the rough phenotype was accompanied by a suppression of red colour in $\operatorname{ad}_{2-1}$ mutants that responds similarly to the effects of the genetic background. It was found that the gene responsible for both suppressions segregates regularly and is linked to one of the tested rough loci. It is most probably not a super-suppressor, for the used strains do not show suppression of any of the 9 tested super-suppressible alleles covering the possibility of detection of 22 supersuppressible loci. The suppression is probably not due to a change in the regulation of purine biosynthesis either for no impairment of the regulation of that process was found in any of the tested mutants or segregants. Probable metabolic causes of the suppression of both red and rough phenotypes are discussed on the basis of the effects of various growth conditions on the phenotypic expression of ad $_{2-1}$ and rough alleles in various genetic backgrounds.

Feedback Regulation of Amino Acid Uptake in Yeasts. A. KotYK, N. H. SAIYID, L. Ř́íhová, Institute of Microbiology, Czechoslovak Academy of Sciences, Prague.

Baker's yeast Saccharomyces cerevisiae, and the lipid-forming yeast Rhodotorula glutinis were shown to take up all natural amino acids, as well as $\alpha$-aminoisobutyric acid, by an active process, inhibited by metabolic inhibitors, oxidative phosphorylation uncouplers, and by uranyl ions. The rate of uptake is a saturable function of amino acid concentration in the medium and is pronouncedly depressed by intracellular amino acids. In both species, the inhibitory potency of intracellular amino acids is substantially greater than that of external amino acids and has negative feedback characteristics. The qualitative affinity patterns are also different on the outside and on the inside face of the plasma membrane. It had been shown before that the efflux of amino acids from yeast cells is virtually nonexistent and it may now be postulated that the inhibition of both influx and efflux is due to intracellular amino acids. It may consist in blocking the movement of the membrane carrier by an amino-acid-recognizing component on the inner side of the membrane. 
Transport of Acyclic Polyols and of Monosaccharides in Torulopsis candida. C. HAŠrovec, A. KoTYK, Institute of Experimentel Biology and Genetics, and Institute of Microbiology, Czechoslovak Academy of Sciences, Prague.

Irrespective of whether they are metabolized, linear polyalcohols and monosaccharides are transported uphill by the yeast Torulopsis candida NCYC 576. Transport cannot be separated from subsequent metabolism by metabolic inhibitors, anaerobic conditions or by flushing the yeast with a readily metabolizable substrate. Plot of rate vs. concentration revealed the presence of two transport components: (1) a specific, "carrier", system with half-saturation constants for polyols of about $10^{-3}-10^{-2} \mathrm{M}$, for monosaccharides of about $10^{-4}-10^{-3} \mathrm{M}$, and (2) a nonspecifie, diffusion-type system with immeasurably high $K_{M}$ and $V$. It was observed that some polyols interfere fully competitively with each other as well as with some monosaccharides for transport so that common carriers for these compounds are envisaged. On the whole, three carrier systems appear to exist for the compounds investigated: (I) predominantly polyol; (2) predominantly sugax; (3) specific ribose-erythritol.

Electron Microscopy and X-ray Diffraction Analysis of the Fibrillary Network from Protoplasts and Cell Walls of Saccharomyces cerevisiae. M. KOPECKÁ, D. R. KREGER, Institute of Biology, Faculty of Medicine, J. E. Purkyne University, Brno and Botanical Laboratory, Rijks University, Groningen.

Electron microscopy and X-ray diffraction were used to compare: (1) a pure sample of fibrillary nets from protoplasts of Saccharomyces cerevisiae isolated after a $\mathbf{2 4}$ hour cultivation of protoplasts in a liquid nutrient medium and (2) fibrillary "hydroglucane" isolated from cell walls of the original culture of the same yeast by boiling the cell walls with $2 \% \mathrm{HCl}$. The results showed that 200 Á thick microfibrillae represent a basic morphological unit of both samples in spite of the fact that the arrangement of microfibrillae is completely different in the two preparations (density and the way the microfibrillae are intertwined, the presence of bunches of microfibrillae, length etc.). The solubility of fibrillar nets from protoplasts in acids and alkalies is comparable with that of the "hydroglucane" from yeast walls. Fibrillary nets of protoplasts hence also contain only glucane and chitin. The removal of ehitin from a sample of the fibrillary nets of protoplasts by chitinase or with $30 \% \mathrm{HCl}$ did not result in any ultrastructural change of microfibrillae and the rtg-diagram of the fibrillary nets after the removal of chitin was found to be identical with the rtg-diagram of paramylon from Euglena gracilis. The results obtained show that single microfibrillae of the fibrillary network of protoplasts of Saccharomyces cerevisiae are formed by a pure polysaccharide $-\beta(1 \rightarrow 3)$ glucane.

The Inhibitory Effect of 2-Deoxyglucose on the Synthesis of the Cell Wall in Schizosaccharomyces pombe. A. Svoroda, D. G. SмIтH, Institute of Biology, Faculty of Medicine, J. E. Purkyně University, Brno, and Department of Botany and Microbiology, University College, London.

Changes of the structure and formation of the cell wall of normal cells and protoplasts of the yeast Schizosaccharomyces pombe in the presence of 2-deoxy-D-glucose (2-DG) were investigated by light and electron microscopy. It was found that the inhibition of growth of the culture is proportional to the 2-DG concentration. Only growing cells were sensitive to the inhibitor and lysis of cell occurred in its presence. An abnormal cell wall deposited in growth zones, i.e. on the cell poles or at the site of septum, was formed in the presence of 2-DG. This aberrant wall is electron-transporent, its structure on ultrathin section does not correspond to the normal wall and is of fibrillary texture as shown on metal-coated preparations. It was found that protoplasts of Schizosaccharomyces pombe grow in the presence of 2-DG, as with glucose alone, however, characteristic clusters are not formed. A fibrillary notwork is formed on the surface of protoplasts. The network is free of amorphous material in preparations with 2-DG, whereas in control preparations fibrillae are partially sealed with an amorphous mass. Secretion of soluble polysaccharides into the medium is also significantly inhibited by 2 -DG. No correlations could be shown between the ultrastructure of cytoplasmic organelles and impaired synthesis of the cell wall or secretion of one component of the cell wall. The results obtained show that the synthesis of the amorphous component of the cell wall (probably amorphous glucane) is inhibited by 2-DG. This results in the synthesis of an abnormal cell wall and in a metabolic lysis of the cell.

The Effect of 2-deoxyglucose on Cell Wall Formation in Saccharomyces cerevisiae. P. BIELY, Z. KRÁTK $\hat{Y}$, S. BaUER, Institute of Chemistry, Slovak Academy of Sciences, Bratislava.

It was found that 2-deoxy-D-glucose (2-DG) inhibits the growth of Saccharomyces cerevisiae in a $2 \%$ glucose medium. The inhibition is proportional to the concentration of $2-\mathrm{DG}$ in this medium and is accompanied by a remarkable decrease in the number of viable cells. The cells grown with 2-DG differ from control cells in morphological appearance. Electron microscopic exam. ination of cell walls prepared from control yeasts 
and from 2-DG-inhibited yeasts showed that the yeasts grown in the presence of 2-DG form weakened cell walls. On such walls, unusually large bud scars occur besides the bud scars having the mag. nitude of those seen on the cell walls from control yeast. The plugs of the large bud scars are composed of more granular material than the rest of the wall and highly overlap the cell wall line. Fractionation of cell walls from control yeast and from yeast grown in the presence of $2 . \mathrm{DG} 10.05 \%$ and $0.2 \%$ ) using ethyldiamine extraction showed that $2 . \mathrm{DG}$ caused about a $30 \%$ reduction in the content of the mannan containing fraction. The results strengthened the view that the inhibition of growth of Saccharomyces cerevisiae by 2-DG is closely associated with the effect of 2-DG on cell wall formation, whioh is probably due to the inhibition of the biosynthesis of structural polysaccharides by phosphorylated metabolites of 2 -DG, e.g. UDP-2-DG and GDP-2-DG.

The Inhibition of Yeast Mannan Biosynthesis by Quanosine. Z. KRÁTKÝ, P. BIELY, Institute of Chemistry, Slovak Academy of Sciences, Bratislava.

2-Deoxy-D-glucose (2-DG), a synthetic analogue of glucose and mannose, is known as a potent growth inhibitor of some yeast strains. Numerous examples have suggested that this effect, usually observed with lysis of cells, is associated with the interference of phosphorylated metabolites of 2-DG (2-DG-6-P, 2-DG-1-P, 2-DG-1, 6-diP, UDP-2-DG, GDP-2-DG) with the formation of cell wall polysaccharides. This communication presents the first evidence that GDP-2-DG, isolated from Saccharomyces fragilis incubated with 2-DG may act as competitive inhibitor of the biosynthesis of yeast mannan. It was found that GDP-2-DG inhibited the incorporation of radioactivity from GDP. (mannose. ${ }^{14} \mathrm{C}$ ) into a particulate enzyme system prepared from Saccharomyses cerevisiae. Of several substances structurally related to GDP-mannose tested in this reaction, GDP-2-DG was found to be the most effective inhibitor. A similar inhibition of the mannan synthesis may be anticipated to take place in intact yeast cells grown in the presence of $2-\mathrm{DG}$.

Immunological Studies of Polysaccharides tn Yeasts. J. SANDULA, L. MASLER, Institute of Chemistry, Slovak Academy of Sciences, Bratislava.

Mannans and mannan containing polysaccharides which are branched and linked by $\alpha(1-6)$ bonds in the main chain and by $\alpha(1-2)$ and $\alpha(1-3)$ bonds in the side chains are the main immunologically active component of yeasts and yeast-like microorganisms. Antisera prepared by immunization of individual species are not specific but exhibit a group character. Some species of the genus Candida, i.e. Candida albicans, Candida tropicalis, Candida stellatoidea, Candida clausenii give mutual strong cross reactions. The similarity of determinant groups of their polysaccharide antigens is responsible for the above cross reactions. Oligosaccharides consisting of $5-7$ mannose units represent the immunologically dominant group for Candida albicans. Short side chains of mannan formed by 2-4 mannose molecules are characteristic determinant groups of the genus Saccharomyces. Glucomannans containing 70-85\% mannose and $15-30 \%$ glucose are antigens of the species Candida utilis, Torulopsis utilis, Candida guilliermondi var. nitratophila and Candida pelliculosa. In addition to anti-mannans, antibodies against phosphomannans are formed when immunizing animals with certain species of the genus Hansenula, e.g. Hansenula capsulata and Hansenula holstii. Data concerning the structure of polysaccharides and their immunochemical activity may be used in the taxonomy of yeasts.

The Study of the Formation, Growth and Regeneration of Yeast Protoplasts by Means of Time-lapse Microcinematography. M. GABRIEL, Institute of Biology, Faculty of Medicine, J. E. Purkyně University, Brno.

The origin of protoplasts of Saccharomyces cerevisiae as a result of the enzymic degradation of the cell wall by snail enzymes, their planary growth on the surface of solid media and the regeneration of protoplasts during cultivation in gels were demonstrated on a $16 \mathrm{~mm}$ negative film made by the time-lapss technique. A "leakage" of protoplasts from the digested wall is shown on the film. Disorganized growth accompanied by changes of vacuolization, changes of nuclei etc. well visible on pictures of flat, growing formations occurs during growth on solid media. Protoplasts cultivated in gels form a solid wall on their surface and cytodieresis then takes place. Cells of the first generation are not uniform, being frequently larger than cells of the original yeast culture. The documentary shots are in agreement with the until now accepted ideas concerning the formation, growth and reversion of yeast protoplasts.

The Effect of Selenium on the Arowth of Bacillus

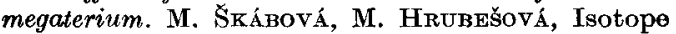
Laboratory of the Institutes for Biological Re. search, Czechoslovak Academy of Sciences, Prague.

The effect of selenium on the growth of Bacillus megaterium and incorporation into intracellular proteins using $\mathrm{Na-selenite}$ and $75 \mathrm{Se}$-selenomethionine were studied. It was shown under the usual conditions of cultivation that sulphur compounds 
are necessary for the growth of Bacillus megaterium and cannot be replaced by analogous compounds of selenium. When cultivating in the presence of $1.1 \times 10^{-3}$ M sulphate and $7.2 \times 10^{-5}$ M selenite, the amount of proteins estimated by Lowry's method in samples taken at different time intervals equalled on the average $60 \%$ of the values estimated in samples from the control selenitefree cultivation of the microorganism. Cells of Bacillus megaterium grown in the presence of selenite were of abnormal shape. During the cultivation olementary solenium was released into the medium. "75e-selenomethionine did not influence the growth of Bacillus mega. terium as compared with the control grown in the presence of $\mathrm{D}, \mathrm{L}$-methionine. A low radioactivity was found in the complex of proteins after isolation from protoplasts and repeated precipitation with ammonium sulphate.

\section{TECHNICAL SECTION}

Relationship between Growth and Division of Candida utilis under Continuous Cultivation Conditions. D. Vraná, Z. Frincl, J. Limblová, K. Beran, Institute of Microbiology, Czechoslovak Academy of Sciences, Prague.

Using two-stage continuous cultivation we studied the possibility of uncoupling growth from division in the yeast Candida utilis $\mathrm{T}_{20}$. The size of cells and the per cent participation of budding individuals in media of various composition and at differont dilution rates (D) were followed. It was found that the process of growth and of cell division can be uncoupled in continuous cultivation by the effect of external conditions. (1) In rich media division is accelerated (a great number of small cells per unit dry weight) in comparison with poor media (a small number of large cells per unit dry weight). (2) The same effect is achieved by lower dilution rate $\mathrm{D}$ (low $\mathrm{D} \div$ small cells, large D - large cells). (3) The difference between the rate of division at lower and higher $D$ is more pronounced in a rich medium. (4) The rate of division in the 2nd stage is affected by the dilution rate in the lst etage. The amounts of nucleic acids in cells under different cultivation conditions re. ferred to the dry weight and to the cell number are also compared.

Influence of Oxygen and Nitrogen Limitation on Hydracarbon Fermentation by Candida lipolytica. M. Y. Chovdry, V. Munk, Z. Fencl, Institute of Microbiology, Czechoslovak Academy of Sciences, Prague.

The yeast Candida lipolytica was cultivated on gas oil and hexadecane mixed with deparaffinated gas oil as the sole source of carbon and energy. The experiments were performed in a chemostat under (a) changing concentration of oxygen but maintaining tho flow rate constant by mixing nitrogen with air, (b) different geration rates, and (c) different levels of nitrogen in the medium. "Ithe culture at various steady states was analyzed for the prcduction of bio-mass, collular and extracellular free fatty acids and esterified fatty acids in the yeast cell. Oxygen and nitrogen limitation was observed to have a pronounced effect on these: metabolic products.

Morphology and Content of Cell Components in Yeasts of Defined Relative Age in Continuous Cul tivation. J. Lrmblova, K. BrRan, D. Vrana. Institute of Microbiology, Czechoslovak Academy of Sciences, Prague.

Changes in the cell volume of Saccharomyces cerevisiae of age defined by the number of cell scars were followed. The number of scars, lengths and widths of cells were determined in a fluorescence microscope after staining with primulin. At dilution rates of $0.05,0.1,0.25$ and 0.35 we followed the volumes in 5 categories of cells with designation of scars: $0,1,2,3$ and 4 , i.e. some $96 \%$ of the population. It was found that with increasing dilution rates the cell volumes of all age categories increase. The largest volume increase in cells of all categories was found on changing I) from 0.25 to 0.35 . Iifferences between cell volumes: of eategory 0 and the other age categories are considerable. The cell content of DNA and RNA was followed at the above dilution rates in three age groups: cells of category 0 , cells with a number. of scars and nonfractionated cultures. It appear: that the content of DNA per dry weight within the range of dilution rates is higher in the cell group of category 0 rather than in cells with more numerous scars. The amount of DNA in this group is lower than in the group with multi-scar cells at the higher dilution rates 0.25 and 0.35 .

Dependence of Biochemical Activity of Surface Culture of Aspergillus niger on the History of the Culture. L. SEIChERT, E. UJCOVA, Z. Frect, Institute of Microbiology, Czechoslovak Academy of Sciencer, Prague.

A study of the biochemical activity of the culture in dependence on its age has shown that during the development of the mycelium the product formation (citric acid) maintains a specific character which cannot be affected by intentional changes of the external conditions. As shown by control experiments, the maximum activity of the mycelium occurs in certain periods regardless of medium change. It follows that the general character of culture development in batch cultivation 
cannot be affected by external conditions. The activity of the culture is determined by its age and can be neither elicited earlier nor postponed by changing the production medium.

Effect of Divalent Cations on the Stability of Proto. plasts in Aspergillus niger. M. MustckovA, Z. FencL, Institute of Microbiology, Czechoslovak Academy of Sciences, Prague.

Using snail gut juice, protoplasts were released from the hyphas of Aspergillus niger $\mathrm{K} 10$ but a considerable amount of them lyzed within a short time. The protoplast stability increases on adding divalent cations to the stabilization solution. Calcium and barium ions are most effective. The difference in the effects of $\mathrm{Ca}^{2+}$ and $\mathrm{Ba}^{2+}$ was investigated in relation to the age of hyphae from which the protoplasts were released and to the composition of the stabilization medium.

Disintegration of Aspergillus niger Mycelium during Production of Glucose Oxidase. M. Rut, J. Hants, Research Institute of Food Industry, Czechoslovak Agricultural Academy, Prague.

Laboratory and pilot-plant experiments with disintegration of the mycelium of Aspergillus niger and extraction of glueose oxidase wore carried out. The laboratory part dealt with the mechanical disruption of a mycelial suspension in a laboratory mixer, Nossal's disintegrator and with mechanical damage in the dry state with subsequent extrac. tion, and also with enzymic destruction of the cell wall by the extrecellular enzyme of the fungus Trichothecium roseum. It was shown that under laboratory conditions the most effective procedure is a combination of enzymic and mechanical treatment. In the case of such a combination even the relative!y little efficient laboratory mixer is satisfactory. The enxyme yield was $90-95 \%$. On a pilot-plant scale mechanical disintegration was carried out by an epparatus for collulose pulping (Superfiner VÚPC), by a bead disintegrator KPD 50 and by a vibration mill (Providence Engineering Works, Burslem). The optimal conditions for maximum yield of glucose oxidase under pilot-plant conditions were established.

Determination of Cx-cellulase Activity of Trichothecium roseum Wa. M. KMínKová, M. GotTWaLdová, J. Hanus, Research Institute of Food Industry, Czechoslovak Agrieultural Academy, Prague.

The $\mathrm{C}_{\mathbf{x}}$-cellulase activity of the enzyme system of Trichothecium reseum was determined reducto. metrically according to Somogyi and Nelson and viscometrically. Carboxymethyl cellulose was used as substrate. The advantage of the viscometric method is mainly in the fact that the initial, stage of hydrolysis can be determined. According to the literature, the reducing method can follow the reaction course only after a certain incubation pariod. An attempt was rade to follow the beginning of the reaction by the formation of reducing substances, after adapting the reaction conditions to those of the viscometric method. Paper chromatography was used for qualitative estimation of the formation of hydrolytic cellulose fragments.

Determination Activity of the Individual Components of the Microbial Cellulase System. J. Hanus, M. Kmínková, M. GotTwatoová, Research Institute of Food Industry, Czechoslovak Agricultural Academy, Prague.

Determination of the activity of individual components of the microbial cellulase system depends on the isolation of and on the recognition of the properties of these components and of the mechanism of substrate eleavage. General information on these problems is lacking. The present communication compares the theories of the mechanism of enzymic hydrolysis of cellulose, and the effects and methods of determination of the swe]. ling factor, of the $\mathrm{C}_{1}$ and $\mathrm{C}_{\mathrm{x}}$ components and of cellobiase are described. The efficiency of the enzyme system of Trichothecium roseum is evaluated on the bases of kinetic measurements and of the quality of hydrolytic products.

Determination of the $C_{1}$ Activity of Trichothecium roseum Wa. M. GotTwatdová, M. KMínková, J. Hanus, Research Institute of Food Industry, Czechoslovak Agricultural Academy, Prague.

To determine the $\mathrm{C}_{1}$ activity of any microorganism producing cellulase, cellulose (cotton fiber, filter paper) is usually employed as substrate. The determination is complicated not only by the com. plexity of the enzyme system but also by the differences in efficiency of such a complex toward substrates of different origin. For this reason, we used a uniform substrate of standard quality, available in Czechoslovakia. A study was made of the effect of the cultivation liquid and of the crude preparation on microcrystalline beech cellulose and introduced several corrections for decomposition of cellulose caused by other factors. The effect of substrate amount on the determination of activity was also examined. The work is supplemented by an examination of the hydrolytic producta of the substrate. 
Isolation of Bacterial Cultures Producing Alkaline Protedses. M. TKADLECOVÁ, J. KOČRA, Research Institute of Food Industry, Czechoslovak Academy of Agriculture, Prague.

For the production of bacterial alkaline pro. teases a production strain was selected from culture collections and from field material. To detect bacterial colonies producing proteolytic enzymes a method was used employing partial destruction of the sensitive layer of photographic paper. This method is a modification of that frequently used during electrophoresis for the detection of pro. teases. In addition to collection cultures of bacteria the proteaseproducing bacteria were isolated from water. Such bacteria are suited for submerged growth because of long-term adaptation to such eonditions. Preliminary experiments in which a total of 25 bacterial strains of various origin were compared showed that strains isolated from natural material do not differ markedly from strains of collection origin in the production of alkaline proteases. It is significant that the addition of citric acid to the fermentation medium pronouncedly increases the formation of proteases. A similar effect is shown by calcium ions. In the case of citric acid we are probably dealing with a stimulation of enzyme biosynthesis whereas it cannot be excluded that in the case of calcium ions the enzyme already formed is being activated. These problems will be dealt with in future re. search.

Production of Fatty Acids by Candida lipolytica during Growth on Pure n-Alkanes. O. Volfová, K. Pecka, Institute of Microbiology, Czechoslovak Academy of Sciences, and College of Chemical Technology, Prague.

Fatty acid production was followed in the course of growth of the yeast Candida lipolytica on pure hexadecane or dodecane dissolved in deparaf finated gas oil. Spectrophotometry which permits distinction between free and bound fatty acids was used for the analysis of the fatty acids, as well as gas chromatography of the methyl esters of fatty acids prepared by esterification of separated lipid fractions. The kineties of formation and distribution of free and esterified fatty acids was examined in cells, in the medium and in the hydrocarbon frac. tion. It follows from the results that in the stationary phase of growth fatty acids accumulate in the hydrocarbon phase, together with decreasing content of free fatty acids in cells. Qualitatively, the fatty acid spectrum in cells reflects the $n$-alkane spectrum in the gas oil. For example, an inoculum grown on nondeparaffinated gas oil contained fatty acids corresponding by the length of their carbon chain to $n$-alkanes present in the gas oil but after transfer to hexadecane the cells formed mostly palmitic acid (48.3 rel.\% in the logarithmic phase).
Together with changes in the $n$-alkane substrates the cell changes the quantitative distribution of the individual fatty acids even at the beginning of the Jogarithmic phase. The predominating acid in cells at all growth phases on dodecane is not lauric acid but rather oleic acid (36.8 rel.\% during stationary phase).

Effect of Fatty Acids on Carbon Source Utilization Z. Hoñková, Z. FencL, Institute of Microbiology, Czechoslovak Academy of Sciences, Prague.

In recent years, problems associated with protein production from hydrocarbons provoked in terest in the toxicity of fatty acids. Evidence exists that in some cases the oxidation of $n$-alkanes is not complete and the medium then contains the intermediate fatty acids. Our present experience with the toxic effects of fatty acids $\mathrm{C}_{2}-\mathrm{C}_{14}$ in Saccharomyces cerevisiae and Candida utilis is presented and compared with the results obtained with Candida lipolytica. In contrast with the other species this last-named yeast can respire under the given experimental conditions on lower fatty acids but their inhibitory effect on the utilization of phosphate by the cell and the increase in bio-mass even here remain unaffected although somewhat higher molarities must be used. The possibilities are discussed of an accumulation of lower fatty acids in the medium affecting the fermentation process.

Testing of Resistance of Asphalts to Microbial Deterioration. J. Hronská, Z. Uliǒná, D. Hadama, Faculty of Medicine, Komenský University, Bratislava, Research Institute for Oil and Hydrocarbon Gases, and Faculty of Chemical Technology, Slovak Technical University, Bratislava.

The course of microbial decomposition of asphalts was tested under laboratory conditions. The asphalt was emulgated with colloid $\mathrm{SiO}_{2}$. Bacteria from soil in contact with asphalt were used as accumulating cultures. Cultivation on a reciprocal shaker at $30 \mathrm{C}$ was done in a mineral medium. The total number of becteria, number of bacteria capable of growth on $n$-alkanes and the analytical decomposition of asphalt were followed. In all cases, the bacterial count rose from $2.3 \times 10^{7}$ to $1.9 \times 10^{8}$ and, starting with the second week of cultivation, the number of bacteria capable of utilizing alkanes did not differ significantly from the total bacterial count. After $2-3$ weeks of cultivation, the bacterial count decreased while the rate of asphalt degradation did not substantially change and the degree of degradation during the 4 th week exceeded $50 \%$. Addition of further organic nutrients did not substantially affect the rate and the degree of degradation. 
New Antiprotozoal Antibiotic Vermiculin. J. Fuska, P. NeMec, I. KUHR, V. Lukášová, Department of Technical Microbiology and Biochemistry, Faculty of Chemica] Technology, Bratislava.

Using a culture of Penicillium vermiculatum CCM.F 276 we isolated a new antibiotic and called it vermiculin. It is effective in vitro against proto. zoans (Trypanosoma cruzi $10 \mu \mathrm{g} / \mathrm{ml}$, Leishmania brasitiensis $0.5 \mu \mathrm{g} / \mathrm{ml}$ ) and, at concentrations of $10-20 \mu \mathrm{g} / \mathrm{ml}$ against a number of Gram-positive bacteria (Bacillus subtilis, Staphylococcus pyogenes aureus, Sarcina lutea). Vermiculin is not identical with any known antiprotozoal antibiotic and with any known fungal metabolite. The pure antibiotic is a colourless compound (mp $173-177 \mathrm{C},[\alpha]_{\mathcal{\nu}}^{20}-$ 12.5) of aliphatic or alicyclic character (UV peak at $244 \mathrm{~nm}$, contains only $\mathrm{C}, \mathrm{H}$ and $\mathrm{O}$. Maxima in the IR spectrum indicate the presence of an ester or lactone bond in addition to a ketone or aldehyde carbonyl group and the absence of a free $\mathrm{OH}$ group. Vermiculin is produced in a static as well as submerged culture on Synthetic Czapek-Dox medium. The addition of corn-steep increases the yield. After attaining maximum production the compound may be isolated from the filtrate of the fermentation medium by extraction with chloroform, concentration of the extract, erystallization and purification. In media with a higher overall production, the antibiotic accumulates in the mycelium from which it can be extracted with chloroform after previous drying and removal of lipid fractions.

Morphological Changes Induced in Some Yeasts and Filamentous Fungi by Mucidin. V. SAšre, V. Mvsflek, Institute of Microbiology, Czechoslovak Academy of Sciences, Prague.

Mucidin, an antifungal antibiotic produced by the basidiomycete Oudemansiella mucida (Schrad. ex Fr.) Höhn, was tested against 16 species of filamentous fungi (mostly phytopathogens) and against yeasts Candida pseudotropicalis and Saccharomyces cerevisiae. The growth-inhibiting effect was evident in all the tests. Using the agar-plate diffusion method, different types of changes were observed in marginal hyphase of many tested filamentous fungi. Addition of the antibiotic at a concentration of $25 \mu \mathrm{g} / \mathrm{ml}$ to a submerged culture of Candida pseudotropicalis changed the shape and the size of cells and inhibited sporulation and re. serve material formation. In some cases, moreover, a concentration of $50 \mu \mathrm{g} / \mathrm{ml}$ induced structural changes in the cell content. Aspects of the mechanism of action of mucidin are discussed.

Aminoacyl-tRNA-Synthetases and Production of Tetracycline by Streptomyces aureofaciens. J. KARNeTOVÁ, K. MIKULík, Institute of Microbiology, Czechoslovak Academy of Sciences, Prague.
Using a tetracycline-producing and a nonproducing strain of Streptomyces aureofaciens a study was made of the activity of aminoacyl-activating enzymes ( $\mathrm{Val}, \mathrm{Ala}, \mathrm{Leu})$. With the tetracycline producer the maximum specific activity was found in preparations isolated after 12 hours of cultivation. Production of tetracycline was accompanied by a pronounced decrease in the activity of the enzymes studied. The inhibitory effect of tetracycline on the activity of aminoacyl synthetases was exam. ined in in vitro experiments. It was found that a pronounced inhibition of the activating enzymes takes place with $10^{-4} \mathrm{M}$ tetracycline.

Contribution to the Study of Qenetic Recombination in Tetracycline-producing Streptomycetes. M. BLUmauerová, A. A. Ismail, M. Alačeviè, Z. HošTÁlEK, Z. VANĚK, Institute of Microbiology, Czechoslovak Academy of Sciences, Prague, National Research Centre, Microbial Genetics Research Unit, Dokki, Cairo, U.A.R., and Faculty of Tech. nology, University of Zagreb, Yugoslavia.

Strains of Streptomyces aureofaciens producing chlortetracycline, tetracycline and the antibiotically inactive pigment aureovocin, after mutagenic treatment yielded various mutants blocked at different stages of the biosynthesis of these compounds. Chromatography showed that many of the mutants produce new metabolites, most likely intermediates or byproducts of the biosynthetic pathway. From the standard strains and from five mutants represonting different metabolie types, a further mutation step lod to a series of genetically labelled strains (auxotrophic mutants and acriflavine- and streptomycinresistant mutants) which was used for studying genetic recombination. A total of 83 crosses of these mutants were done and the biosynthetic activity of the recombinants was analyzed. The results obtained were compared with those of crossing various types of auxotrophic mutants of $S$. rimosus differing in changes in the production of oxytetracycline, aureovocin and further compounds related to the metabolites of $S$. aureofaciens, and with results of interspecies recombination between $S$. aureofaciens and $S$. rimosus. The position of the first four loci controlling the secondary metabolism in the two atrepto. mycetes was determined. The probable function of these loci is discussed from the point of view of present knowledge of the biogenesis of tetracyclinetype compounds.

Biosynthesis of the $A$ Ring of Tetracyclines. M. PoDOJIL, Z. VANĚK, Institute of Microbiology, Czechoslovak Academy of Sciences, Prague.

It has been proved that the molecule of tetracycline was formed by "head to tail condensation" of malonic acid units whereby the terminal unit 
being not yet determined. The study of enzyme systems of Streptomyces aureofaciens led us to the consideration that the terminal group could be biosynthesized by oxidative decarboxylation of asparagine. To verify this idea experimentally we followed the specifity of $\left(\mathrm{U}-{ }^{14} \mathrm{C}\right)$ asparagine incorporation into tetracycline molecule. Radioactivity of degradation products of active tetracycline proved practically all the activity to be localized in carbons of tetracycline skeleton and $-\mathrm{CONH}_{2}$ group. The activity of $-\mathrm{CONH}_{2}$ carbon was approximately 10times higher than that of rings $C$ and $D$. On the basis of our experimental results metabolic pathways leading to the formation of the terminal group of tetracycline molecule were discussed.

Regulation of the Biosynthesis of Chlortetracycline: The Pyruvate Dehydrogenase Complex. V. JEchová, V. BĚHaL, Z. HoŠtúlnk, Z. VANĚK, Institute of Microbiology, Czechoslovak Academy of Sciences, Prague.

The study of the pyruvate dehydrogenase complex was part of a research program dealing with enzyme systems participating in the formation of precursors of the tetracycline molecule. The activity of the complex was studied in relation to the synthesis of the antibiotic in low-producing and high-producing strains of Streptomyces aureofaciens. The activity of the pyruvate dehydrogenase complex was measured by the ferrocyanide method (colorimetric determination of ferrocyanide produced by oxidative decarboxylation of pyruvate with ferricyanide as electron acceptor) and by the dismutation assay (colorimetric dotermination of acetyl phosphate generated by a coupled reaction catalyzed by the pyruvate dehydrogenase system, by phosphotransacetylase and by lactate dehydrogenase). Both methods gave similar results, Maximum activity was found after about 24 hours of cultivation in both strains. In the production phase, mainly in high-production fermentations, the activity of the pyruvate dehydrogenase system was very low. The role of the pyruvate oxidase system and of other alternative metabolic pathways in the formation of acetylCoA (or malonylCoA) as a precursor of the tetracyclic nonaketide is discussed.

Origin of the Terminal Group in Tetracycline. V. B.̈HAL, Z. VANĚK, F. LYNEN, Institute of Microbiology, Czechoslovak Academy of Sciences, Prague, and Max-Planck Institut für Zellchemie, München.

The terminal group of tetracene nucleus of chlortetracycline molecule is supposed to be formed by semiamide of malonic acid. There are several hypotheses about the origin of this group. Our work concerned with the incorporation of $1,3-14 \mathrm{C}$ semiamide of malonic acid (prepared from malonic acid and gasseous ammonia) proved that the incorporation of the compound in question into chlortetracycline was very slight. The whole amount of radioactivity was left in nutrition medium whereas radioactive malonic acid added under the same conditions was exhausted within 96 hours. To improve the permeability, the methylester of semiamide of malonic acid $1,3.14 \mathrm{C}$ was prepared (by diazomethane in absolute ether). In this form, the semiamide of malonic acid was found to be incorporated into tetracyclines more readily, its specific radioactivity being 6,900 counts $/ \mathrm{min} \mu \mathrm{mol}$ which corresponds to $2.1 \%$ of radioactivity inserted. Specifically degraded carbonamide carbon contained only $1 / 10$ of total tetracycline radioactivity, i.e. semiamide of malonic acid has not. been incorporated only into the terminal group but the radioactivity has been spread over all carbons of tetracycline skeleton originating in the carboxyl group of malonic acid.

Mass Production of Clostridial Collagenase and Lecithinase $C$. A. LetTL, Institute of Sera and Vaccines, Prague.

Production of Clostridium histolyticum collagenase and Clostridium perfringens type A lecithinase ( $\alpha$-toxin) by cultivation in large volumes and by a semicontinuous process is described. Both methods of cultivation are suitable in view of easy execution and of the possibility of reaching higher enzyme yields. Semicontinuous cultivation of Clostridium histolyticum requires a two-stage system to reach the atoxic culture with a high collagenolytic activity. Tween 80 was demonstrated to have a favourable effect on the yields of lecithinase $C$ of Clostridium perfringens type $\mathbf{A}$.

Self-inhibition of Germination of Claviceps purpurea Conidia. J. Kybal, K. StrRnadová, Research Institute of Antibiotics and Biotransformations, Roztoky near Prague.

It was found that conidia of Claviceps purpurea Fr. (TUL) produce compounds which inhibit their germination. The inhibitors can be extracted with water. The significance of the inhibitors of ergot development on the host plant is discussed.

Characteristic Phase of Ergot Alkaloid Fermentation. Z. К̌Háček, J. Kozová, P. SaJdL, K. A. MaLIK, Institute of Microbiology, Czechoslovak Academy of Sciences, Prague.

Three cell-pool tryptophan phases were recorded as characteristic of the alkaloid formation by 
Claviceps paspali grown in a simple defined medium without tryptophan. In the early phase designated as "tryptophan down" tho alkaloid-biosynthetic activity of the mycelium attains its maximum, protein synthesis is reduced and extrecellular proteasos are formed. Cell-pool tryptophan level (b) drops, tryptophan synthetase activity (c) is intensified and sums of $\log b+\log c$ after different time intervals remain constant. In the subsequent "tryptophan up" phase, tryptophan level (b) increases, the alkaloid yield (a) becomes a function of time and reaches a top level still tolerated by tryptophan synthetase. The difference between $\log b$ and $\log c$ is constant. The tryptophan synthetase diminishes its activity simultaneously with the alkaloid-biosynthetic activity of the mycelium. The region between the "tryptophan down" and "tryptophan up" phases is an especially promising target for the investigation of the control of alkaloid biosynthesis and for continuous fermentation of those compounds. During the third, "tryptophan over", phase, cell-pool tryptophan accumulates and attains a concentration exerting a negative effect on alkaloid biosynthesis.

Production of Aspartic Acid. J. РцachÝ, Research Institute of Antibiotic and Biotransformations, Roztoky near Prague.

Organisms capable of converting fumaric acid to aspartic acid were sought. From the organisms tested, the collection strain Alcaligenes metalcali. genes CCEB312 was selected. Bio-mass serving as the source of the enzyme was prepared by two. stage cultivation in TPB and Asp- 2 media in which glueose or glycerol serve as carbon sources, and peptone and meat broth as complex nitrogen sources. The efficiency of the conversion was affected by the following factors: composition of the growth media, concentration of fumaric acid in the substrate and duration of the conversion. The conversion efficiency can be increased by the application of surface-active compounds and by using homogenates. When optimum conditions were maintained, a conversion efficiency of $84 \%$ was achieved on pilot-plant scale.

Biochemical Dehydrogenation of Some Deoxysaccharides. M. KulHÁNEK, M. TADRA, K. LiNEK, S. KDCÁ, Research Institute of Pharmacy and Biochemistry, Prague, and Chemical Institute, Slovak Academy of Sciences, Bratislava.

Three oxidizing strains (Aspergillus niger, Acetobacter gluconicum and Acetobacter suboxydans) were used to test the fermentative dehydrogenation of 2-deoxy-D-glucose, 2-deoxy-p-galactose, 2-deoxyD-ribose, 6-amino-6-deoxy-D-glucose and D-glucosamine hydrochloride. Aspergillus niger converted
2-deoxy-D-glucose fully to 2-deoxy-D-gluconic acid, in the two acetate bacteria the dehydrogenation proceeded further. The heretofore undescribed reducing sugar formed should be, by analogy with dehydrogenation of aldonic acids, identical with 2-deoxy-5-keto-D-gluconic acid. 2-Deoxy-D-galactose and D-glucosamine were dehydrogenated only by the Acetobacters, to the corresponding aldonic acids. 2-Deoxy-D-ribose and 6-amino-6-deoxy-Dglucose remained unchanged. The same acetate bacteria dehydrogenated 2-deoxy-D-glucitol, 2deoxy-D-ribitol and 2-deoxy-D-galactitol. The ketoses formed from the first two alditols should be 5-deoxy-L-sorbose (D-threo-5-deoxy-2-hexulose) and 4-deoxy-L-ribulose according to Bertrand-Hudson's rule. Dehydrogenation of 2-deoxy-D-galactitol to the ketose under these conditions can be explained only by the formation of 2-deoxy-D-3-galactulose (D-threo-2-deoxy-3-hexulose). The identification and structure determination of the new metabolites are now in progress.

Contribution to the Study of Microbial Proteolytio Activity in Eatables. P. Marešová, V. HáJeK, S. Hrubs, Institute of Nutrition Hygiene, and Faculty of Hygiene, Charles University, Prague.

The ability to hydrolyze gelatin and casein in solid media was demonstrated with selected representatives of microbial genera, frequently occurring in foodstuffs. These findings were compared with the results obtained during chromatography of low-molecular fragments formed in the substrate tested after a certain incubation period and further with results of quantitative determination of total ammonia and amide nitrogen in these substrates after deproteinization with trichloracetic acid. It was shown that the rate of proteolysis depends on the proteolytic activity of microorganisms and on their amount, the degree of proteolysis depends on the proteolytic properties of the microorganisms (i.e. on the presence of various proteolytic enzymes). When working with a mixture of two microbial strains, each of which hydrolyzed the protein molecule to different fragments it was found that many of the original fragments were not found in the hydrolyzates while new fragments occurred. It appears that under these conditions we are dealing with a qualitatively different process of protein degradation than encountered in work with isolated strains.

Contamination of Egg Dough Products with Staphylococcus aureus; Results of Cleaning and Disinfection in Dough Production. S. VYchodruoví, Regional Station of Hygiene, Ceské Budł̋jovice.

In 1969-1970 the hygiene station tested a total of 1,972 samples (raw material, dough, nondried 
product, final product) and some 200 surfacescraped samples from the production lines, machines, hands and clothes of the factory workers. The aim was to localize the sources of contamination and contaminating nodes and to liquidate Staphylococcus aureus from dough products. The counts of St. aureus in the individual final products were at first $10^{3}-10^{9} / \mathrm{g}$. The primary contamination could not be identified. At that time the constant source of contamination was the ground recycled waste, the secondary contamination nodes being remains of dough in inaccessible and closed parts of machines which may, in spite of regular cleaning and disinfection, occasionally contaminate the product, a finding of $10^{5}$ cocoi/g final product not being uncommon toward the end of a production cycle. The two-year investigation of incidence of St, aureus in dough products may be concluded by stating that when strict hygienic measures are obeyed primary contamination by man could occur only at the end of the production line, during cutting or packaging. If economic considerations prevent the discarding of the ground waste it can be recycled only after previous microbiological examination. Once Staphylococci are introduced into the production line (particularly with long products) they will readily convert it to a continuous-flow cultivator.

Microbiological Findings in Vacuum-Packaged Milk. M. Gabrhelová, Regional Station of Hygione, Coské Budéjovice.

The microflora of vacuum-packaged milk was investigated. During the first period a total of 235 samples of dairy milk and 181 samples of partly skimmed milk were investigated. In both types of milk, high counts of Escherichia coli, Enterobacter, and some Pseudomonas aeruginosa and Staphylococcus aureus were found. The presence of Enterobacteriaceae indicates that the milk was contaminated after pasteurization bofore pouring it into the polyvinylchloride bags. The bags themselves were found to be completely sterile. In the second period of survey a total of 61 samples of dairy milk and 42 samples of partly skimmed milk were examined. The milk was collected directly in the dairy plant as well as from the dairy shops. The supervision over pasteurization and filling was increased in the plants. The results confirmed our assumptions: when all the hygienic measures were adhered to the quality of milk rose and microbiological findings dropped to a minimum

Influence of Montmorillonite on the Formation of Bio-mass and Metabolic Products by Some Techni. cally Important Microorganisms. Z. FILIP, K. HAI. DER, J. P. Martin, Department of Microbiology, College of Agriculture, Prague; Institute of Soil
Biochemistry, Agricultural Research Institute, Braunsehweig; Department of Soil Science and Agricultural Engineering, University of California, Riverside, Calif.

The addition of montmorillonite to stationary and shake-cultures of various microorganisms usually increased the total bio-mass formation and accelerated the utilization of nutrients. These effects were noted especially under aerobic conditions and during the initial growth phases. The formation of ethanol by Saccharomyces cerevisiae and citric acid by Aspergillus niger was accelerated but not significantly increased. Manometric measurements with Saccharomyces cerevisiae showed a higher respiratory quotient which increased with rising concentrations of montmorillonite. The relation between bio-mass formation and glucose consumption indicates a more officient utilization of the energy source for synthetic processes.

Effect of Growth and Substra:e Concentration on the Development of Bacterial Growth under Chemostat Conditions. P. Punčochář, Hydrobiological Lab. oratory, Czechoslovak Academy of Sciences, Prague.

The attachment and development of the growth of several bacterial strains on the surface of glass exposed in a single-stage continuous-flow apparatus was investigated. The bacterial strains used were isolated from natural surface waters - both from growth and from free water. Glucose or starch were used as the sole source of organic carbon in a defined medium where the ratio of carbon to nitrogen to phosphorus was $10: 4: 1$. The intensity of growth of bacteria on the glass surface under steady-state conditions was compared at different dilution rates and substrate concentrations. Two of the three strains studied formed more pronounced growth at the higher growth rate $(\mu=$ $\left.=0.3-0.5 \mu_{\max }\right)$ rather than at the very low $\mu$ $\left(0.1-0.2 \mu_{\max }\right)$. The effect was more pronounced in experiments with starch. In the third bacterial strain no analogous relationship was found at $\mu=0.04-0.5$ hour $^{-1}$.

Contribution to the Estimation of Aeration Efficiency of a Fermentor Provided with a Draft Tube. A. PRo. KOP, M. SoboTkA, Institute of Microbiology, Czechoslovak Academy of Sciences, Prague.

Two estimation methods of volumetric transfer coefficient of oxygen, $K_{\mathrm{L}} \mathbf{a}$, in a fermentation equipment, are briefly reviewed: gassing-out and dynamic methods. The actual records and the corresponding graphical solutions are illustrated for two distinct geometrical configurations of the fermentor: an open flat turbine and a turbine provided with a draft tube. The revolutions of the 
turbine appear to be an important variable. Above a certain critical level of mixing, the turbines selfinduce a certain amount of air into the liquid from the space above the stationary liquid level. The vortex formed during the start-up period above critical revolutions complicates the estimation of aeration efficiency. A method is suggested for overcoming the problem. Comparison of the data is presented for both geometrical configurations with and without vortex formation. Usually, the volumetric transfer coefficient is lower in the presence of a vortex under otherwise identical conditions.

Droplet Size Frequency Distribution of the Dispersed Hydrocarbon Phase in a Fermentation Process. A. Prokop, M. Ludvík, Institute of Microbiology, Czechoslovak Academy of Sciences, Prague and Institute of Chemical Technology, Technical University, Prague.

In growth models proposed for a culture with two liquid phases (Biotechnol. Bioeng. 11, 449; $467 ; 489 ; 1969$ ) it was assumed that the growth of yeasts on gas oil occurs at the surface of the dispersed phase where the growth-limiting substrate is dissolved. In such a bateh fermentation, according to models and experimental results, relatively long regions of linear growth occur. This linear growth is probably due to dispersed phase surface area limitation. The technique for estimating the size frequency distribution of drops has been applied to batch fermentation. A gradually increasing interfacial area was observed from the beginning to the end of fermentation. The shape of the distribution and experimental limitation of the technique are discussed. An attempt to fit the distribution data by an empirical function and the use of interfacial area for design purposes will be outlined.

Oxidation of $n$-Alkanes by Yeasts. Z. RADĚJ, J. Axtušek, D. Hatama, Research Institute for Oil and Hydrocarbon Gases, and the Faculty of Chemical Technology, Slovak Technical University, Bratislava.

Using a mineral medium with pure $n$-alkanes and their mixtures we compared the growth and the amount of lipids in the bio-mass in cultures of Candida lipolytica. Suitable combinations of nitrogen sources were compared. During limitation with nitrogen $(C: N+75: 1)$ it was found that the content of the lipid fraction rises from the usual cultivation values on $n$-alkanes, i.e. from $8-10 \%$ to about $40 \%$ lipids per yeast dry weight. The fraction of fatty acids in the lipid fraction was about $33 \%$. During nitrogen limitation it is reduced only insignificantly. When growing the yeast on narrow distillation fractions of $n$-alkanes the predominating intracellular fatty acids correspond in their number of carbon atoms to the hydrocarbons used. In contrast to this, cultivation on $n$-tetradecane resulted in a majority of even-numbered fatty acids $\left(\mathrm{C}_{14}, \mathrm{C}_{16}, \mathrm{C}_{18}\right)$, the content of myristic acid amounting to only $11.1 \%$ of the total amount of fatty acids. The content of phospholipids varies about the value of $3.7 \%$ per bio-mass dry weight and decreases to $2.4 \%$ in nitrogen limitation. A relatively high nonsaponifiable fraction was found. A greater part of the fraction is hydrocarbons. For the sake of comparison, the lipid fraction of Bacillus licheniformis was characterized. The lipids amounted to $9.2 \%$ dry weight, the fatty acids representing $44-48 \%$ of this. The amino acid content was similar to cultivation on sugar substrates, except for the greater content of lysine, glutamic acid and leucine.

Methods of Determination of Hydrocarbon Toxicity. M. Cerñárova, D. Hacama, H. Rajnohová, Faculty of Chemical Technology, Slovak Technical University, and Research Institute for Oil and Hydrocarbon Gases, Bratislava.

The determination of the microbicidal and microbistatic effects of hydrocarbons is complicated by their relatively low solubility in water and high volatility. The testing methods must proceed from these properties. The authors compared the applicability of several testing methods using bacteria and yeasts, differing in their ability to utilize hydrocarbons.

Comparison of Toxicity of Aromatic Hydrocarbons. D. Hatama, M. Čern̆áková, H. Rajnohová, Faculty of Chemical Technology, Slovak Technical University, and Research Institute for Oil and Hydrocarbon Gases, Bratislava.

The microbicidal and microbistatic effects of cyclohexane, benzene and of some alkylbenzenes were compared in growing and resting microbial cells. Most cultures were fresh isolates from accumulating cultures with aliphatic and aromatic hydrocarbons as the sole source of energy and carbon. The microorganisms tested were Saccharomyces cerevisiae, different cultures of Candida (mostly C. lipolytica), Escherichia coli, and different species of Pseudomonadaceae. The hydrocarbons used included cyclohexane, benzene, toluene, $\mathbf{x y -}$ lenes, ethylbenzene, cumene and naphtalene, and their mixtures with aliphatic hydrocarbons. The results obtained are compared with literature data on physical toxicity. 
Use of Invertase for Blocking Fermentation of Confectionery Products. V. Országhovi, D. RoNovsKÁ, N. Kiestinaerová, Czechoslovak Chocolate Factories, Modřany.

Final confectionery products are frequently damaged by osmophilic yeasts. The possibility of the application of yeast invertase to suppress the reproduction of osmophilic yeasts has been mentioned in the literature with reference to some special products. It was found that for yeast activity in confectionery products the composition of the liquid phase is of importance. As soon as the liquid phase attains a concentration of different sugars corresponding to $62 \%$ reproduction of yeast cells is blocked. Solutions of $66 \%$ may also offer sufficient protection. By using invertase, this value may be achieved in some confectionery pro. ducts. We took up the problem and observed that some species of osmophilic yeasts may even grow in sugar solutions with $66 \%$ and hence the application of invertase will only reduce the danger of infection with yeasts but will not prevent it.

Problems of Definition of Osmophilic Yeasts. V. ORszághová, N. Kiestangerová, M. RuML, Czechoslovak Chocolate Factories, Modrany, and Research Institute of Agricultural Technology, Repy near Prague.

Some fifty yeast strains from the State collection as well as from the raw materials or final products of the confectionery industry were tested for their ability to grow on liquid and solid nutrient media containing different concentrations of glucose (2 to $60 \%$ ). Series of transfers (sudden, alternating and gradual) between media with different concentrations of glucose were used. It was found that (1) in most yeast strains some cells could survive and reproduce even in media with a high glucose content, (2) with the yeast strains used the term "osmophilic" does not describe their properties since even cultures growing finely in the most concentrated solutions of glucose will grow and metabolize better in media with a low glucose content.

Medium for Selection of Pseudomonas aeruginose from Mixed Populations in Nonsterile Pharmaceutical Products. M. A. F. Aвpou, Boehringer Sohn, Department of Quality Control, Ingelheim/Rhein.

In accordance with USP XVIII, as well as with Swedish, Swiss and Czech proposals, nonsterile pharmaceutical products, particularly the "topicals", may not contain some Pseudomonas aeruginosa. Since these products contain few, particularly saprophytic, microorganisms, it is hardly possible to detect Pseudomonas aeruginosa if it is present in a small minority, by the hitherto recommended diegnostic methods. On the basis of an extensive study of the biochemical propertios of 95 Pseudomonas aeruginosa strains it was es. tablished that adipica cid and sebacyl chloride are utilized by all strains within $24-48$ hours at $37-40$ C. Both compounds are of special practical significance since it was shown here that they are utilized by very few microorganisms besides Pseudomonas aeruginosa and if at all, then only rather slightly. On adding Ampholyt KKP 70 which is known to affect Gram-positive and Gramnegative bacteria, as well as fungi and yeasts, only Pseudomonas aeruginosa remains able to utilize adipic acid and sebacyl chloride. Samples of several nonsterile pharmaceutical products were homogenized in a phosphate buffer and inoculated with a suspension of 100 different microorganisms when the fraction of Pseudomonas aeruginosa amounted to $10^{-5}-10^{-8}$. The suspensions were prefiltered and microorganisms removed by mem. brane filtration. The membrane filters were then rinsed with phosphate buffer, laid on plates and covered with $20 \mathrm{ml}$ of a broth containing adipic acid, sebacyl chloride and Ampholyt. After 36 to 48 hours of incubation at $40 \mathrm{C}$, a loop of the broth was removed and smeared either on modified peptone-glycerol-Ampholyt agar or on Bacto Pseudomonas Agar $\mathrm{P}$ with the addition of Ampholyt. The agar was then incubated for 24 to 36 hours at $38 \mathrm{C}$ to enhance the production of fluorescent pigments and pyocyanine, as well as to obtain a pure culture of Pseudomonas aeruginosa. With the aid of this selective procedure, Pseudomonas aeruginosa was isolated from sewage water and from animal dung. The procedure can be applied to selective isolation of Pseudomonas aeruginosa from water, raw matorials, foodstuffs, and clinical material.

Thermoresistance of Mycobacterium avium in Artificially Infected Cured Meat Products Containing Pork Liver. J. HoLec, Veterinary College, Brno.

When studying the thermal resistance of $M y c o-$ bacterium avium in artificially infected liver loaf and in choice liver sausage it was found that the decrease of Mycobacterium avium can be taken as a linear function of time between 60 and $70 \mathrm{C}$. The slopes of the regression lines amounted to $0.23-0.30$ in the present experiments. In practical application of the results obtained when account must be taken of errors of the measuring equipment, of the effect of differences in raw material composition, of errors and fluctuation of the temperature regime in different types of technological equipment and of the biological variability of the heat resistance of various strains of $M y$ cobacterium avium, it is recommended to consider a factor of $5-7$ as a safety coefficient. 
Occurrence of Desulphurizing Bacteria in Mineral Waters and Their Cultivation. L. Svoncová, Research Institute of Balneology at Mariánské Láznè, Microbiological Laboratory, Karlovy Vary.

The incidence of desulphurizing bacteria in mineral waters was examined. A total of 16 different nutrient media were tested for these purposes, most of them rather complex, demanding in terms of time and labour and hence unsuitable for routine control. An original medium (DSB) was prepared here on the basis of essential nutrients and checked by using a pure culture of Desulfovibrio desulfuricans Hildenborough 8303 and other desulfovibrios, as well as soliform bacteria isolated mostly from mineral waters. At the same time, the method was used for examination of 366 samples of mineral waters where, in addition to desulphurizing bacteria, the counts of psychrophilic, mesophilic and coliform bacteria were determined. The ferric bacterial count was determined microscopically. A greater incidence of desulphurizing microorganisms was observed in samples with a high count of contaminating, mostly coliform bacteria. In samples from boreholes with a small incidence of contaminating microorganisms, the presence of Desulfovibrio was detected together with a high incidence of ferric bacteria of the genus Siderocapsa, particularly in waters where multiplication of contaminants during storage is predictable (Podèbradka, Rudolfův pramen). In waters with with a high content of iron and hence with abundant ferric bacteria which have a bacteridical or bacteriostatic effect (Vincentka, Bílinka) the occurrence of desulphurizing microorganisms is rare. It can thus be concluded that the occurrence of high counts of desulphurizing bacteria is caused by the presence of higher counts of contaminants.

Some Factors Influencing the Rate of Bacterial Reproduction in the Slapy Reservoir. V. STRAŠkRABovÁ, Hydrobiological Laboratory, Czechoslovak Academy of Sciences, Prague.

It was found in laboratory experiments that changes in bacterial count on membrane filter after short-term incubation (Ch) are proportional to the rate of bacterial reproduction in a liquid medium. The same method was applied to samples from the Slapy reservoir. In samples from the reservoir outflow Ch was directly proportional to the flow of water at the time of sample collection. Bacterial counts in water were indirectly proportional to the flow. Ch in samples from the water level was in direct relation to the concentration of phosphate $P$ in water as long as there was ample ammonium nitrogen. At the time of its deficit the $\mathrm{Ch}$ was low in spite of a considerable concentration of nitrate nitrogen and dissolved organic nitrogen. During the period examined no relationship between $\mathrm{Ch}$ and the primary production of algae was established except where the primary production was extraordinarily high. There the value of $\mathrm{Ch}$ was also high even at a low concentration of phosphate $\mathrm{P}$ and ammonium $\mathrm{N}$ in the water.

Effect of Banana Pulp and Extracts on Some Members of Enterobacteriaceae in vitro. H. PUzovA, L. Dúbay, V. Janigová. D. Kahanec, Department of Microbiology and Pediatric Clinic, Faculty of Medicine, P. J. Safárik University, Košice.

Banana pulp as well as its extracts release a substance into the medium which inhibits the growth of the genera Shigella, Proteus, Escherichia and Salmonella. In addition to a direct effect on the corresponding strain, we also examined the effect on the association of Proteus with Escherichia. In this association Escherichia shows much better growth than in a monoculture while Proteus is more pronouncedly inhibited than in the monoculture under the same conditions. On the basis of the in vitro findings it can be concluded that a banana diet (as supported also by clinical oxperience) controls the association of Proteus with Escherichia in favour of the latter. Toward salmonellas and shigellas it acts bacteriostatically and bactericidally which makes it possible to use bananas and related dietary preparations directly in therapy.

Contribution to the Evaluation of Fresh Milk by its Microbiological Quality. I. HuDEC, Department of Food Hygiene, Central State Veterinary Institute, Bratislava.

The world-wide trend as well as our experience indicate that nutrition hygiene requires greater attention to be paid not only to the chemical composition of milk but also to its microbiological quality. Microbiological testing of milk reveals first of all whether it contains pathogenic or toxicogenic microorganisms as well as its overall microbio. logical quality. A poor quality of fresh milk is caused mainly by its insufficient microbiological purity as well as by inadmissible contamination with milk from mastitic cows. It is also undesirable that other inhibitory compounds be present, such as antibiotics, some nonapproved preservatives, especially soda, hydrogen peroxide and formaldehyde which are sometimes used to "improve" the microbiological quality of milk. In addition to brief results of the laboratory tests of fresh milk connected with the campaign for dif. ferentiated prices of milk according to its microbiological value in 1970 in Slovakia, the report contains several original observations made in the microbiological testing of fresh milk. The results achieved are to be taken as a very useful contribution to the improvement of the level of hygiene 
in milk production and hence to an increase of its biological value. In addition to classical microbiological tests, enzyme tests (on account of their technical feasibility) may be considered as useful in the evaluation of fresh milk quality. For rapid orientation in the hygiene of production, correct refrigeration and possible bacterial contamination of fresh milk, satisfactory results may be obtained by the resazurin test.

Significance of Bacterial Nitrate Reduction in Vege. tables. D. Hlavsová, J. Černá, J. Tư̌́EK, B. Turek, District Hygiene Station, Klatovy, and Regional Hygiene Station, Plzen̆.

The participation of microflora in biochemical processes in foodstuffs is displayed in various ways. The authors examined the importance of microflora for reduction processes in vegetables with a view to the reduction of nitrates to nitrites. Bacterial reduction of nitrates to nitrites is an essential pre. requisite for the occurrence of alimentary methemoglobinemia of infants. Conditions of bacterial reduction were investigated with reference to the presence of individual microorganisms in the bacterial flora of vegetables and other media and with special emphasis on the presence of nitrate reductase. The reduction processes were evaluated under conditions of artıficial contamination with Escherichia coli. In view of the different conditions exogenous and endogenous reduction may be distinguished. The hygienic aspects of these problems are discussed.

Myceliostatic Activity of Organic Tin Compounds. J. Drga, Institute of Hygiene, Faculty of Medicine, Komenský University, Martin.

The myceliostatic activity of two organo-tin compounds was examined: Mellite 131, an organotin stabilizer with a sulphur bridge, and the stabilizer 554, a dibutyl-tin compound. To determine the efficiency we used a fungus from the Collection of the Biological Institute, Czechoslovak Academy of Sciences, designated as Fungi imperfecti 107. The nutrient medium used was wort with agar on which the fungus grew in an area with a clearly defined growth zone. Slide cultures were used for inoculation. The myceliostatic activity of the com. pounds studied was evaluated on the basis of absolute growth activity. Under our conditions we observed a statistically significant inhibitory effect during the very first day of applying the compounds.

\section{SECTION OF AGRICULTURAL MICROBIO- LOGY}

Use of Oxygen Electrode for Measuring Respiration in a Soil Suspension. V. DroBníková, V. PaŚA-
Ková, Z. Př́kry,, Department of Plant Physiology and Soil Biology, Charles University, Prague.

Clark's oxygen electrode was used for measuring respiration in a soil suspension. The electrode system is formed by a platinum disc cathode $1 \mathrm{~mm}$ in diameter covered with a polyethylene membrane $35 \mu \mathrm{m}$ thick, and a silver anode. Potassium chloride solution serves as the electrolyte. The measurements were made at an applied voltage of $-0.6 \mathrm{~V}$, corresponding to the lst plateau of the polarographic wave of oxygen. In view of the dependence of the diffusion current on temperature $(7 \% / 1 \mathrm{C}$ ) all the measurements were done at constant temperature $(25 \mathrm{C})$ in a glass constant-temperature vessel. The consumption of oxygen determined with the electrode was compared with the values determined by Warburg's manometry. Both methods produced identical results, both asconcerns a pure bacterial culture and a suspension of different soils. The relative standard deviation for the rate of respiration of bacterial suspension was $2 \%$, for soil suspensions $3-4 \%$. The concentration of oxygen was so high during the $15-20 \mathrm{~min}$ that it could not be the limiting factor in respiration. The results show that, in view of its simple and quick bandling, the erectrode can be used for measuring actual respiration of freshly collected samples and for determining the instantaneous reaction to various physical and chemical factors.

Effect of Incubation Soil Humidity on Respiration. Intensity. Z. PřIKRyL, Department of Plant Physiology and Soil Biology, Charles University, Prague.

Warburg's method was used to study the effect of different incubation humidity on the intensity of respiration of four different soils not enriched with substrate. The starting humidity was determined by the humidity of soil dried in air. The results supported the assumption that the oxygen consumption depends on the value of water po. tential of the soil corresponding to the given in. cubation humidity. The dependence may be described by equations identical with those described by Seifert for the intensity of nitrification and bacterial count (Folia microbiol. 14:89, 1969). For the sake of clarity of graphical representation the value of $\log f_{r}$ in these equations has been replaced by its negative value and designated $\log Q_{\psi}$. The first equation then takes the form $\log \left[\mathrm{O}_{2}\right]=$ $=\log K+\log Q_{\psi}$ where $\left[\mathrm{O}_{2}\right]$ is the oxygen consumed in $\mu \mathrm{l} / \mathrm{g}$ and $K$ is a constant. $Q_{\Psi}$ is then related to the value of water potential as follows: $\log Q_{\psi}=k \cdot p F+q$ where $p F$ is the water potential of the soil defined by its incubation humidity and $k$ and $q$ are constants.

Microbiological Reduction of Sulphates in Agricultural Soil. M. AmBrožová, Research Institute of Agrotechnical Principles, Hrušovany near Brno. 
The merits of two methods of microbial reduction of sulphate were compared and the possibility of their application to the examination of agricultural soils was studied. Both the plate and the titre methods were able to indicate the relative degree of anaerobiosis in a soil medium and the relative value of intensity of reduction processes in soil. In this context both methods can be considered as suitable for soil research, in particular where irrigation and fertilization with sulphate and superphosphate are used. The addition of organic components had no effect on the development of desulphurizing bacteria or on the reduction of sulphates. In field experiments a dependence of sulphate content in soil on the degree of biological desulphurization was observed under certain conditions.

Excretions of Germinating Plant Seeds. V. VANČURA, G. STotzky, Institute of Microbiology, Czechoslovak Academy of Sciences, and New York University, New York.

Colonization of germinating seeds by soil micro. organisms is substantially affected by the amount and composition of exudates released into the soil by seeds. Before the first root appeared, the germinating seed of cucumber, barley, wheat and bean released as much as $108-517 \mu \mathrm{g}$ different compounds into the medium, besides gaseous and volatile substances. The amount of exudates by the plants examined was directly proportional to the size of the seed although apparently various deviations are found, in particular between varieties of the same species. A greater proportion of the total nitrogen was formed ky nitrogen of proteins and peptides rather than by that of free amino acids, which is the opposite to the situation with root exudates. Peptides represented $8-26 \%$ of the protein + peptide fraction, the greatest amount being found in the bean. The spectrum of the released amino acids differed from the root exudates only little, considerable differences being found in the spectrum of released sugars. The spectrum of organic acids in the seed exudates of the bean was poorer than in root exudates. With other seeds the differences were small. The liberation of gaseous and volatile compounds by germinating seeds precedes the appearance of the first root. The amount produced by a single bean will reduce $6.5 \mathrm{ml} 0.01 \mathrm{~N}-\mathrm{KMnO}_{4}$, by a single maize seed $9.0 \mathrm{ml}$, by different species of pea $1.0-11.0 \mathrm{ml}$. Gas chromatography was used to study the time changes of liberation of ethanol, methanol, acetaldehyde, propionaldehyde and/or acetone, formic acid and ethylene. Release of formaldehyde and propylene is also assumed.

Formation and Decomposition of Bacterial Polysaccharides in the Rhizosphere. J. LAstK, L. KoFrA-
Ková, Institute of Microbiology, Czechoslovak Academy of Sciences, Prague.

A group of polysaccharide-producing bacteria were isolated from wheat roots. Intense decomposition in soil particularly affects exocellular polymers. of two bacteria, diagnosed as Pseudomonas desmolyticum and Achromobacter delicatulum. Their utilization and that of the exocellular polysaccharide of Xanthomonas fuscans by bacteria isolated from control soil and from soil preincubated with the corresponding polysaccharides was examined. The decomposition of the polysaccharides by various bacterial isolates took place with different intensity. The constituents of the polysaccharides were utilized simultaneously but not evenly. The composition of the individual sugar components and their mutual proportions after hydrolysis were investigated. With all the polymers, the presence of uronic acids and of bound pyruvic acid was found. To provide evidence for polysaccharide pro. duction in the rhizosphere and to differentiate between plant polysaccharide mucus on roots and the products of bacterial origin, the root exudates of sterile-grown bean were studied in a control untreated variant, in one grown in a soil suspension and with the addition of cells of Xanthomonas fuscans. Differences in the content of free and bound sugars, amino acids, organic acids, uronic acids etc. indicate that plant roots are covered with a gel sheath priginating both from the plants and from the surrounding bacteria.

Decomposition of Coumarin in Soil. F. KUNC, Inf stitute of Microbiology, Czechoslovak Academy oSciences, Prague.

The decomposition of coumarin in samples of chernozem soil was investigated on the basis of manometric measurements of oxygen consumption, of chromatographic analysis of aromatic metabolic intermediates in the soil extract and of their UV spectra, and of a technique of simultaneous adaptation. It was found that coumarin is decomposed in the soil via o-coumaric acid and at least two other aromatic compounds, one of them probably being melilotic acid. The well-known metabolic pathway via salicylic acid and catechol could not be dernonstrated. 39 strains of bacteria capable of decomposing coumarin were isolated from the soil. Of these, 25 belonged to the genus Pseudomonas, 7 to Cellulomonas and 7 to Achromobacter. It followed from a comparison of the amount of bacteria capable of utilizing coumarin as the sole source of carbon in garden soil, two samples of chernozem and brown acid soil that their incidence is not related to the total bacterial count (grown on an agar medium with a yeast and soil extract and tryptone) or to the content of carbon and nitrogen in soil. 
The Effect of Montmorillonite on the Growth and Formation of Humic Substances by Epicoccum nigrum. Z. Filip, W. Flaig, H. Beutelspacher, Department of Microbiology, College of Agriculture, Prague, and Institute for Soil Biochemistry, Agricultural Research Institute, Braunschweig-Völkenrode.

Changes in $\mathrm{X}$-ray spectra of montmorillonite were observed during cultivation of Epicoccum nigrum. Expansion of the interlayers takes place due to embedding of metabolic intermediates of the fungus during the first 10 days. During further growth of the fungi a contraction takes place and the initial state is recovered. This may be caused by an ex. change of organic substances for ammonium ions which are formed by autolysis. The surption removal of noxious substances (presumably phenols) from the culture medium may be one of the reasons for an increase of biomas which leads secondarily to an increased formation of humic substances in the case described.

Contribution of the Study of the Turnover of Organic Material by Anaerobic Microflora. J. PokoRná, S. Bönischová, Laboratory for Soil Biochemistry, Institute of Plant Nutrition, Research Centre of Plant Production, Prague-Ruzyně.

Liquid and semiliquid forms of farm fertilizers give rise to conditions for anaerobic processes. It is hence important to check to what extent the dynamies of organic matter is changed by anaerobic micro. flora. To study the anaerobjc conditions of farm manure we suggesred an application of stimultaneous cultivation of an anaerobic microorganism with anaerobic microflora in a closed regime. As suitable indicator organism for incubation under microaerophilic conditions we chose Serratia marcescens. An optimal growth of Serratia marcescens was observed during cultivation with an anaerobic suspension of the tested material in a Petri dish. An aluminium foil is used as a suitable barrier between the nutrient medium for the anaerobic microflora and the Serratia marcescens grown on the surface of the growth medium on an aluminium foil. The purpose of the foil was to protect the colonies of Serratia marcescens from the anaerobic microorganisms and vice versa, further to prevent diffusion of the metabolites of Serratia marcescens and their effect on the growth of the anaerobic microorganisms. The aluminium foil also served as a suitable surface for individual detection of colonies of anaerobic microorganisms. The method ensures the removal even of traces of oxygen, macroscopic identification of the degree of aerobiosis in a closed system and prevents the growth of microaerophilic microorganisms. The cultivation technique was found especially suitable for the detection of anaerobic microflora in several samples of farm manure.
Effect of Fresh Ground Town Refuse on the Intensity of Microbiological and Biochemical Changes in the Course of Maturation of Industrial Composts. A. Stikova, F. LöBL, J. Košatková, lnstitute of Plant Nutrition, Research Centre of Plant Production, Prague - Ruzynè.

Preliminary results of composting fresh ground town refuse indicate that its negative effects on direct application might be removed (see the paper by Löbl, Stiková, Vána) and, on the other hand, that the refuse might increase the quality of maturation of industrial organic fertilizers. During com. posting fresh ground town refuse with its $40 \%$ raw material composition $(25 \%$ bark from the barker, $20 \%$ peat, $10 \%$ inoculation compost, $5 \%$ lime dust, plus sewage sludge) not only was a favourable temperature acheved during maturation (48-63 C for 2 months) but also an appreciable multiplication of thermophilic and mesophilic microorganisms of some investigated cultivation groups. This was reflected particularly in the pronounced multiplication of thermophilic and mesophilic growing on MPA and of mesophiles growing on starch and Thornton agar. The high representation of sporeforming microorganisms and the minute representation of actinomycetes toward the end of maturation indicate ample quantities of easily decomposed organic compounds. This fact is further demonstrated by the gradually decreasing basal respiration (from 16.2 at the beginning to $10.2 \mathrm{mg} \mathrm{CO}_{2} / 100 \mathrm{~g}$ dry weight per hour toward the end of maturation), together with decreasing relative respiration expressed by $\mathrm{N}: \mathrm{B}, \mathrm{G}: \mathrm{B}$ and $\mathrm{NG}: \mathrm{B}$. The decreasing stability of organic compounds (NG : B) indicatos that we are dealing here with a slow decomposition of the organic matter present, together with utilization of the intermediates of the degradation (high basal respiration). It thus follows that by adapting the technology of compost production to the conditions of microfloral growth a high degree of conversion of town refuse to good-quality organic fertilizer might be achieved.

Changes in the Microflora and Some Biachemical Changes in Soil Following Application of Ground Fresh Town Refuse. F. LöBL, A. Struková, J. VÁN̆a, Institute of Plant Nutrition, Research Centre of Plant Production, Prague--Ruzynè.

The present production of refuse in Czechoslovakia is $150 \mathrm{~kg}$ per capita annually and it is expected to rise soon to $250-270 \mathrm{~kg}$. In many countries the refuse is incinerated or, in view of the $60 \%$ content of organic material and nutrients, composted. The composting is frequently described as expensive and hence cheaper ways of application to soil are being sought. One of them is a direct application of fresh ground refuse to soil. Under field vegetation conditions, we followed the application 
of 30 and 90 tons of fresh ground refuse per hectare introduced in the spring without and with NPK fertliizers $\left(100 \mathrm{~kg}\right.$. N, $80 \mathrm{~kg} \mathrm{P}_{2} \mathrm{O}_{5}$ and $100 \mathrm{~kg} \mathrm{~K} \mathrm{~K}_{2} \mathrm{O}$ ) in a potato field, comparing the effects with a control lot without fertilizer and with compost. It was found in the soil samples collected during vegetation that the town refuse, especially at the dose of 30 tons/hectare + NPK, decomposes intensely, as indicated by the pronounced increase of participation of bacteria growing on MPA, starch, nuclein and phosphate agar and particularly of filamentous fungi growing on Jensen's agar. The increased activity of the microflora powerfully influences the basal soil respiration. In view of the content of readily decomposable compounds in ground refuse and of the suitable amount of NPK nutrients, there was no lack of utilizable carbon and nitrogen and the turnover of organic matter was observed throughout the vegetation period, as indicated by the gradually increasing stability of organic compounds ( $\mathrm{NG}: \mathrm{B})$. In spite of this positive fact and of a simultaneous increase in potato yield the procedure is not to be recommended at present as the dose of $\mathbf{3 0}$ tons refuse/hectare diminishes the market quality of the potatoes, due to inferior quality of the soil, which after the treatment described has the typical stench of town garbage.

Central European Alluvial Grasslands: Production and Decomposition of Organic Matter (IBP Project). B. ÚlemlovA, Botanical Institute; Czechoslovak Academy of Sciences, Brno.

The production and decomposition of organic matter was studied in grassland communities of the alluvial deposits of the Morava and Dyje Rivers in southern Moravia. The aim of the study was to obtain information on the following points. (1) an. nual production of grassland vegetation and the quantity of underground organs. (2) The part of this production that returns to the soil. (3) The decomposition and transformation rates of some organic materials in the soils under study. (4) The role played by soil fauna and microflora in the de composition. (5) The verification, in model laboratory experiments, of the conclusions reached in field studies. The study is based on: (1) General characteristics of vegetation, soil and climate. (2) The measurement of some important environmental factors during the growth seasons. (3) The plant biomass and litter estimation. (4) The soil microflora biomass estimation. (5) The composition and dynamics of the soil mesofauna. (6) Soil activities: cellulose decomposition, $\mathrm{N}$ transformations. (7) Complete evaluation of field results. (8) Model experiments reflecting the influence of environmental factors on some soil biological processes.

Utilization of $N, P$ and $S$ Additions by the Cellulolytic Microflora of Some Grassland Soils. M. TEsa-
Řová, Botanical Institute, Czechoslovak Acaderny of Sciences, Brno.

Soil samples of three grassland plant communities were used for the experiments. The effect of $\mathbf{N}$, $P$ and $S$ additions on the intensity of cellulose decomposition was studied in seven experimental variants ( 1 control, $2+\mathrm{P}, 3+\mathrm{S}, 4+\mathrm{N}, \mathbf{5}+\mathrm{P}+\mathrm{N}$, $6+\mathrm{S}+\mathrm{N}, 7+\mathrm{P}+\mathrm{S}+\mathrm{N})$. The incubation of soil samples proceeded for the period of 21 days at $28 \mathrm{C}$ and at constant soil moisture $(60 \% \mathrm{MWC})$. Whatman No. 2 paper was used as a source of cellulose. The utilization of individual nutrient addi. tions by cellulolytic soil microflora, expressed by the amount of cellulose decomposed per mg of applied nutrients, was in close connection with the soil condition at the beginning of the experiments. The degree of utilization of $N, P$ and $S$ by the cellulolytic microflora varied in the soils studied. On the average, the greatest effect on the rate of decomposition was found on the addition of $\mathrm{N}$, followed by additions of $P$ and $S$.

Distribution of Soil Micromycetes and Their Signifi. cance. J. BrRNAT, Department of Microbiology, Faculty of Natural Sciences, Komenský University, Bratislava.

Micromycetes form an important component of the microbial soil population. They can thus influence the character as well as the intensity of microbial processes by their activity. Although their significance in individual soil types is not understood it can be said that in soils where they form a predominant component of the population they can be of decisive importance. We followed their distribution from semidesert soils of arid regions to podzols. Besides the representation of the individual species we also studied their significance during various processes. The results make it possible to draw several general conclusions. From the factors affecting the distribution we should men. tion first of all humidity and, in association with it, also the osmotic value of the soil solution, further acidity of soil, character of organic com. pounds, content and composition of mineral nutrients. It appears that temperature only affects the distribution of thermophilic species. Decomposition of cellulose proceeds in soils of arid regions predominantly through the action of micromycetes, especially by members of the genus Chaetonium and by some species of the family Dematiaceae. A considerable proportion of species from arid re. gions have the power of nitrification while the same species from humid regions_lack this ability. Species from arid regions can even decompose humus sub. stances. The arid soils contain much fewer Penicillium, Absidia and Mucor species while Cunningham. iella and Aspergillus are more abundant. Further differences exist especially in species representation. 
Decomposition of Humus Acids by Micromycetes. A. Dubovská, Department of Mierobiology, Faculty of Natural Sciences, Komenský University, Bratislava.

The principal problem in the dynamics of humus is the mineralization of humus acids during which some nitrogen and carbon compounds important for plant and soil microorganisms are liberated. It is hence understandable that the decomposition of humus acids by microorganisms is being studied with great intensity. To obtain humus acids from four types of soil we used different isolation proce. dures. It was confirmed that fulvo acids (FA) and humus acids (HA) differ in quantitative and qualitative parameters depending on the type of isolation, type of soil, kind of fraction used, and method of its purification. The facts thus observed affect the extent of microbial decomposition of these compounds. In view of the great representation of micromycetes in soils, particularly of podzol type, we concentrated on this group of microorganisms. We isolated a number of species and, using their pure cultures for decomposition of FA (or of readily decomposable fractions of $H A$ ) the following relationships were established. The optimal concentration of the FA fractions used for decomposition and utilization by micromycetes depends on the species and on whether the fulvo acid serves as a source of nitrogen or of carbon. Independently of the species of micromycetes used the nitrogen in the FA fractions is utilized more than carbon. The amount of $C$ and $N$ utilized by the micromycetes from the FA applied also depends on the soil type.

Mycaflora of Wheat Roots after Foliar Application of Urea. J. VRANÝ, Institute of Microbiology, Czechoslovak Academy of Sciences, Prague.

Spring wheat (Triticum vulgare Vill. var. Octavia) and winter wheat (Triticum vulgare Vill. var. Mironovská) were grown in loamy-clayey soil (Ćáslav) and in loamy-sandy soil (Modrany) in a greenhouse or in an air-conditioned box. The root mycoflora was studied by the method of serial washings. The count of fungi in the clayey-loamy soil did not change substantially during the experiment, the genera Penicillium, Fusarium, Gliocladium, Humicola, Sporotrichum and Trichoderma predominating. The relative occurrence of fungi of genera Cladosporium, Penicillium and Gliocladium decreased while that of Humicola and Sporotrichum increased during the experiment. The mycoflora of spring wheat seeds contained thirteen species, with predominating Alternaria, Aspergillus, Cladosporium, Myc. sterilia and Penicillium. The mycoflora of spring wheat roots treated with urea and of the control contained 40 fungal species, with Fusarium, Penicillium, Cephalosporium and Cladosporium predominating. The effect of foliar application of urea was reflected in an increased occurrence of Fusarium, Humicola and Torula on the roots while the occurrence of Penicillium, Cladosporium and Pullu. laria was diminisled. Fungi present in smaller numbers on roots cccurred more frequently in control plants. These representatives of the mycoflora belonged mostly to the Dematiaceae. With winter wheat the effect of foliar application of urea was studied under extreme conditions. Changes in the root microflora were studied in soil artificially infected with a fungus. The effect of foliar application under these conditions was to decrease the number of fungi and to change the relative occurrence on the roots of treated plants. The mycofloral changes were related to the changes in plant growth.

Microbiological Characterization of Peat Soits under Various Phytocoenoses. A. Fraño, Department of Geobotany, Faculty of Natural Sciences, Komenský University, Bratislava.

Peat soils differ clearly in their physical and chemical properties frcm mineral soils. The low $\mathrm{pH}$, the high content of organic compounds, high soil humidity and specific type of vegetation are the principal factors bearing on the amount, species representation and intensity of microbial processes. Four peat soils from the upper Hron valley occurr. ing under different phytocoenoses were studied. In the microbial coenoses of the soils, the majority of species are bacteria, followed by actinomycetes and finally micromycetes. From the physiological point of view, ammonization bacteria predominate. The number of microorganisms decomposing cellu. lose is also rather high. Nitrificators are suppressed, Azotobacter being practically absent. Sporulating bacteria form a small proportion of the total count. Among the spore-forming bacteria the most abundant is Bacillus cereus $(30-45 \%)$, followed by Bacillus megaterium and by Bacillus idosus, Bacillus mesentericus, and Bacillus subtilis The ammonization process takes place in all the soils studied very intensively. Nitrification is only slight or absent. Cellulose decomposition is relatively intense and, in the first phase, is due to micromycetes, later to bacteria. The biological activity (production of $\mathrm{CO}_{2}$ ) of the peat soils is high under laboratory conditions. The dynamies of microbial count, representation of various physiolegical groups, intensity of microbial processes over the year, do not display any clear regularity. On the whole, it may be said that peat soils are relatively well colonized by soil micro. organisms and it is only necessary to improve the humidity conditions to bring about a vigorous increase of the activities.

Comparison of Fertilizaticn with NPK Fertilizers, Manure and Straw on the Microbial Activity of Soil. R. Apfelthaler, Institute of Plant Nutrition Research Centre of Plant Production, Prague. Ruzyne. 
In a field experiment we compared lots treated with NPK fertilizers, manure + NPK and straw + NPK for their direct effect (sugar beet) and subsequent effect (wheat). Treatment with straw considerably decreased the amount of soil moisture but the basal respiration $\left(\mathrm{CO}_{2}\right)$ remained vary in tense. The stability of soil organic matter as a whole, indicated by the respiration test, was highest in the variant treated with NPK and lowest upon treatment with straw + NPK. Symptoms of lack of available nitrogen were more pronounced in the variant treated with manure + NPK than in the one with straw $+\mathrm{NPK}$. The capacity of converting mineral $\mathbf{N}$ to organic compounds decreased in the sequence: NPK, manure + NPK, straw + NPK. The nitrification capacity, on the other hand, rose in the same sequence. Fertilization with manure + + NPK increased the presence of amino acid nitrogen, that with straw + NPK the content of amino sugar nitrogen. In comparison with manure, straw with mineral additives undergoes intensive transformations with the lowest level of immobilization of mineral $\mathbf{N}$ of all the variants tested.

Effect of Herbicides on Microorganisms. L. ŠLMoN. Department of Microbiology, Faculty of Natural Sciences, Komenský University, Bratislava.

Attention was focussed on the effect of 7 herbicides (trichloracetic acid, metachloral, pyramine, simazine, atrazine, zeazine and selectine) on soil microflora and on the intensity of some microbial processes. The experiments were carried out under laboratory conditions in four soils, originating from the $\mathrm{SW}$ region of Slovakia. In addition to the usual doses, 10.50-fold greater doses were also employed. This was done because upon application of the usual amounts of herbicide certain microzones can be formed in the soil where the concentration of the herbicide is substantially highor; also, after repeated application of the uneasily decomposable herbicides, a more substantial amount may accumulate which is noxious for th? soil microflora. The results of microbial estimations indicate that the practically used amounts of herbicides (with a few exceptions) do not harmfully affect the soil microflora and the intensity of microbial processes, actually stimulating the activity in most cases. After application of higher doses of herbieides, mierobial aetivity of soils decreased, together with the formation of nitrates, carbon dioxide and, similarly, the aerobic degradation of cellulose was slowed down. Even if the inhibition of the processes is not uniform in the various soils and with the different herbicides used, the drop is appreciable. It was also observed that micromycetes, aerobic cellulolytic microorganisms and sporulating bacteria are most affected by the herbicide application.
Competition between Inoculum Strains of Rhizobium japonicum in Nodulation of Soybean during Three Planting Periods. V. SkrDLETa, Department of Soil Microbiology, Institute of Plant Nutrition, Research Centre of Plant Production, PragueRuzyne.

Competition between D 216 and $311 \mathrm{~B}$ inoculum strains applied in double-strain inocula to the soy. bean seed was directly proportional to the inoculum strain cell ration in the mixtures, especially during the year of inoculation. In the uninoculated plants grown in soil contaminated with seed-borne Phizobium in August 1969 and maintained for 8 months without irrigation in the priginal pots, a nodulation shift in favour of the $D 216$ strain was recorded in the spring (May) and summer (August) 1970 sowings. This nodulation shift was statistically significant. The root-nodule origin was determined by immunodiffusion in agar gel. In all inoculation treatments the highest root-nodule formation was observed in the spring sowing of 1970.

Possibility of Virulence Transfer by Transformation between Two Serotypes of Rhizobium japonicum. H. Marečková, V. Škrdeteta, Research Centre of Plant Production, Prague-Ruzynè.

To elucidate some methodical problems, transformations of virulence between strains of Rhizobium japonicum of different serological groups and different virulence were conducted during symbiosis with soya, eultivar mukden. Identification of the donor strain in root nodules was done serologically on the basis of agar immuno-diffusion of homogenized suspensions of root nodules as antigens. The original method of serollogica identification was modified so that in place of homogenized fresh nodules we used nodules dried at $80 \mathrm{C}$. In further work the effect of storage of dried nodules on the reliability of serological reactions as compared with fresh material was followed.

Factors Influencing the Nodulation and i ield of Vicia faba L. H. Movchová, J. Apltaver, Research Centre of Plant Production, Prague-Ruzyn.

The nodulation and the yield of horse bean, grown in a soil rich in effective thizobia strains, were determined in greenhouse pot experiments. Horse bean plants were harvested at the beginning of flowering. All values are compared with corresponding values of variants without nitrogen added. When CCC (4 and $40 \mathrm{~kg} / \mathrm{ha}$ ) or Gramoxone $(5,10$ and $20 \mathrm{~kg} / \mathrm{ha}$ ) was applied to soil where ammonium sulphate $(25 \mathrm{ppm} \mathrm{N})$ was added both the nodule volume and the yield of dry aerial parts were influenced only slightly. In an experiment where ammonium sulphate $(105,210,420 \mathrm{ppm} \mathrm{N})$ or ammonium sulphate and straw $(6 \mathrm{~g} / \mathrm{kg}$ ) were added 
to the soil, the gradually increasing levels of nitrogen gradually decreased the nodule volumes. These were nearly the same as in the corresponding $\mathbf{N}$ levels, except for the variant without $\mathrm{N}$. The yields increased from $83 \%$ to $114 \%(0-420 \mathrm{ppm} N)$ in the variants with straw, while maximum yields in the $N$ variants without straw were reached at 105 and 210 ppm N. In a similarly arranged experiment where urea $(80-600 \mathrm{ppm} N)$ was applied the yield of dry overground parts of the plants increased from $77 \%(\mathrm{no} N)$ to $149 \%(280 \mathrm{ppm} \mathrm{N})$. At the higher levels of $\mathrm{N}$ the yields gradually decreased. Addition of potassium nitrate $(210 \mathrm{ppm} \mathrm{N})$ at the beginning of nodule formation decreased their volume to $23 \%$. The highest yield was found when $\mathrm{N}$ was added at the time of sowing.

\section{SECTION OF MEDICAL AND VETERINARY MICROBIOLOGY}

Haemolysins of Staphylococci Isolated from Milk and Dairy Products. J. LUkÁŠová, H. JARChovská, Veterinary Faculty, Brno, and State Veterinary Institute, Hradec Králové.

Individual haemolysins were demonstrated in $\mathbf{3 4 9}$ strains of Staphylococcus aureus isolated from milk and dairy products. All the strains displayed positive plasma coagulase or plasma agglutination reaction, produced golden pigment and formed lecithinase. The majority fermented mannitol and glucose. Fifty-five of the 349 strains (15.7\%) displayed only one type of haemolysis, alpha, beta and delta haemolysins occurred in varying combinations in $260(76.5 \%)$ and no haemolysins was found in $35(7.8 \%)$. Of the strains which produced only one haemylosin, 11 produced alpha haemolysin, 33 beta haemolysin and 11 delta haemolysin. In joint production, alpha and beta haemolysin were the commonest combination (216 strains). Alpha-delta combination was found in 26 strains, beta-delta combination in 16 and alpha-betadelta combination in only one. The various haemolysins and their combined forms were demonstrated by the method of Jasper and Jain.

Effect of a New Bacteriolytic Enzyme on Staphylococci and Other Microorganisms. K. PlHáČKová, F. SMćkal, Research Institute of Antibiotics and Biotransformations, Roztoky near Prague.

The specific effect of the bacteriolytic enzyme (lysostaphin II, Institute of Antibiotics and Biotransformations, Roztoky near Prague), which was isolated from Streptococcus sp. culture medium, consists in lysis of the cell wall of intact staphylococcal cells and other bacteria. Lysostaphin IT acts on the cells of nonpathogenic and pathogenic strains of staphylococci, including clinical Staphylococcus pyogenes aureus isolates characterized by antibiotic resistance. Among 95 Staphylococcus pyogenes aureus isolates (strains resistant to penicillin and other antibiotics), 91 were sensitive to lysostaphin II (minimum inhibitory concentration 0.015-2 units $/ \mathrm{ml}$ ), which also had a lytic effect on Micrococcus lysodeikticus, Alcaligenes faecalis, Aerobacter aerogenes and Proteus vulgaris strains. The effect of lysostaphin II depends on a number of factors, e.g. the growth phase of the cells, the composition of the culture medium, etc. Other strains tested, e.g. Escherichia coli, Streptococcus faecalis, Corynebacterium sp. and Saccharomyces cerevisiae, were lysostaphin II-resistant. The lytic effect of the enzyme was demonstrated in electron microscopy photomicrographs.

Significance of the DNA Guanine and Cytosine Content for Taxonomy of the Staphylococcus. J. BOHÁČ́E, M. Kocur, T. Martinec, Institute of Biophysics, Czechoslovak Academy of Sciences, Brno, and Czechoslovak Collection of Microorganisms, Brno.

The object of the study was to determine the guanine and cytosine (GC) content of the deoxyribonucleic acid (DNA) of 50 strains of Staphylococcus aureus and 20 strains of Staphylococcus epidermidis. Lysostaphin was used for lysis of Staphylococcus aureus atrains and a lysozyme-butanol combination for lysis of Staphylococcus epidermidis strains. The DNA GC content was determined (a) by determining GC from the denaturation temperatures (Marmur \& Doty, 1962) and (b) by a method utilizing the extinction quotient E260/E280 (Fredericq et. al., 1961). The GC content of the DNA of both types of staphylococci varied from $30 \%$ to $35 \%$. The results of determination of the GC content are compared with the chemical composition of the cell wall and the biochemical properties of the strains.

Differentiation of Staphylococci of Different Oecological Origin and a Suggestion for Their Taxonomic Classification. V. HÁder, E. MarŠ́lé, Department of Microbiology, Faculty of Medicine, Palacký University, Olomouc.

Staphylococci are regularly present on the mucosa of the respiratory passages of man and domestic animals, but are rare in wild animals. Unlike human staphylococei, most animal staphylococei are fibrinolysin-negative, occassionally produce alpha lysin and always produce beta haemolysin. The animal strains most similar to human staphylococci are those which occur in pigs and the only significant differences between them are in the 
properties montion ad abova. Staphylococoi isolatad from cattle and shэep have th 9 furthor proporty of being able to clot bovine plasma and are sonsitive to phagas balonging to Davidson's ast. In strains obtained from hares, which are likewis positive in boving plasma, loss of pigmont occurs and creamy or white colonies are form $\rightarrow$ d. Complete loss of pigment occurs in staphylococei isolated from dogs and all the colonies aro white. In addition, the majority lack coagulas 9 astivity in human plasma. They are resistant to phag ss of both tho international and Davidson's sat. On t't 3 basis of differences in the biological propərties of staphylococci of difforent oscological origin, the authors suggest that thy spэcies Staphylococcus aureus should be divided into six biotypos according to the Baird-Parker clasisfication schome. The properties of tho individual biotypos are not fixed to such a degree as to warrant thoir taxonomic classification as variatos hominis, bovis or canis.

Effect of Passage on the Stability of Staphylococcal Strains J. Pillich, M. Kǔ́rvánkoví, E. JANovská, M. Vizonlová, Instituto of Biophysics, Czэchoslovak Academy of Sciences, Brno.

Since thore is a stoady incremont in the number of nonsonsitive staphylococcal strains and the significance of phag 3 typing for epidemiology is constantly insreasing, we wondered whother the proparties of regularly employed typing phagas and bactorial strains remiined constant. We thərefore procured host 55 strains of staphylococcal 55 phag $\ni$ s of thə intornational typing səries from various inter. national laboratories and subjectod thom to a comprehensive analysis. Apart from doing the usual biochomical tests, we studied lysog $3 n y$ and sonsitivity to polyvalent phagəs, baotoriocins and similar substane 3 . The results showod that, in tims, tha proporties of originally id ontical strains passaged under diff $3 r e n t$ conditions altered. It can be assumed that thesэ altəred propэrties of host 55 strains səcondarily infuэnce tho proporties of 55 phages propagatid on thom and thus also socondarily influence tho rasults of phag 3 typing the furthor staphylococcal strains.

Associations of Pigmont Markers in a Wild Population of Pyogenic Staphylonocci. J. SoHINDLER, A. Marešová, Z. Sohind ler, Dopartmont of Mədical Microbiology and Immunology, Faculty of Medicine, Charles Univarsity, Prague.

In a population of wild strains of pyogenic staphylococci, association of pigm nnt markers with following respoctive markərs was studied: staphylokinas $\theta$ production (Kin), clumping factor production (Clu) mannitol fermentation (Man), haemolysis of rabbit erythrocytəs (Hər), həmolysis of sheep erythro. cytes (H3s), resistance to ponicillin (Pen), ţtra. cyeline (Tet), chloramphonicol (Clf), erythromycin (Ery), Kanamycin (Kan), Neomycin (Neo), Cd (Cad), Hg - (Mer) and production of penicillinase (Pna). Laboratory results were evaluated by means of a digital computer. Associations of respective markers were calculated and only those obtained on relatively high level of significance $(P=0.005)$ were taken into consideration. Pna, Cad, Mer, Kin, Man, Her, Hes occurred significantly associated with $\mathrm{Ora}$ and $\mathrm{Yel}$ markers (pigmented strains). Monoresistance to penicillin occurs predominantly in orango coloured strains (Ora marker). Only one strain was monoresistant to tetracycline. Tet is associated with Yel (yellow-coloured strains). Markers of multipls resistance Pen CLf Tet occur in $52 \%$ of yellow strains, whereas in $17 \%$ of orange strains and $21 \%$ of white strains only. Significant associations are discussed with respect to possible linkage groups.

The Biological Properties of Staphylococci Isolated from the Urinary Tract. J. STOKLAsová, V. HÁJEK, P. BÉLÁKOVÁ, Institute of Microbiology, Faculty of Modicine, Palacký University, Olomouc.

The biological properties of 233 staphylococoi, isolated from the urinary tract, were studied using 28 bioshomical tests and phagotypisation. 152 strains wore classified as Staphylococcus aureus and 71 as Staphylococcus epidermidis species based mainly on the criteria of pathogenicity. Only $24 \%$ of pathogenic staphylococci formed orange colonies, whereas $76 \%$ formed yellow pigment. Alpha haemolysin could be demonstrated in $82 \%$ and beta lysin in $17.2 \%$ of staphylococci. A striking correlation was found between the production of beta haemolysin and the loss of fibrinolytic activity. Out of 116 fibrinolysin-positive strains, only 6 formed beta hamolysin. The protease activity was found in $90.6 \%$ of orange, but only in $31.6 \%$ of yellowpigmonted cultures. 19 strains of Staphylococcus aureus $(12.5 \%)$ formed a special group; these strains were different with respect to certain properties that are considered to be the main criteria of

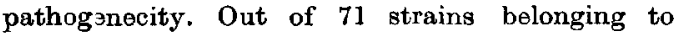
Staphylococcus epidermidis species, 35\% grew on agar with crystal violet as typ $\Theta C$ and $D$. This is obviously connected with a rather broad resistance to antibiotics of these strains. The strains were further classified according to the modified Baird Parker classification system. In 5 strains the classification was impossible and they were denoted as atypical. In all 223 strains the sensitivity to antibioties and sublimate was studied. It was found that a high number of orangə-pigmented strains was resistant to ponicillin only, whereas the strains forming a yellow pigment were characterised by polyresistance that was correlated to the resistance to sublimate. Using the sensitivity to phage test, it was found that $74 \%$ of strains of Staphylococcus aureus belongad to the IIIrd phage group and only 
4 strains belonged to group II. In $21 \%$ of cultures the typing by phage was impossible. Using the phage $77,79 \%$ of yellow-pigmented staphylococci was lyzed.

Biological Properies of Staphylococci Isolated from Patients with Secondary Staphylococcal Bronchopneumonia following the 1970 Infuenza Epidemic. E. Maršálek, W. Mryer, V. HÁJek, Department of Microbiology, Faculty of Medicine, Palacký University, Olomouc.

During the influenza epidemic in the spring of 1970,91 strains of Staphylococcus aureus were isolated from 88 patients with secondary staphylococcal bronchopneumonia in different parts of Czechoslovakia. All the strains isolated were subjected to detailed biochemical tests and to phage typing with the international and Davidson's set. The following results are worthy of special note. Despite their high activity in human, rabbit and pig plasma, only four strains were coagulase-positive in bovine plasma (and only after 24 hours' incubation). Beta, haemolysin was demonstrated in only seven strains, six of which were fibrinolysin-negative. Orange pigment was produced by 40 strains and yellow pigment by 49 . There was a close correlation between yellow pigmentation, polyresistance to antibiotics, resistance to sublimate and absence of proteolysis on milk agar. Eighty seven strains were found to be highly sensitive to basic set phages and 16 strains to bovine provisional set phages. Strains belonging to phage group III formod the largest group ( $45 \%)$. Sensitivity to phage 77 as particularly frequent. An $84 / 85$ phage complex was found alone in five staphylococci which were polyresistant to antibiotics and resistant to sublimate, grew in yellow colonies, produced beta haemolysin and were fibrinolysin-negative. On the basis of an analysis of all their properties, 81 of the strains were classified as human and one as the bovine biotype. Conclusive classification of the other strains was impossible, as they displayed certain differences as regards key properties. These strains were denoted as being atypical.

Heterokaryosis in Dermatophytes. K. LENHART, Department of Biology, Faculty of Medicine, Palac. ký University, Olomouc.

A microconidial cream mutant (cre, No, 155) of the dermatophyte Microsporum gypseum was used as the initial strain. Series of biauxotrophic and colour mutants were prepared from the two strains cre bio (No, 1/1) and cre ino (No. 1/5). Pairs of mutants were inoculated on minimum (MM) and complete (CM) medium and the formation of hetero. karyotic mycelium (het. m.) was determined: (a) directly, by the isolation of individual hyphae; (b) indirectly, on the basis of colour or trophic complementation. The environmental conditions significantly influeneed het. $\mathrm{m}$. formation and growth. Het. m. growth on MM was very slow and limited and the proportion of nuclei of the two components was usually unequal. Some pairs of mutants formed stable het. m. even on non-selec. tive CM. The het. $\mathrm{m}$. was morphologically identical with the initial strain, i.e. cream-coloured, richly sporulating het. $m$. was formed from aconidial colour mutants. The coloration of the spores was not autonomous. Heterokaryotic constitution was transferred by hyphal fragments, but not by micro. conidia. Het. m. in Microsporum gypseum mutants has already been successfully used: (1) to obtain diploid strains; (2) for the differentiation of similar phenotypes on the basis of intergenic complementation: (3) for the identification of nuclear and extra. nuclear frctors (Jinks's test)

Discriminatory Analysis in the Taxonomy of Derma tophytes. S. Komenda, K. LenHaRt, E. Lenhar roví, Faculty of Medicine, Palacký University, Olomouc.

The aim of the study was to determine how much taxonomically significant information could be obtained from a series of quantitative markers of dermatophyte macroconidia. Three strains of Trichophyton ajelloi, Microsporum gypseum and Microsporum cookei and one of Microsporum praecox were used and 100 macroconidia from each strain were evaluated under standard conditions. The length and width of the macroconidia, the number of cells and the length-width index were determined. The resultant data were used for the calculation of discriminatory functions and for the determina. tion of standard rules. Each object (macroconidium) was classified correctly with 0.96 probability if it really belonged to the species Microsporum praecox, with 0.863 probability if it belonged to Trichophyton ajelloi, with 0.923 probability if it belonged to Microsporum gypseum and with 0.807 probability if it belonged to Microsporum cookei. The results confirmed the exceptionally great usefulness of discriminatory analysis for the taxonomy of dermatophytes.

Toxic Factors of Corynebacterium ulcerans. A. SovČKová, A. Sovóer, Department of Medical Microbiology and Immunology, Faculty of Medicine, Charles University, Prague.

Corynebacterium ulcerans is usually described as a variant of Corynebacterium diphtheriae because of the similarity of their morphological and cultivation charactéristics and because a number of strains are able to produce a toxin whose effect and antigenic properties are indistinguishable from those of diphtheria toxin. Toxic activity demonstrable even in animals passively protected with diphtheria 
Entitoxin was detected in broth cultures. In broth culture filtrates of Corynebacterizm ulcerans strains we demonstrated a toxic protein different from diphtheria toxin, with a characteristic effect in experimental animals. In guinea pigs and rabbits it produced haemorrhagic necrosis similar to the form which develops after the administration of Corynebacterium pseudotuberculosis toxin. The toxic protein also inhibited the haemolytic effect of Staphylococcus pyogenes alpha and beta lysin and of Clostridium perfringens alpha toxin. Study of the behaviour of this toxin on Sephadex and ion exchangers and in electrophoresis showed that it had different mobility from Corynebacterium pseudo. tuberculosis toxin in electrophoresis. Identity of the toxin with an enzyme of the phosphatidylcholine phosphatidohydrolase group with an affinity for sphingomyelin and lysolecithin was demonstrated. The enzyme also decomposed these phospholipids in serum lipoproteins. An attempt to identify this enzyme with the factor which induces turbidity formation in animal sera was unsuccessful.

Correlation of Growth and Cytochrome $b_{1}$ Production in Corynebacterium haemolyticum to the Haemin Concentration in the Medium. M. MÁRA, D. KALvodová, F. Patočka, Laboratory for Special Medical Microbiology, Faculty of Medicine, Charles University, Prague; Department of Medical Microbiology and Immunology, Faeulty of Medicine, Charles University, Prague.

In a study of the taxonomic classification of Corynebacterium haemolyticum we demonstrated cytochrome $b_{1}$ with differential spectrum maxima at 430,530 and $560 \mathrm{~nm}$ in the microbial cells. This finding differentiated the microorganisms from pyogenic streptococi, but we failed to demonstrate production of a complete cytochrome system as known in Corynebacterium diphtheriae. Later, after adding haemin to the medium, Patočka and Kalvodová observed improved production and the development of L-forms of Corynebacterium haemolyticum. With reference to these findings and to the structural similarity of haemin to group b cytochromes, we attempted to determine the effect of haemin on growth and cytochrome $b_{1}$ synthesis. It was found that growth of the mieroorganism depended on the presence of haemin in the medium and that this dependence was more marked under aerobic conditions, when growth in liquid synthetic media and on Tryptic-Soy-Broth agar was minimal. Haemin stimulated growth in a dose range of $1-20$ $\mu \mathrm{g} / \mathrm{ml}$ medium. Under anaerobic conditions, haemin also improved growth on solid medium in amounts of up to $10 \mu \mathrm{g} / \mathrm{ml}$ medium. Similar dependence was observed when determining cytochrome $b_{1}$ in the particulate fraction of the bacterial endoplasm obtained by differential centrifugation of disintegrated bacterial cells. The amount of particulate fraction rose proportionally to the amount of haemin in the medium within a dose range of $\mathrm{I}-20 \mathrm{\mu g} / \mathrm{ml}$. Cytochrome $b_{1}$ was also produced in small amounts under anaerobic cultivation conditions. It was found that haemoglobin could be substituted for haemin, but the effect was smaller. The results show a corre. lation between growth and cytochrome $b_{1}$ production, particularly under aerobic conditions.

Listeria monocytogenes Lipids: Their Dependence on the Cultivation Conditions and Strain Virulence. M. MÁra, B. Beneš, F. Patoǒka, Laboratory for Special Medical Microbiology, Faculty of Medicinø. Charles University, Prague.

Renewed attantion has recently been evidenced in the lipids of Listeria organisms and the relationship of these substances to the virulence of the strain. In this study the authors investigated the total lipid and fatty acid content of Listeria cells and their dependence on the medium. Todd-Hewitt broth and tryptose broth were used as the basic medium. The lipid content of the virulent India strain corresponded to the values given in the literature for other strains $(6.1 \%$ of the dry weight). On using TrypticSoy-Broth (TSB) it attained $13.7 \%$. The addition of glucose to these media significantly stimulated growth of the bacteria, but did not influence the total lipid concentration. The addition of glycerin significantly raised the lipid content, however to $10 \%$ in the first two media and to actually $18 \%$ in TSB medium. The avirulent $\mathrm{K}_{3}$-Welshimmer strain displayed much lower lipid production $(3.7 \%)$ than the virulent test strains. The addition of glycerin to the medium raised the klipid content of this strain to $10.6 \%$. Glycerin likewise raised the total fatty acid content of Listeria lipids. Paper and gas chromatography showed the presence of 8- 10 fatty acids, the reciprocal ratio of which varied in association with the culture medium. A fatty acid with a large number of carbon atoms was detected by paper chromatography.

Differentiation of Pathogenic and Non-pathogenic Escherichia coli Sirains Isolated from Piglets and Calves by the Dilatation of Ligated Irtestinal Loops Test and the Possibility of Influencing This Reaction by Pre-Contact with a Pathogenic Escherichia coli Strain. E. Salajka, L. TlmanN, M. HoRnich, Z. Sarmanová, Research Institute of Veterinary Medicine, Brno.

In 1953 De and Chatterje described the dilatation of ligated intestinal loops test in rabbits for differentiating enteropathogenic $V i b$ rio cholerae strains from non-pathogenic strains. Three years later, De and Bhattacharja submitted a report on the possibility of using this method for the demonstration of pathogenicity of Escherichia coli strains from coliform intestinal infections in chil lren. Rabbits are not suitable for the differentiation of pathogenic and 
non-pathogenic Escherichia coli strains from intestinal infections of piglets and calves, however, and the direct hosts can be used for this purpose. Escherichia coli strains pathogenic for piglets dilate intestinal loops in both piglets and calves, while strains pathogenic for calves dilate intestinal loops in calves only. In our own experience, this test can be satisfactorily used in weaned piglets both for differentiating pathogenic Escherichia coli strains from non-pathogenic strains and for demonstrating the inhibitory effect of hyperimmune serum. Considerably reduced reactivity is found in some piglets, however. Comparison of the reactions in piglets from a stye infected with a pathogenic strain of Escherichia coli with those in piglets from an uninfected environment showed that several days' colonization of the piglet's intestine with a pathogenic type of Escherichia coli resulted in a significant selective decrease in the reactivity of its intestine to strains of the same Escherichia coli serotype, which produced typical reactions in animals from a different environment.

Frequency of Colicin Synthesis and Incidence of Transmissible Resistance in Haemolytic Escherichia coli Strains Isolated from Pigs with Diarrhoea. F. Federič, A. Sokol, Z. Koppel, Department of Microbiology and Zoohygiene, Veterinary Faculty, Košice.

A series of 50 haemolytic Escherichia coli strains was tested for colicin synthesis by Frederieq's method, Colicin production by isolated colonies was also demonstrated by a modification of Gratio's double agar layer technique. The strains ROW and B-1 were used as indicator strains. The reciprocal sensitivity of the producer strains to the various colicins was determined. The sensitivity of the given strains to eight antibiotics was tested by the dise method. In resistant strains, the transmis. sibility of resistance determinants to the recipient strain $185 \mathrm{Nx}$ was tested by conjugation crosses and their mobilizability was tested by Anderson's triple test. Strains in which neither colicin production nor antibiotic resistance was found were tested with a view to their suitability as indicator strains for testing colicin production or as acceptor strains in conjugation crosses with good donor strains. The possibility of using haemolytic Escherichia coli strains as standard acceptors in conjugation crosses and the relationship of the presence of these two episomes to haemolytic activity of Escherichia coli strains are discussed.

Contribution to the Study of Infective Resistance in Shigella. K. ČrvinKa, District Hygiene Centre, Mladá Boleslav.

Over a period of two years the author isolated 119 strains of polyresistant Shigella strains from
197 patients, contacts and subjects who continued to excrete Shigella organisms after treatment. Eighty-nine polyresistant Shigella sonnei strains and 30 Shigella flexneri strains were isolated. Most of the strains were resistant to chloramphenicol tetracycline, streptomycin and sulphonamides (93), 24 had varying, mostly deficient, antibiograms and two strains were resistant to neomycin as well as to the other antibiotics. The low incidence of neomycin resistance is interesting, as most of the patients were treated with this antibiotic ( $80 \%$ according to information from the district hospital). The resistance of Escherichia coli strains isolated from the stools of patients with polyresistant Shigella strains was also regularly studied. The percentage of polyresistant Escherichia coli strains in these subjects was high compared with the control group of similarly treated patients with sensitive Shigella strains. We assume that the number of resistant Escherichia coli strains rose as a result of resistance transmission from resistant Shigella strains. When the resistant Shigella strains had been eliminated, the resistant Escherichia coli strains disappeared quickly and spontaneously. In most cases, the resistance level of the given Escherichia coli strains was lower than that of the Shigella strains. Attempts were made to transmit the resistance of the isolated Shigella strains to sensitive Escherichia coli and Shigella strains by cultivating them together in vitro, while others were made to abolish resistance by cultivating polyresistant strains in the presence of acriflavine after first irradiating them with UV light. The success of attempted resistance transmission in vitro and of attempts to abolish resistance depended on the length of the postisolation interval and on integrity of the strain's antibiogram. Freshly isolated strains and strains with a complete antibiogram displayed greater capacity for transmitting resistance and greater susceptibility to acriflavine abolition of resistance than old strains or strains with a deficient antibiogram. We successfully demonstrated the ability of nalidixic acid to abolish resistance in strains cultivated in the presence of this acid, in the same frequency as in cultivation with acriflavine.

Characteristics of Escherichia coli Strains Sensitive and Resistant to Some Antibiotics. K. DRNDaRSKI, L. Markovič, S. ZmiJanac-Jovanovič, Department of Microbiology, Faculty of Medicine, Belgrade.

Five Escherichia coli strains (0111 B4) isolated from various pathological materials (sputum, cerebrospinal fluid, urine, vaginal secretion, stolos) were selected for the purpose of determining whether Escherichia coli loses any of its essential characteristics by acquiring antibiotic resistance. Under laboratory conditions, the given strains acquired a high degree of resistance to Negram and chloramphenicol. Examination before and after they acquired resistance showed no differences in the 
basic biochemical properties of the selected strains. Three of the strains were isolated from pathological material from patients (cerebrospinal fluid, stools, urine) and two from healthy subjects (sputum, vaginal secretion). Taking into account the origin of the strains, it might have been anticipated that the death rate would have been higher among embryos inoculated with strains from pathological material. The actual data showed that, in this case, the number of bacteria was the main factor, how. ever. With a large dose of bacteria, death sometimes occurred after only 16 hours, while reduction of the inoculum substantially prolonged this period. Strains which acquired a high level of resistance to Negram were primarilly lethal for a large number of embryos, while among strains resistant and sensitive to chloramphenicol there was a small difference in favour of greater pathogenicity of strains resistant to chloramphenicol.

Study of Tetracycline Sensitivity of Escherichia coli Strains Isolated from Humans and Animals Exposed to Chlortetracycline. Z. Mandlíková, E. Schön, V. Ziegleroví, Regional Hygiene Centre for Central Bohemia, Prague.

The authors studied the sensitivity of intestinal flora isolated from subjects in contact with chlor. tetracycline, i.e. poultry breeding farm employees and feed mixers, and from poultry fed on a mixture containing chlortetracycline, and compared it with the sensitivity of the intestinal flora of control subjects. In the Escherichia coli strains isolated they determined the incidence of tetracycline-resistant strains and resistance to other antibiotics by the disc method, and in selected resistant strains they determined the minimum inhibitory concentration (MIC) for tetracycline by the plate dilution method. In some cases they attempted to demonstrate the infective character of tetracycline resistance by the method of acridine elimination of resistance factors and of contact transmission to acceptor strains. The disc method showed that the incidence of tetracycline-resistant Escherichia coli strains in the control group was $17 \%$, in feed mixers $37.2 \%$, in poultry farm employees $70 \%$ and in poultry litter $100 \%$. The tetracycline MIC in the selected group of these resistant strains varied from 100 to $800 \mu \mathrm{g} /$ /ml. In each group tested there were some strains in which elimination and transmission of tetracycline resistance factors. occurred and the authors therefore regard these strains as bearers of infective resistance.

Possibilities of Modifying the Turbidimetric Method of Titrating Streptococcal Hyaluronidase and Antihyaluronidase. I. HÁNA, R. Bfcová, Postgraduate Medical and Pharmaceutical Institute, Prague and Institute of Epidemiology and Microbiology, Prague.
The authors studied the frequently employed turbidimetric method of titrating streptococcal hyaluronidase and antihyaluronidase. They concentrated on several factors which might play a role in the reaction, with the aim of elucidating the basis of some problems encountered in titration, of establishing clearly some of the quantitative and qualitative relations and eventually of attempting to improve the method. Dependence of the enzyme curve on the use of different amounts of potassium hyaluronate was studied in detail, together with the scatter of the values in repeated titration and whether it was better to use arithmetical or geometrical progression. Attention was paid to the protein substrate which reacts with the hyaluronic salt and thus gives rise to the turbidity forming the object of measurement, and to the use of different amounts and batches of hyaluronidase. Finally, the method of reading the antihyaluronidase titre was analysed. On the basis of their results, the authors established the optimum conditions for assay and elaborated an economical laboratory technique. They introduced a simple and di. stinctly more accurate way of reading the antihyaluronidase titre, replacing the existing inaccurate method of establishing the value approximating to the end of the S-shaped enzyme curve by exact reading of a precise value, by interpolation within the steep straight portion of the curve. This method gives a reading at least five times more accurate than the former method.

Evaluation of Antistreptolysin and Antihyaluronidase Titres in Experimental Animals Inoculated with Streptococci. O. BERGER-JEkIć, M. NEDELJković, Department of Microbiology, Faculty of Medicine, Belgrade.

The aim of the study was to examine serological reactions used in the diagnostics of rheumatic diseases. In the experimental model (40 rabbits inoculated with five standard laboratory strains of groüp A streptococei by different methods and at different intervals), the increment, decrement and ultimate disappearance of streptococcal antibodies was studied. For routine laboratory work the authors had previously used a modification of the ASTO reaction (Rantz and Randall) and they now wished to test the possibility of employing the antihyaluronidase raaction (using Harris's turbidimetric method) and the antiproteinase reaction (Rotta's method of inhibition of milk curdling). Analysis of all the serum samples from the immunized and control rabbits yielded the following results: No increase in the titre was found in the sera of rabbits immunized by the intrapharyngeal and intranasal route. The sera of rabbits immunized intradermally and by the intraperitoneal implanation of a chamber containing group A streptococci (Rałka and Rotta's method) gave positive results; the titres rose in the third week, the ASTO titre being the highest (100 to 600 units $/ \mathrm{ml}$ ), while the antihyaluronidase and 
antiproteinase titres were significantly lower (AHD 80 units/ml, APT 40 units/ml). It is important to note that a positive ASTO titre was always followed by AHD and APT antibodies, in a lower titre. It can thus be seen that a correlation exists between the above serological reactions and that the ASTO re. action is the most sensitive of the three.

Electron Microscopy Analysis of Effect of Cell Wall Mucopeptide of Group A Streptococci in Blood Platelets of Different Species of Animals. M. R $\mathrm{YC}$, H. Rašková, J. Rotta, Institute of Epidemiology and Microbiology, Prague.

The cell wall mucopeptide of type 6 group A streptococei, isolated with hot formamide, purified and solubilized by ultrasound, causes complete destruction of rabbit thrombocytes associated with the release of 5-hydroxytryptamine from the cells, when administered in concentration of over $10 \mu \mathrm{g} /$ $/ \mathrm{ml}$. The limiting membrane of the cells is fragment. ed, releasing hyaloplasm and granulomeres. The membrane structures of the granulomeres themselves, which contain 5-hydroxytryptamine, remain morphologically intact. A dose of $0.1 \mu \mathrm{g}$ mucopeptide/ml is sufficient to initiate changes in the ultrastructure of rabbit thrombocytes. The presence of plasma and $\mathrm{Ca}^{-\div}+$ions is essential for development of the above phenomenon. The sensitivity of the blood platelets of different species of animals to mucopeptide displays very marked differences. Of the isolated animal cells so far studied, rabbit thrombocytes are the most sensitive to this streptococcal product. Rat thrombocytes are much less sensitive and require mucopeptide doses 10 to 100 times largar than for rabbits. Dog and human thrombocytes are completely insonsitive under analogous conditions. Neither submicroscopic changes nor pronounced 5-hydroxytryptamine releass occur in human thrombocytes incubated with very large doses $(500 \mu \mathrm{g} / \mathrm{ml})$ of mucopeptide.

Use of Fluorescent Antibody Technique in Differentiation of Cross Reactions between Brucella abortus and Proteus O.X 19. B. TRRić, M. Stojkovió, Department of Microbiology, Veterinary Faculty, Belgrade.

Serological methods are generally used for the detection of brucellosis (chiefly the agglutination test and CFR). Very often, especially when testing pig sera, nonspecific eross reactions occur, influencing the accuracy of the results. Cross reactions are commonest between Brucella and Proteus O-X 19, Salmonella gallinarum and other Salmonella D species possessing factor XII. In recent years the fluorescent antibody technique (FAT) has been frequently employed with success in the diagnostics of many infectious diseases, including brucellosis. It can be used for the examination of organ smears from infected animals, as well as for testing serum. Many authors (e.g. Karásek et al.) consider the use of fluorescent antibodies to be an important contribution to the investigation of brucellosis. Other authors (Gentile, Siminitzis, Ignateva, Hajdu, Jenzzsch, etc.) also regarded the FAT as an important factor in the detection of brucellosis, especially in sera displaying the zone phenomenon. We determined the antigenic relationship between Proteus OX-19 and Brucella abortus by immunizing rabbits with these strains. We found that the sera of rabbits immunized with Brucella S 19 agglutinated both the specific antigen and Proteus antigen, but the latter in lower dilutions. Conversely, serum from animals immunized with Proteus O-X 19 agglutinated the specific antigen and, in lower dilutions, Brucella antigen also. In further experiments we employed the direct FAT method. We marked the antigenantibody complex by using immune anti-rabbit gamma globulin sera marked with fluorescein isothiocyanate. With this method we also found cross fluorescence between Brucella abortus and Proteus $\mathrm{O} . \mathrm{X} 19$, but the reaction occurred in lower dilutions than with classic agglutination.

Properties of Strains of Aeromonas Hydrophila Isolated in East Slovakia. M. TARABČ́t, I. KRAToCrvit, Regional Hygiene Centre, Košice.

In association with a cholera epidemic which occurred in East Slovakia at the end of October 1970, over 100 strains of Aeromonas hydrophila were isolated from the stools of subjects who had been in contact with cholera patients and from surface water in the area of the epidemic. When the epidemic subsided, during extensive investigations carried out from November 15, 1970 to the end of February, 1971, over 200 more strains of Aeromonas hydrophila were isolated from surface water and stools. The authors describe the properties of the above strains and compare them with strains of Aeromonas hydrophila isolated in their laboratory before the cholera outbreak. The incidence of Aeromonas hydrophila in various population groups is compared and the significance of differences in its incidence is discussed. Attention is drawn to possible difficulties if rapid differentiation of Aeromonas hydrophila from related microorganisms (especially Vibrio cholerae and NAG vibrions) is needed. The authors cite their experiences with their own material in this connection.

Effects of Aeromonas hydrophila Products. A. SouČEK, A. SouČ́nová, V. Rosová, Department of Medical Microbiology and Immunology, Faculty of Medicine, Charles University, Prague.

Considerable attention has been paid in recent years to the toxic effects of Gram-negative rods. We studied the effect of human strains of Aero. 
monas hydrophila on experimental animals. In a strain which was pathogenic for guinea pigs and produced lethal haemorrhagic septicaemia, we studied the active factors in filtrates of cultures grown in liquid medium, in products concentrated by precipitation with ammonium sulphate and after methanol fractionation. In addition to haemolytic activity of the samples, we demonstrated a toxic effect, with haemorrhagic necrosis and oedema formation, after intradermal administration to rabbits and guinea pigs. We also studied the effect of aeromonad products on erythrocyte phospholipids and purified lecithin, lysolecithin and sphingomyelin. Hydrolysis of lecithin and lysolecithin was demonstrated by chromatography. We attempted to find a relationship between the given active components by means of purification techniques, gel chromatography and heat inactivation.

Proteolytic Properties of Serratia and Proteus Strains. M. Rusinko, P. KoHúx, Department of Medical Microbiology and Immunology, Faculty of Medicine, Comenius University, Bratislava.

The proteolytic properties of Serratia marcescens and Proteus vulgaris strains were determined by qualitative plate methods and by the same methods allowing quantitative determination of proteolytic activity. We also tested the correlations between the composition of the culture media and protease production and the growth phase. Known culture media (M-63, P.I and TSB) were employed. When determining proteolytic activity in correlation to the growth phase of the microorganisms, we found that the given strains already produced proteolytic enzymes during the exponential phase, with the maximum on the 4 th to 5 th day. Another finding was that differences existed in the proteolytic enzyme-producing capacity of individual strains of Serratia marcescens and Proteus vulgaris.

Biochemical Properties and Serum Typing of Pseudomonas aeruginosa Organisms in Veterinary Medicine. M. BAŚTÁ Ŕ, M. BABICKá, Central State Veterinary Institute, Prague.

Over 80 strains of Pseudomonas aeruginosn isolat. ed from different veterinary materials were tested. Pigment production at different temperatures and during different incubation periods, fluorescein production (evaluated under an UV lamp), degradation of certain carbohydrates, gelatin and urea, citrate utilization, nitrate reduction (rapid), the change in litmus milk, motility and growth at different temperatures were studied. The biochemical properties of the strains corresponded to the data in the literature. Pigment production was very variable and was manifested in a colour change from cream to reedish brown and then to light or dark bluish green. Like haemolysis, it depended on the incubation temperature, the time of growth and the presence of certain substrates in the medium. Nitrate reduction occurred after only 8 hours; the test at 10 hours was already negative. Serum typing was done by slow and drop agglutination, using our own rabbit sera produced with 12 reference strains by Habsovís method. We determined the serum type of $83 \%$ of the strains, but failed to determine it in $17 \%$; of the latter, about $8.4 \%$ did not react with any of the sera. Attempts to classify these strains are still continuing. The commonest type was $06(49.2 \%)$, followed by types $01(27.1 \%)$ and $03(17.4 \%)$. It is impossible to consider any associations related to the different material origin of the strains and the serotype, but the number of strains so far available was very small. It seems more feasible to consider the occurrence of a given serotype in a given locality.

Gram-Negative Rods of Nosocomial Significance. J. Duben, M. Neubauer, Department of Microbiology, District Hygiene Centre, Havlíckúv Brod.

One of the negative consequences of progress in the medical care of severely ill patients with general depression of defence mechanisms is the mounting incidence of infections caused by bacteria formerly considered to be non-pathogenic. Whereas at one time pyogenic staphylococci predominated in hospital infections, Gram-negative rods are now being isolated with increasing frequency. Apart from the usual intestinal bacteria (Escherichia coli, Klebsiella, Enterobacter, Proteus), we also oncounter less common types of Gram-negative rods. Because of the increase in their clinical significance, we felt it necessary to identify them more exactly and, together with the clinician, to re-evaluate their relationship to the disease and environment and select the antibiotics accordingly. On the basis of the diagnostic charts of von Graevenitz and of the experiences of the big American clinical laboratories, we elaborated and tested our own diagnostic techniques, which allow relatively quick and accurate identification of fermentative Gram-negative rods. We regard only the system for the identification of heterogeneous groups of rods which do not degrade carbohydrates by fermentation as still incomplete. Our findings on the frequency of Gramnegative rods in clinical material from hospitals in 1970 as a whole, and also in relation to age, time and place, provide a basis for an epidemiological survey of antibiotic resistance and for a study of hospital infections. The results are compared with a control group consisting of patients attending out patient departments.

Bite Media in the Differentiation of Pasteurella and Actinobacillus Organisms. O. MRÁ, Department of Microbiology and Immunology, Veterinary Faculty, Brno. 
The differentiative properties of bile and bile salst have not been properly investaigated in the Pasteurella-Actinobacillus group and many experienced workers are unaware of their real value. The author worked with over 140 Pasteurella (Pasteurella multocida, Pasteurella pneumotropica, Pasteurella ureae) and Actinobacillus (Actinobacillus lignieresii, Actinobacillus equuli, Actinobacillus haemolyticus) strains. He inoculated meat-peptone agar containing bullock's bile, taurocholate or sodium deoxycholate with broth cultures of the strains and incubated them three days at $37 \mathrm{C}$. He found that the optimum concentration which inhibited Pasteurella strains, but still allowed growth of Actinobacillus strains, was about $20 \%$ for bile, about $1.5 \%$ for taurocholate and about $0.07 \%$ for sodium deoxycholate (total error on both sides up to $10 \%$ ). In a subsequent study of eight Czechoslovak-, English-and American-produced commercial media, only MacConkey's agar containing bile salts, NaCl and crystal violet gave satisfactory results, although the products of the individual firms (Bioquest, Difeo, Oxoid, Sevac) differed somewhat, especially in relation to Pasteurella pneumotropica. It can therefore be claimed that, after minimum modification and pre-titration with the producer, MacConkey's agar can definitely be included among the diagnostic media for Pasteurella and Actinobacillus organisms. Even then, however, sporadic errors will probably still be unavoidable, so that comprehensive evaluation of the test strain will be necessary.

The 250th Anniversary of Smallpox Vaccination in Slovakia. L. DUBAy, Department of Microbiology, Faculty of Medicine, Safaŕík University, Košice.

In July and August 1721, the town of Prešov in Slovakia was visited by a smallpox epidemic. When the epidemic started to subside, the town physician, Dr.'J. A. Raymann, vaccinated his 2 1/2-year-old daughter with matter from a pustule on his infected son, on the basis of findings which he published in 1717 in the journal "Sammling von Natur- und Medicin-Geschichten". J. Weszprémi, a biographer of Hungarian and Transylvanian doctors (in those days Slovakia belong ${ }^{2}$ d to Hungary), wrote in 1774 that Raymann taught the nations of Europe this art in order to protect their health.

Growth of Saprophytic Mycoplasms in Culture Media of Organic Origin and in Chemically Defined Media. B. LISKKA, P. F. Sмiтh, Institute of Biophysies, Czechoslovak Academy of Sciences, Brno, and Department of Microbiology, School of Medicine, University of South Dakota, Vermillion.

The nutritional requirements of saprophytic myoplasms were studied in media of organic origin fcontaining combinations of peptones, beef heart extract, nutrient broth, horse blood serum, PPLO serum fraction, and yeast extract and autolysate) and in chemically defined media (prepared from solutions of inorganic salts, buffers, amino acids, vitamins, nucleic acid derivatives, lipids and sugars). Nutritional characterization in this group of microorganisms (in which serological relations and the absence of cholesterol requirement are the main classification criteria) provides further information on genetic relations and differences among these strains. The results showed that the strains in question, most of which had only recently been isolated, were a group with highly varied nutritional requirements. This gives rise to the question of the homogeneity of the genus Mycoplasma (Acholeplasma) laidlawii.

Submicroscopic Structure of $L$-forms of Group $\boldsymbol{A}$ Streptococci Prepared by Means of Penicillin and Bacitracin. M. RÝc, J. RoTTA, Institute of Epidemiology and Microbiology, Prague.

Differences in the stabmicroscopic structure of L-forms typ $\ominus 6$ and 14 group A streptococei prepared by means of penicillin $(1,000 \mathrm{units} / \mathrm{ml})$ and bacitracin $(0.5$ units $/ \mathrm{ml})$ were studied. Their ultrastructure was compared with that of L-colonies grown on media with an antibiotic concentration several times higher than the dose used for passage. All L-forms contained the following basic types of structures: (1) Large bodies $0.5 \mu \mathrm{m}$, to several $\mu \mathrm{m}$ in size, with a surface membrane unit, granular cytoplasm with no mesosomes and a clearly marked nuclear zone; (2) elementary bodies measuring $0.3-0.5 \mu \mathrm{m}$, also with a surface membrane unit and with less distinctly differentiated cytoplasm; (3) very small granules $(0.01-0.05 \mu \mathrm{m})$, usually with no internal structural differentiation; (4) vesicular formations of widely varying sizes (from a few tenths of a $\mu \mathrm{m}$ to several $\mu \mathrm{m}$ ), often containing a quantity of smaller vesicles. In addition to the above structures, other particles were also constantly present in bacitracin-induced I-forms. These were large polymorphous bodies measuring several $\mu \mathrm{m}$, with a surface membrane unit, a clearly differentiated nuclear zone in granulated cytoplasm and frequent isolated membrane structures in the cytoplasm; these membranes were the most striking structure differentiating bacitracin-induced L-forms from penicillin-indue ad L-forms. In penicillin-induced L-forms elementary bodies were often observed inside large bodies; this localization was never observed in bacitracin-induced L-forms, in which the elementary bodies clearly broke away from the large bodies in an irregular manner resembling budding. In cultivation on media with a high antibiotic concentration, the large polymorphous formations of bacitracin-induced L-forms acquired a syncytial character and their separation into smaller formations was not completed. The results demonstrate that bacitracin interferes radically 
with the metabolism of streptococcal L-forms and thereby causes severe discoordination of their diviaion mechanisms.

The Nature of Bacterial Destruction on Disinfection by Halogens. L. N. Kuzminski, T. H. Feng, C. C. LIU, University of Massachusetts, Amherst, Massachusetts, USA.

In halogen disinfection investigations, a variety of different methods to expose test cultures and evaluate survivors have been employed. Consequently, varied surviving times for bacterial genera under apparently comparable conditions have been reported. This has made correlation of effective halogen concentrations with microorganism resistance at pertinent environmental conditions most

fficult. Accordingly, there is need for the use of a universal procedure for exposure to a disinfectant. There are a few such methods available but death kinetics studies of the gərmane microbial genera and species have not all been performed, using one method. It is the purpose of this paper to present information on the relative resistance of several genera of bacteria on exposure to equivalent doses of chlorine, bromine, and iodine. A singular exposure procedure and survivor evaluation technique have been employed throughout the study. Death kinetics of six public health significant microbial genera were determined on separate exposure to initial free halogen concentrations of $0.28 \mathrm{mg} /$ liter free chlorine, $0.63 \mathrm{mg} /$ liter free bromine, and 1.00 mg/liter free iodine respectively. The temperature at which these were ascertained was $3-4 \mathrm{C}$ and the $\mathrm{pH}$ values of the distilled water exposure sub. strate were 5.0, 7.0, and 9.0. The test bacteria used were Streptococcus faecalis, Staphylococcus aureus, Escherichia coli, Aerobacter aerogenes, Pseudomonas aeruginosa and Salmonella senftenberg. Exposure of cells was accomplished using a three-neck flask, equipped with appropriate thermometer and stirring devices, suspended in a thermostatically controlled water bath. Only slight differences in bacterial resistance were generally observed between those at $\mathrm{pH}$ 5.0 and those at pH 7.0. The significance of these variations seemed to be a function of bacteria] genes and particular halogen. At pH 9.0, a marked reduction in the microbicidal efficacy of iodine was noted. Of the six test microorganisms, Streptococcus faecalis, was found to be the most resistant to disinfection by each of the three halogens. Using the criterion of time requirred fo $99.99 \%$ destruction, Streptococcus faccalis resistance was at least three times that of the fecal pollution indicator microorganism, Escherichia coli. In addition, a comparison of the efficacy of cell destruction by the three halogens is made for each of the test bacteria.

Antimycobacterial Activity of 3,5-disubstituted tetrahydro-1, 3, 5-thiadiazine-2-thiones. Z. ODLERovÁ, J. Adgustif, P. Nemec, Institute of Epidemiology and Microbiology, Bratislava; Department of Microbiology and Biochemistry, Faculty of Chemis. try, Technical University of Slovakia, Bratislava.

The antimycobacterial activity of a series of $\mathbf{3 3}$ substances of the 3,5-disubstituted tetrahydro-1, 3 , 5-thiadiazine-2-thione group against $M$ ycobacterium $\mathrm{H}_{37} \mathrm{Rv}$, Mycobacterium bovis BCG and Mycobacterium fortuitum was tested. The disubstituted 3,5-radicals were: aryl-, aryl-; aryl-, alkyl; arylalkyl-, arylalkyl-; arylalkyl-, alkyl-; arylalkyl-, arylJudging from the $\mathbf{E D}_{50}$ or minimum inhibitory concentration values, the most effective derivatives were those in which the $\mathbf{R}_{3}{ }^{-}$substituent was an arylalkyl- (1-naphthylmetyl-, benzyl-, furylmethyl-) and $\mathbf{R}_{5}{ }^{-}$was benzyl-, carboxymethyl- or its triethylammonium salt. The MIC of the given substances in Youmans medium was within limits of $3 \times 10^{-5} \mathrm{M}$ (the lowest concentration tested) and $7.5 \times 10^{-5} \mathrm{M}$. The activity of the test substances was compared with that of known antituberculotics, particularly isothiocyanates which, under certain conditions, are thiadiazine degradation products. On the basis of the findings on the relationship between the chemical structure of thiadiazines and their stability at a physiological pH (J. Augustín, L. Drobnica, P. Nemec, M. Zemanová: Fol. microbiol., $15: 203,1969$ ), attention is drawn to the antimycobacterial activity of substituted thiadiazine-2-thiones and its relationship to the stability of these substances. The results demonstrate the in. dubitable significance of detailed study of the antimycobacterial activity of thiadiazines and of other substances belonging to the group of synthetic isothiocyanate producers.

Note on the Standardization of Tests of Antifungal Agents in vitro: Natural Heterogeneity of Qualitative Properties of Dermatophyte Inoculum. Z. JEsENSKÁ, Department of Medical Mycology, Postgraduate Medical and Pharmaceutical Institute, Bratislava.

In tests of bacterial sensitivity to antibacterial agents, the bacterial inoculum is known to be heterogeneous as far as the sensitivity of the individual cells in concerned. Heterogeneity of the qualitative properties of fungal inoculum has not previously been studied. As the indicator of heterogeneity we chose the sensitivity of growing mycelium of macrocolonies of the dermatophytes Trichophyton rubrum, Trichophyton mentagrophytes var. interdigitales, Trichophyton mentagrophytes var. granulosum and Epidermophyton interdigitale. On principle, we worked with cultures from a single maternal colony from a primary culture. As the model inhibitor we used griseofulvin incorporated, in different concentrations, in Sabouraud glucose agar. To avoid random errors and conform to the law of averages, we worked with selective series of relatively large extent. The results confirmed that fungal inoculum is subject to the same biological laws as bacterial inoculum and that it contains individuals with low, 
moderate and high sensitivity. Using an objective eriterion, we occasionally isolated individuals with an extreme reaction. We shall have to investigate this finding further, as the individuals in question occurred in the presence of griseofulvin concentrations attainable in patients in vivo. At present we do not know whether the heterogeneity found in vitro corresponds to mechanisms which act in natural infections in vivo.

Changes in the Cholesterol, Phospholipid and Esterified Fatty Acid Level in Bacterially Contaminated Rabbit and Human Serum. J. BuRAnskÝ, A. Buahová, J. SAFRÁnek, Department of Medical Microbiology and Immunology, Faculty of Medicine, Comenius University, Martin.

Bacterial contamination and cholesterol nonspecifically raise the antistreptolysin 0 titre. The mechanism of nonspecific inhibition of streptolysin 0 by different bacteria present in the serum has not yet been properly explained. One possibility is that the bacteria affect the serum lipid level. In the present study, therefore, we investigated changes in the cholesterol, phospholipid and esterifiod fatty acid level in rabbit and human serum contaminated by Pseudomonas aeruginosa, Bacillus subtilis and Staphylococcus aureus. We found that the presence of these bacteria in rabbit serum significantly reduc. ed the level of the above components after 24 and 48 hours' incubation at $37 \mathrm{C}$, compared with both the initial value in contaminated serum and also with the value in uncontaminated control serum at the same interval $(P<0.001)$. In human serum, only the cholesterol level fell after contamination with Pseudomonas aeruginosa $(\mathrm{P}<0.001)$, Bacillus subtilis $(\mathrm{P}<0.01)$ and Staphylococcus aureus $(\mathrm{P}<0.05)$, except after 48 hours' incubation, when a decrease in the esterified fatty acid level in serum contaminat. ed with Bacillus subtilis was also recorded $(\mathrm{P}<0.05)$.

Actinomyces viscosus, a Catalase-positive Member of the Genus Actinomyces and Pathogen of a Pulmonary Actinomycosis. J. Scharfen, National Reference Laboratory for Pathogenic Actinomycetes, Department of Microbiology, District Hygiene Centre, District Hospital, Turnov.

The author gives the history of a "hamster organism", its classification as a new genus, Odontomyces viscosus, among the Actinomycetaceae and the final inclusion of its two serologically different types (corresponding to their animal and human origin) in the genus Actinomyces as Actinomyces viscosus. The course of a pulmonary infection in a 43 -year-old female worker in the dusty environment of a lime kiln is described. Because of bilateral involvement of the lungs, accompanied by serious general symptoms the patient spent several long periods in different hospital departments in one year. After unsuccessful treatment with antibiotics and cytostaties, we were sent a sputum sample for analysis. Microscopic findings of large numbers of actinomycotic microgranules indicated the possibility of an actinomycotic process. A microaerophilic actinomycete strain, 348/70, highly sensitive to penicillin in vitro was isolated and when the patient was given penicillin she made a dramatic recovery. The determinant properties of strain 348/70 are compared with type strains of Actinomyces viscosus, Rothia dentocariosa and the genus Nocardia and attention is drawn to the danger of confusion catalase-positive actinomycotic organisms with diphtheroids. In conclusion, the pathogenicity of Actinomyces viscosus is discussed. In the case in question, the finding of actinomycotic microgranules in pathological material, isolation of the actinomycete and complete recovery after penicillin provide ovidence that Actinomyces viscosus can play a primary role in the pathogenesis of human infections.

An Aerotolerant Clostridium perfringens Mutant. M. Závadová, M. SEbald, Department of Microbiology, Thomayer Hospital, Prague, and Depart. ment for Anaerobes, Institut Pasteur, Paris.

A mutant capable of limited proliferation and survival in the vegetative form for several weeks under aerobic conditions was isolated from Clostridium perfringens A spores from a case of myositis. The mutant retained its ability to produce alpha toxin. The paper mentions some of the conditions for its manifestation and describes its biological properties as compared with the initial wild strain and another mutant of the strain highly sensitive to $\mathrm{O}_{2}$.

Toxic Activity of Bacillus cereus Culture Filtrate. F. ProkůPEK, Bioveta, Ivanovice na Hané.

Bacillus cereus culture filtrates are characterized by toxicity which can be determined by a lethality test in mice. The best toxin production was obtained in fresh beef broth in which the $\mathrm{pH}$ of the medium was modified so as to be in the neutral reaction zone during the exponential phase of growth. The addition of glucose and normal horse serum stimulated toxin production. Initial synthesis of lethal toxin was demonstrated after 8-10 hours' incubation at $37 \mathrm{C}$, maximum production being reached after 16-20 hours. After that, no further increase occurred in the rate of production, but toxic activity could still be detected after 72 hours. The toxicity of the filtrate usually attained 4-6 LD 50 units. Bacillus cereus culture filtrates are also characterized. by haemolysin and phospholipase production. The maximum haemolytic activity recorded was 32 to 64 units and phospholipase activity 512 to 1,024 
lecithovitellin units. Heating the filtrate to $100 \mathrm{C}$ reliably destroyed the activity of all three components. Trypsin decomposition of the filtrate inactivated toxic and haemolytic activity, but not phospholipase activity. Medium with a markedly acid $\mathrm{pH}$ significantly reduced toxieity. It can be concluded from these findings that the given com. ponents are of a protein character. The toxicity of the filtrate did not seem to be related to the activity of the phospholipase produced. Among the 40 Bacillus cereus filtrates tested, those characterized by lethal toxicity for mice were in the minority (about $40 \%$ ). Strains which did not display haemolysis on blood agar were non-toxic and non-haemolytic in our experiments and possessed only negligible phospholipase activity.

\section{IMMUNOLOGICAL SECTION}

The Application of the Method of Inhibition of Migration and of Cytoblastic Transformation in order to Demonstrate Tuberculin Hypersensitivity. I. Čenná, S. Hanáková, H. Malota, V. Ŕtha. Microbiological Institute, Faculty of Medicine, Palacký University, Olomouc.

The method of inhibition of migration and cytoblastic transformation was used to demonstrate the hypersensitivity to tuberculin both in experimentally sensibilized animals and in patients suffering from pulmonary tubereulosis. In all guinea-pigs sensibilized by $\mathrm{BCG}$ vaccine the inhibition of migration was significantly positive. The inhibition-migration index oscillated between 0.38 and 0.83 and was inversely proportionate the extent of the skin reaction to tuberculin. A certain dependence was observed between the results obtained from the leukocytic layers and standard spleen fragments according to Johanovský and Svejear. The lymphoblastic transformation in cultures with tuberculin was positive only in sensibilized animals, it has not been demonstrated in the control group. In the cultures with phytohaemagglutinin the percentage of transformed cells in sensibilized guinea-pigs was substantially lower than in control guihea-pigs. In patients with pulmonary tuberculosis the inhibition of migration was foliowed by the method of leukocytic layer and the method of capillary test. Both methods are equally sensitive. In comparison with the group of healthy subjects the inhibition in patients was significantly positive. The results of cytoblastic transformation in patients were similar to that in experimental animals. The number of transformed cells in cultures with phytohaemagglutinin was significantly lower in patients than in healthy subjects.
The Isolation of the Migration Inhibition Factor (MIF) Using Column Chromatography on Sephadex $G 200$ and Electrophoresis in Polyaerylamide. $\mathbf{K}$. ¿̈eh, J. Śvejcar, J. Pekárek, J. Johanovský, Institute of Sera and Vaccines, Prague.

The supernatants obtained by cultivation of hypersensitive cells with antigen were fractionated using the Sephadex G 200 column. Four peaks were obtained and subsequently tested for migration inhibitory activity using the spleen fragments of normal rabbits. The migration inhibition activity was mostly localised in the third peak, i.e. the region of elution of serum albumin. In order to obtain further separation, qualitative and preparative electrophoresis in polyacrylamide gel was used. The third peak revealed $6-10$ lines that could be stained by amidoblack. The migration inhibition activity was demonstrated in the albumin zone and also in the material that migrated further towards anode than albumin. The fractions obtained during separation were then analysed immunoelectrophoretically. The possible presence of antigen in individual fractions was studied using the 131 I labelled antigen.

Studies of Experimental Aspermatogenesis (EAA) by means of the Migration Inhibition Test. Z. PokoRná, J. Perárek, J. SvejCar, Institute of Experimental Biology and Geneties, Czechoslovak Academy of Sciences and Institute of Sera and Vaccines, Prague.

The course of EAA was studied using the migration inhibition test that was carried out on spleen fragments of mice at different periods of the disease. Partially purified lyophilised extracts of mouse testes were used as antigon. A direct correlation was found between the course of EAA and the positivity of the migration inhibition test, i.e. when the symptoms of EAA were at their peak, the test was strongly positive at the same time; on the other hand, the test became negative when the disease declined. A similar test was employed in order to study the mechanism of EAA. The eluate of mouse lymph nodes was found to be able to transfer EAA to healthy recipients passively. The same eluate contained further substances that possessed the ability to influence spleen cells of normal mice in such way that they reacted by migration inhibition in the presence of specific antigen, i.e. they behaved like cells obtained from an animal with delayed hypersensitivity.

Studies on the Antimacrophage Effect of Antilymphocytic $(A L S)$ Serum. K. Barnet, J. PEKÁreK, J. Johanovský, J. ŚEJcar, Institute of Sera and Vaccines, Prague.

Different dilutions of antisera were added to the monolayers of peritoneal macrophages. and cultivat. 
ed in special chambers. The antimacrophage effect of antisera was demonstrated by the decrease of motile forms of macrophag 3 s. A similar result was obtained using the inhibition migration test. In order to elucidate the mechanism of this phenome. non, similar tests were performed using trypsin. treated cells. It was shown, that in all types of experiments trypsin significantly increassd the resistance of macrophag 38 to the effect of ALS. This activity of ALS could be effectively absorbed by macrophag $>$ s and, to a lessor extent, even by lymphocytes (i.e. nonadherent cells of lymphnodes). The technique ussd throughout the experiments permitted the quantitative evaluation of the degree of absorption. Optimum results were obtained using the combined absorption with both macrophag ss and lymphocytes. Absorption with kidney homogønate was practically without effect. The antimacrophage effect of antimacrophage serum (ANS) could be absorbed effectively by macrophag 3 s only, whereas lymphocytes were almost without effect. These results seem to demonstrate the different mechanisms of the antimacrophage effect of ALS and AMS.

The Development of Early Haemopoietic and Lymphopoietic Centers During Intrauterine Life in Pigs and Sheep. J. KRUML, F. Kovář̉, P. ŚMA, Institute of Microbiology, Czechoslovak Academy of Sciences, Prag $1 \theta$ and Laboratory of Gnotobiology, Czechoslovak Academy of Sciences, Nový Hrádek

The $a, m$ of these experiments was to define the period of haemopoietic activity bound to the structures of the yolk sac and, further, to the early periods of hepatic haemopoiesis. Whereas the yolk sac fulfilled this function only temporarily, in both models studied, foetal liver repressnted a haemo. poietic center, covering a long period. The haemopoietic activity of this org in was significantly reduced only after the full functional capacity of bone marrow was turned on. Histologic and ultrastructural characteristics of individual structures were described within the period of yolk sac haemopoiesis. Great emphasis was laid on the study of stem cells and their properties. In addition, the period of the onsat of the function of the thymus and its possible role in lymphocytopoiesis and formation of other haemopoietic cells, was evaluated. Furthermore, the proportion of individual haemopoietic cell lines was established using the quantitative cytological method; electron-microscopic studies revealed that thes $\Rightarrow$ cells were formed extravascularly. An attempt was made to describe the kineties of certain cell types during the early embryonic period.

The Specific Pyrogenic Response Elicited by Injection of Antilymphocyte Serum. A. Castrová, J. Pekárek, J. Johanovský, Institute of Sera and Vaccines, Prague.
The intravenous injection of ALS in rabbits was followed by a pyrog onic response, characterised by a long latent period, high increase of body temperature and long duration. The intensity of fever elicited in rabbits tolerant to endotoxin, did not differ from that obtained in normal rabbits. Endogenous pyrogen could be demonstrated in sera of rabbits in the period of increment of fever. In some cases a biphasic response was observed following the injection of serum. The first peak of fever, occurring practically immediately after the injection, was obviously caused by the endogenous pyrogen; the second peak that occurred after a long latent pe. riod was probably caused by the traces of the antilymphocyte activity. In further experiments, a correlation was found between the increase of fever and decrease of pheripheral blood lympho. cytes. In addition, a striking similarity in the course of this type of fever and so called systemic pyrogenic reaction was observed. The pyrogenie response elicited by ALS was found to be specific for this serum. Other antisera, like serum against macrophages or polymorphonuclear leucocytes, caused also typical pyrogenic responses, however, the course of fever was quite different from that observ. ed after injection of ALS.

The Rate of Epithelial Renewal in the Duodenum of Chickens During their Early Postembryonal Development (an Autoradiographic Study). L. RoDáx, Z. Prochazka, Research Institute of Veterinary Medicine, Brno.

A histoautor adiographic study was made on the rate of celluiar renewal in the duodenum of 1., 7 . and 2-day-old chickens. At 72 hours after isotope injection, labelled cells sccupied only $30-40$ per cent of the height of the villi in both 7-and 21-day-old chickens. The changes in the rate of epithelial renewal were found to coincide with previously described histochemical changes in the bursa of Fabricius which communicates with the elimentary tract. It is suggested that the changes occurring in the chicken alimentary tract (as well as in organs com. municating with the alimentary tract) as early as the first post-hatching days are related to the adaptation of the young organism to environmental bacterial and antigenic effects.

The Cooperation of Lymphoid Cells During the In. duction of the Immune Response. J. STERzL, H. TLAsKALOVÁ, Institute of Microbiology, Czechoslovak Academy of Sciences, Prague.

Following the transfer of lymphoid cells isolated from the spleen, to lethally irradiated recipients, an increase in the number of groups of antibody producing cells (foci) could be found from the fourth day. The number of antibody producing cell colonies was directly proportional to the number of 
transferred cells. This fact was evaluated from two points of view: (1) the number of foci was limited by the number of immunocompetent cells present in the suspensions (B-cells); (2) the number of foci was limited by the cells reacting with antigen (T-cells). The results of experiments employing the transfer of spleen cells, B-and T-cells, either separately or in a mixture with different mutual quantitative proportion, demonstrated that the T-cell played a role of a helper cell in the initiation of the immune response. If sheep erythrocytes were used as antigen, the synergist effect of $B$ - and T-cells could be obtained under appropriate experimental, conditions; however, when Escherichia coli was used as antigen, the transfer of $B$ - and T-cells did not evoke the enhancement of the antibody response. These results made it possible to evaluate the basis of cooperation of cells from different lymphoid sources.

Cellular Manifestation of the Recognition of Histocompatibility Antigens in Tissue Transplantation. V. Viklický, A. Lengerová, M. Poláčková, J. ReJzková, Institute of Experimental Biology and Genetics, Czechoslovak Academy of Sciences, Prague.

The main chang ${ }$ in the cell composition of graftdraining lymph nodes is the transformation of lymphocytes into blasts; the lack of correlation between the intensity of this process and the time taken for graft rejection point to not all the activated cells being involved in graft destruction; a portion of them might be associated with antigen recognition. In order to ascertain the involvement of the blasts in these two processes use was made of the possibility to experimentally manipulate both the immunog necity of and responsiveness to the male-specific transplantation antigon (MSA). The experiments showed that: (1) The blastic reaction occurs even in specifically tolerant recipients (antigen recognition ?). (2) A part of the reaction is accounted for by the graft rejection process. (3) An altered form of the MSA (obtained by various experimental procedures) which is less immunogenic tends to induce a weaker blastic reaction. An antigenic tissue graft also stimulates an increase of lymphocytes with antibody-like receptors in the draining lymph node detectable by immunocyto. adherence. The bearing of results obtained by means of this technique on the interpretation of the blastic reaction will also be reported.

The Heteroplastic Formation of Lymphocytes in Mouse Omentum. T. HAJDU, M. HoLUB, L. JaRošKová, I. Trebtchavskŕ, Institute of Microbiology, Czechoslovak Academy of Sciences, Prague.

Using the omentum from lethally irradiated mice as an experimental model, the precursor of lymphoid cells was studied autoradiographically and electronoptically: it was found that the precursor appears to be a cell, morphologically analogical to the sessile non-differentiated stem cell. The relationship of this particular cell (which belongs to so-called active mesenchyme) to the stem cell of lymphoid and haemopoietic cell series, is discussed.

The Stimulation of Cells of Different Lymphoid Organs by Phytohaemagglutinin. L. JAROŠKovA, Institute of Microbiology, Czechoslovak Academy of Sciences, Prague.

The response of cells of lymphoid organs to phytohaemagglutinin (PHA) was studied in germfree and convential animals and in pig foetuses at different stages of the gestation period. The cells obtained from lymph nodes, spleen and thymus were incubated in vitro with PHA and the incorpora. tion of labelled precursors of nucleic acids into RNA and DNA was measured. Variations in the response of the cells of thymus to PHA were found in different animal species. Good stimulation of synthesis of both RNA and DNA was obtained with thymocytes from pig foetuses and newborn precolostral piglets. No differences in the increase of synthesis of DNA were found in lymphocytes of germ-free animals after PHA (young rabbits, piglets and rats) as compared with conventional animals of the same species and age.

The Immune Reaction in Germ-free Piglets Monoassociated with Viruses. P. HÁJEK, J. KLEPalová, F. KováŘư, J. KaUmL, J. Trávnf́ČeK, L. Mander, Laboratory of Gnotobiology, Institute of Microbiology, Czechoslovak Academy of Sciences, Nový Hrádek.

Newborn germ-free piglets represent an ideal model for studies of a true primary immune response. Piglets were obtained by hysterectomy, reared in rigid plastic isolaters, fed an artificial sterile diet. Microbiological examination of these piglets revealed that no aerobic or anaerobic bacteria or yeasts and molds could be found. However, the question arises, to what extent the model of "germ-free" piglet can be considered as truly germ-free, expecially because the virological aspect in this gnotobiotic animal has been neglected. The aim of the present experiments was to study the immune response to possible contamination with live virus. Suspensions of different viruses (virulent strain of Teschen disease of pigs, avirulent variant of the Teschen disease virus, attenuated strain of Aujeszky disease virus) were added into the milk formula, and newborn piglets were fed with these suspensions on the first day after birth. Monocontaminated piglets responded by the formation of neutralizing antibodies demonstrable in the serum soon after monoassocia 
tion with the virus: the negative (inductive) phase took 3-5 days followed by pronounced formation of $19 \mathrm{~S}$ antibodies; $7 \mathrm{~S}$ antibodies appeared in the second week. No antibodies could be found in piglet sera against any of the viruses used before monocontamination. Morphological changes in lymphoid organs together with the formation of immunoglobulins demonstrable in sera of monocontaminated animals, represent a positive proof indicating that the immune reaction took place. In addition, these results indicate that the virus contamination of germ-free animals may represent an important factor, responsible for the changes in basal charac. teristics of "germ-free" (i.e. abacterial) animals.

The Formation of Haemolytic Antibodies in Young Rabbits After the Injection of Antigen and Macrophages Possessing Different Enzymatic Activity. D. Kotulová, Department of Microbiology and Immunology, Faculty of Medicine, Comenius University, Bratislava.

It was found that alveolar macrophages possessed a significantly higher activity of proteolytic enzymes in comparison to the cells of peritoneal exudate obtained by oil irritation. In further experiments, the influence of these cells with different enzymatic activity on the formation antibody to sheep erythrocytes (plaque forming cells PFC) was studied in young rabbits. Newborn rabbits were injected intraperitoneally with $1 \mathrm{ml}$ of a $10 \%$ suspension of sheep erythrocytes together with $10^{7}$ cells of macrophage character that were obtained from adult donors. It was found that the addition of peritoneal macrophages enhanced the number of PFC as compared with control rabbits from the identical litter that were immunised with sheep erythrocytes only. The addition of alveolar macrophages obtained from adult rabbits to the suspension of sheep red blood cells, suppressed the formation of haemolytic antibodies. The participation of different types of cells of macrophage character with different enzymatic activity in the induction of the antibody formation, is diseussed.

The Possibilities of Enhancement of the Effect of Adjuvant Immunisation According to Freund. C. John, M. Morávková, K. Benešová, Institute of Medical Microbiology and Immunology, Medical Faculty, Charles University, Prague.

We have shown that the effect of adjuvant immunisation could be enhanced, provided a waterin-oil emulsion was injected into immunised animals prior to the appropriate antigenic stimulus. The effect of the preliminary injection of oil was evaluated according to the level of circulating antibodies. In the present experiments, an attempt was made to demonstrate the effectiveness of preliminary injected adjuvant at the tissue and cellular level. Three weeks before adjuvant immunisation with bacteriophage T2, rabbits obtained a complete Freund adjuvant that was divided into separate components. At different time intervals after adjuvant immunisation, Iymph nodes draining the site of antigen injection were taken and fragments were cultivated in vitro. Bone marrow was cultivated under similar conditions. It was found that fragments from lymph nodes of animals that received the preliminary dose of complete Freund adjuvant, formed three times more antibodies than fragments from non-presimulated animals on the 6 th day of cultivation in the tissue culture. The differences in the amount of antibodies found between these two experimental groups became even more promounced provided the fragments were taken eleven days after the adjuvant immunisation. Furthermore, at this time, quite significant antibody formation could be demonstrated in bone marrow obtained from prestimulated animals. At later stages of cultivation, the amount of antibodies released into the cultivation medium by lymph node fragments of prestimulated animals differed only insignificantly from the amount of antibodies produced by lymph node fragments of non-prestimulated animals.

Prestimulation with complete Freund adjuvant was also used in mice subsequently immunised with sheep erythroeytes. Using the haemolytic plaque assay, a higher percentage of haemolytic antibodies forming cells was found than in non-prestimulated mice.

Studies on Immune Paralysis at the Cellular Level. J. MEDLfN, Institute of Microbiology, Czechoslovak Academy of Sciences, Prague.

The paralytic dose of pneumococcus polysaccharide of type III led to the occurrence of a low number of haemolytic antibody forming cells. The dynamics of this response was quite different from the reac. tion to an optimum low dose of antigen. The results of experiments in which the incorporation of ${ }^{14} \mathrm{C}$ thy. midine into antibody forming cells was used, revealed that after a large dose of antigen major fraction of these cells passed directly into the production stage without previous stimulation. 'The antibody forming cells that disappeared completely within 12 days after immunisation with a large antigen dose, reoccurred again on the 30 th day or later at very low number. Irradiation with $\mathbf{5 5 0} \mathbf{R}$ immediately after immunisation very significantly inhibited the number of antibody-forming cells provided a low dose of polysaccharide antigen was used; on the other hand, this radiation dose only slightly influenced the population of cells occurring after the paralytic dose. Injection of pertussis vaccine together with antigen had a characteristic influence on both the dynamics and number of antibody forming cells after the paralytic dose, and to a lesser extent after the optimum dose. The transfer 
of cells, using the combination thymus-bone marrow, seem to indicate that pneumococcus polysaccharide is the thymus-independent type of antigen.

\section{Studies on the Proliferative Activity of Antibody Forming Cells Using the Continuous Infusion of $C^{14}$ Thymidine. P. Stma, Instituts of Microbiology, Czechoslovak Acadomy of Sciences, Prague.}

It is assumed that the number of antibody forming cells dytəctid by Jerne's plaque mothod, increases aft $\ni$ r th 3 antig $\rightarrow n$ injection by $2-3$ orders. This increase in number of antibody forming cells may take place by two mechanisms and is dэpэndont on thэ charactir and amount of antig $3 n$ us $\ni$ d: by mitotic division (proliferation) or direct differentiation of immunocomp cells. Each cell, before passag s through th $\rightarrow$ mitotic division, reduplicat3s its DNA in tho synthotic phase. This nowly synthэtisəd DNA can be labelled with radioactive $\mathrm{C}^{14}$ thymidine that becomes specifically incorporat $\ni$ d into tho coll. Labelled cells can thon bo studiod by moans of autoradiography. $C^{14}$ thymidine was injectsd into mice of strain $\mathbf{A}$, immunis in single dosэs (pulsəs) at five hours intorvals within 72 hours aftor immunisation. However, th9 pulse dosag 3 did not exclud 3 tha possibility that all proliforating cells will contact th 3 radiactive isotopэ. This m 3 ans that thy proportion of antibody forming cells that diffэrentiat nocompetənt cells, might increas3. Thorefore tho method of continuous infusion of isotop? was usod in furthər exp эrim эnts. Thэ isotopэ was introdused by moans of a cannula subcutansously or intra. peritoneally, Using tho latt $\exists r$ mathod, the pэrcentag of labslled antiboxy forming cells inereasyd from $80 \%$ to $96 \%$. This result m $m a n s$ that after immunisation with shэөp erythrocyt 39 , th 3 enhance. ment in number of antibody forming cells took placs mainly via proliferation, i.e. by mitotic division.

Studies on the Immunoglobulin Structure on the Surface of Lymphoid Cells. I. KfHA, Institute of Microbiology, Czэchoslovak Acadəmy of Sciences, Prague.

The reaction of lymphoid cells with antiglobulin antibodies prodused noith damag ${ }^{3}$ of th ${ }$ cells. Incubation of spleon cells with anti-Ig $\mathrm{M}$ or anti-Ig $\widehat{A}$ sərum and complemant did not decreas 3 th $\rightarrow$ viability of cells and thoir ability to colonize lethally irradiat 3 d recipients. Similarly, incubation with anti-Ig s rra and complemont did not influmese th 3 ability of lymphoid cells, obtained from donors that wəre immunis erythrocyt3s, to form both direct and indirect plaques. Thəsэ rosults səэm to indicato that th 3 immunoglobulin struetures on the surface of lym. phoid cells are presənt in low numbor and distri- buted on the cell surface in such way a that they do not allow a dense aggregation of anti-Ig molecules, neccessary for complement activation. There exists another explanation. i.e. that these $\mathrm{Ig}$ structures are localised in areas resistant to complement action.

The Influence of Certain Factors on the Course of the Immune Response (a Mathematical Model). M. J'́LEK, Z. Unsfrvová, Institute of Microbiology, Czechoslovak Academy of Sciences, Prague.

Using the computer, extensive calculations were perform $3 d$ according to formula, derived for calculation of the averag 3 course of the number of antibody forming cells. On the basis of the numeric material obtained, the influence of individual factors was studied on the cours $\theta$ of the primary immune response and preparation for the secondary response. The influence of the following factors was studied: the time period, for which the cell stays during differentiation in transitional stag 78 betwesn $X$ and $Y$ and between $Y$ and $Z$; the highest possible number of ginerations of cells $Y$; the generation time of cells $Y$; the amount of injected antigon and rate of its elimination. It was found that the course of the primary reaction was substantially influenced by the parameters describing the behaviour of antig $\rightarrow n$, whereas other parameters did not significantly influence the course of the immune reaction. For this reason, these parameters received special attention: besid $ə$ s the presumed exponential decrease of the amount of active antig $m$ present, even the course of the immune reaction was studied under different forms of the decrease in the amount of present antig on. The calculated values for certain parametters were compared with experimental data, and good correlation was reached between the theoretical and empirical values.

A Survey of the Production of Antigens for Skin Tests. V. Mucha, Institute of $\mathrm{S} \ni$ ra and Vaccines, Prague.

The diagnosis of a number of dissases caused by various mieroorganisms is usually impossible only on the basis of evaluation of clinical symptoms or by a direct diagrostic method. Sorological tests are in certain casss difficult to perform routinely for various reasons (e.g. the availability of suitable mothod or matarial). Therefore the allergic reaction of tho organism to certain microbial antigans has ofton been us $ə$ d for diagnostic purposəs. The intradormal tast does not require special equipment, can be dons even in non-specialis $ə d$ laboratories; howəver, it requires an accurats, standardişd mothod of application and reading the result of the raation. In addition, the final evaluation of the test for diagnostic purposas should be done by an expэrianced physician and should be bassd on a com. plex clinical evaluation, or eventually, combined 
with other diagnostic methods. The existing objections to the reliability of skin tests are very often caused by the use of bad preparations of antigen or bad execution and evaluation of the production of these diagnostic preparations throughout the world.

The Complement Levels in Patients Suffering from the Nephrotic Syndrome During Immunosuppression

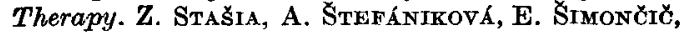
Institute of Medical Microbiology and Third Clinic of Internal Medicine, Medical Faculty, Comenius University, Bratislava.

The complement (C) level was studied in the sera of patients with the nephrotic syndrome. The values found in sera of 32 healthy individuals were taken as normal $\mathrm{C}$ levels (the average value determined by the Mayer method was $31.54 \mathrm{CH}_{50} ; \mathrm{s}=\mathbf{2 . 3 3}$ ). In 10 patients out of 17 tested, a decreased level below the lower limit of normal value was found (8 patients with chronic glomerulonephritis, 1 with acute glomerulonephritis, I with systemic lupus erythematosus); a normal $C$ level was found in 4 patients with chronic glomerulonephritis and finally, in 3 patients with systemic lupus erythematosus the $C$ level was increased. In 8 patients with lowered C levels, immunosuppression therapy with Imuran was started. It was found that the C levels increased in all cases within four weeks; in most cases the levels returned to normal values, in 2 cases the $C$ levels temporarily exceeded the upper limit of normal values. During the long-term observation of these patients it was found that in cases of successful Imuran therapy, the $\mathrm{C}$ level normalised definitely in accordance with clinical recovery and normalisa. tion of other biochemical criteria (erythrocyte sedimentation rate, proteinuria, Addis sediment, point activity according to Brod and Benešové). As regards the chronic process with progressive irreversible changes, the effect of immunosuppression therapy was only temporary. In agxeement with this, the $\mathrm{C}$ level returned to normal also only temporarily. It was shown that $C$ changes are a much better refection of the actual activity of the disease than other clinical and biochemical criteria.

The Bactericidal Activity and Lysozyme Level in Sera of Different Animal Species After Bacterial Contamination. J. Buransk Ý, L. KLÚČ́rKová, Institute of Microbiology and Immunology, Faculty of Medicine, Comenius University, Martin.

The presence of bacteria in the sera in vitro has a negative influence on certain biochemical and immunological properties of sera. The aim of the present study was to establish what changes in bactericidal activity and lysozyme level might occur in rabbit, pig, bovine and human sera after bacterial contamination. Different bacterial species were used and the changes in the sera of different animal species were compared. A significant decrease in bactericidal activity was found which was dependent on the type of microbe used, length of incubation and type of serum. No significant changes in the lysozyme level could be found in any of the sera tested with the exception of bovine sera.

The Peroral Vaccination Against Coli Dyspepsia in Neuborns and Infants. I. ODLER, D. GWORCH, M. Draškoviơová, M. Toldyová, Research Institute of Epidemiology and Microbiology, Bratislava, Institute of Biochemistry and Microbiology, Faculty of Pharmacology, Comenius University, Bratislava and Institute of Sucklings, Bratislava.

The effectiveness of a peroral enterovaccine against epidemic diarrhea of newborns and infants, was tested. This study was based on our previous experience with the preparation, application and evaluation of certain vaccines against intestinal infections. The acetate-treated entero vaccine, prepared from Escherichia coli strain 0111-B4, was suspended in $5 \%$ glucose solution and given to a group of 24 infants in three consecutive daily doses in an increasing amount: 10,20 and $30 \mathrm{mg}$ of dry weight. The effectiveness of vaccination was evaluated on the basis of immunological criteria: the formation of 0 -agglutinating and 0 -haemagglutinating antibodies, the increase in specific bactericidal activity of the sera, tested before vaccinated. and 1 and 2 weeks and $I$ month after immunisation. No 0-agglutinating antibodies were found after vaccination. Using haemagglutination assay, however, a three-fold increase in the average titre (M) was found within one week, and a two-fold increase 2 weeks or 1 month after vaccination. The specific bactericidal activity in the sera of vaccinated sucklings increased from the prevaccination value $M=1.76$ to 2.92 and 2.15 within 1,2 and 4 weeks after vaccination. The positive results of both latter tests demonstrated the presence of an immune response in vaccinated sucklings as a result of the peroral administration of the enterovaccine; the most interesting feature of this response seems to be the fact that the increased bactericidal activity was maintained even one month after vaccination.

The Changes in the Composition of the Bacterial Population in Germ-free Piglets After Long-term Monocontamination with $S$ and $R$ Strains of Salmo. nella typhimurium. V. Dlabač, J. KLepalová, L. Mandel, Institute of Microbiology, Czechoslovak Academy of Sciences, Prague and Nový Hrádek

Newborn piglets, reared under germ-free conditions, were infected (contaminated) perorally with different $\mathbf{S}$ and $\mathbf{R}$ mutants of Salmonella typhimurium, possessing a known structure of lipopoly- 
saccharide, within the 14 days of life. In surviving animals, the gradual chang 98 in the composition of intestinal microflora was systematically observed. The original strain was replaced by a strain, form. ing chemically and antigenetically different lipopolysaccharide. These changes were probably elicited by the selection pressure of the immune organism.

Peroral Treatment of Enteral Coliinfections of Piglets and Calves by Specific Polyvalent Antisera. E. SALaJKa, Z. Śarmanová, L. ULman, Research Institute of Veterinary Medieine, Brno.

In our previous experiments, done in gnotobiotic piglets that were infectod with species-pathogenic strains of Escherichia coli (sərotypo 08: K87, K88; 0147: K89, K88 and 0149: K91, K88) a very good protective and therapeutic effectiveness of perorally administered specific antis $\ni$ ra was found. Sera were prepared by immunisation of pigs with Escherichia coli strains that were previously tested for pathogonicity using the dilatation of ligated intestinal loop test. A short-lasting occurrence in th 9 predominance of stable pathog ${ }^{\prime}$ ic types of Escherichia coli in the intestines of piglets was found a fow days after weaning in breeds of pigs liable to enteral coli in. fections of weaned piglets. The occurrence of disease could be prevented by the addition of specific antiserum to drinking water after weaning. On the basis of these results an experimental treatment of enteral coli infections in piglets and calves was started during the early postnatal period by peroral administration of polyvalent colisera, preserved by beta propiolactone. $3 \mathrm{ml}$ of polyvalent pig coliserum was administered perorally $3-4$ times/ day to each experimental animal. This treatment appeared to be successful in saveral litters of 4 breeds originally suffering from the enzootic occurrence of diarrhea of piglets, with positive microbiological demonstration of the presence of pathogenic serotypes of Escherichia coli. The recovery of piglets was usually reached within 102 days after the beginning of treatment. In addition, the coliserum therapy was found to be effective in 8 breeds of cattle with enzootic oceurrence of coli enteritis of newborn calves. The diseased calves recovered within $1-3$ days after the peroral administration of polyvalent bovine antiserum.

$A$ Contribution to the Immunochemical and Biological Heterogeneity of Endotoxin. V. DLABač, J. Hofman, Institute of Microbiology, Czechoslovak Academic of Sciences, Prague.

Endotoxins were isolated and purified from a series of smooth salmonella strains. Using immunoelectrophoretic examination of all preparations, the single, relatively homog strated that reacted, however, not only with appro. priate antiserum but even with some anti-R sera.
When these preparations were then examined immunoelectrophoretically in the presence of disaggregating agents, relative partial soparation of the fraction reacting with anti-S serum and the fraction reacting with anti-R-serum, was obtained. The isolated and partially purified fractions differed in chemical and antig mic composition and showed certain differences in the biological activity.

Immunoglobulin IgA in the Serum of Newborn Precolostral Piglets Reared under Sterile Conditions. J. Rejnek, L. Prokešová, B. Seniusová, J. TrávNí̌Ex, Institute of Microbiology, Czechoslovak Academy of Sciences, Prague.

A number of works have described the presence of IgG in the sera of newborn precolostral piglets, however, IgM was never found. It was necessary to extend the knowledge as to the presence or ab. sence of IgA in piglet sera and, further to establish whether antibodies of this type are formed after immunisation with soluble antigen. Using immunochemical methods we were able to demonstrate IgA in the sera of newborn precolostral piglets by means of specific antisera against alfa-chains of adult $\mathrm{IgA}$. The serum level of IgA was extremely low (approximately 25-50 times lower than the level of IgG that amounts to several tenths of $\gamma / \mathrm{ml}$ ); therefore, in order to be able to demonstrate the presence of this immunoglobulin manifold concentration of the globulin fraction of serum was required. Newborn precolostral piglets, reared under germ free conditions, were immunised with human serum albumin and the antibody response was studied using radioimmunodiffusion, permitting the establishing of antibody activity and the serum immunoglobulin level at the same time. The results obtained showed that the first antibodies, as usual, were of the IgM type. Soon antibodies of the IgG type also appeared. Antibodies of the $\operatorname{IgA}$ type, however, appeared approximately six months after immunisation. Studies on the properties of $\operatorname{Ig} \mathbf{A}$ antibodies demonstrated that they exist in two forms, having the sedimentation constants of $13 \mathrm{~S}$ and $7 \mathrm{~S}$.

The Occurrence of Immunoglobulins in the Meconium of 70-100 Day Old Pig Foetuses. A. Sokol, F. HrUŠvskÝ, M. FotxA, School of Microbiology and Zoohygiene, Veterinary Faculty, Košice.

Samples of meconium obtained from the small intestine and colon of 70 and 100-day-old foetuses were submitted to an extraction procedure with physiological saline at $\mathrm{pH}$ 7.2, added at the ratio 1 : 5, with occasional shaking; finally, the material was centrifug 3 . The concentrated supernatant was separated by gel filtration on a Sephadex G-200 column and by chromatography on DEAE cellulose. Two peaks were obtained by gel filtration. The eluates were divided into six fractions. 
These fractions were tested using immunoelectrophoresis and precipitation in agar according to Ouchterlony. The antisera used: RASw serum and monospecific antisera to pig colostral $\operatorname{IgA}$, to serum IgG and to serum IgM of adult pigs. Using immuno. electrophoretic assay of individual fractions against RASw serum, the following proteins were detected: albumin, alpha- and beta-globulins, and in the fifth fraction, even proteins in the region of immuno. globulins. Using comparative immunoelectrophoresis and comparative immunodiffusion with monospecific antisera, immunoglobulins of the IgA and IgG class were detected in the fifth fraction obtained by gel filtration. More IgA was found in samples of meconium of 100-day-old pig foetuses. The origin of immunoglobulins in meconium is discussed.

The Identification of Immunoglobulins Present in the Sera of 70-100 Day Old Pig Foezuses. H. HRUSovsk Ý, A. Sokol, M. FotTA, School of Microbiology and Zoohygiene, Veterinary Faculty, Košice.

In 1967, we reported data dealing with the occurrence and dynamics of immunoglobulins in the sera of pig foetuses in the third of intrauterine development. Two precipit in lines, localised in the region typical for immunoglobulins, were found in 74-104 day-old foetuses, using the comparative immunoelectrophoresis with ISF antiserum, directed against proteins of 86-94-104 day-old foetuses. One of these two lines was considered to be IgA globulin. This assumption was based on its electrophoretic mobility and areactivity with $\mathrm{H}$ s srum, directed against heavy chains of $\mathrm{IgG}$, and with $\mathrm{M}$ serum, directed against heavy chains of IgM of adult pigs. The present report deals with the identification of this particular precipitin line using monospecific antiserum to pig colostral IgA. Individual samples or pools of sera of 70 and 100-day-old foetuses were concentrated by salting out with ammonium sulphate, dialysis of dissolved sediment and lyophilisation to $1: 30$, of the original volume. Part of concentrated sera was separated by gl filtration on a Sephadex G-200 column and chromatographi. cally on DEAE cellulose. Another portion of concentrated sera, as well as 12 fractions obtained from the peaks of gel filtration separation, were analysed by immunoelectrophoresis and immunodiffusion according to Ouchterlony. Two precipitin lines were detected in the immunoglobulin region using comparative immunoelectrophoresis of con. centrated sera and medium fractions with RASw antiserum and monospecific antiserum to pig colos. tral IgA, to serum IgG and serum IgM of adult pigs. Two immunoglobulins were identified: one, antigenically identical with IgG and second, antigenically identical with $\operatorname{IgA} A$, using the comparative immunodiffusion of both concentrated serum and medium fractions of gel filtrates with three monospecific antisera. The origin of immunoglobuling in sera of pig foetuses is discussed.
The Isolation and Characterisation of Pig IgA Immunoglobulin and its Chains. J. ČERNA, J. REJNEK, Institute of Microbiology, Czechoslovak Academy of Sciences, Prague.

Using the radial diffusion in agar gel, containing specific antisera, the behaviour of three main immunoglobulin classes was studied during the gel filtration of proteins of serum and colostrum on the 2-200 Sephadex column in tris buffer: finally, the distribution of these immunoglobulins in the elution diagrams was compared. Following this basic characterization, our attention was drawn to the isolation of IgA immunoglobulin from serum and colostrum. The combination of gel filtration on a G-200 Sephadex column and chromatography on DEAE cellulose in tris buffer, was used. Using this procedure, an immunoelectrophoretically pure IgA immunoglobulin was obtained. Using dithiothreitol IgA was split into heavy and light chains, that were subsequently separated on Sephadex G-100 in disaggregation medium. IgA and its chains were characterised by chemical and physico-chemical methods, sedimentation constants and molecular weights were established.

The Macrostructure of Human IgM. J. ZIKÁN, J. C. BenNet, Institute of Microbiology, Czechoslovak Academy of Sciences, Prague and University of Alabama, Medical Center, Birmingham, Alabama, U.S.A.

Human Waldenström IgM (Dau), subunits $\mathbf{H}$, $K, F c$ and Fab and their bromcyanide fragments, were analysed after complete or partial oxidative sulphitolysis. Molecular weights, immunochemical and electrophoretical behaviour, peptide maps, aminoacid and sugar composition, number of disulphide bonds and $\mathrm{S}$-sulphocysteins, terminal aminoacid residues and partial primary structure, were established. On the basis of these data it was posib. le to determine the sequence of bromcyanide fragments and the arrangement of inter-and intradisulphidic bonds. The comparison of the primary structure or aminoacid composition of some peptides with analogical peptides of another species of human IgMI (Wikler, M., Köhler, H., Shinoda, T., Putnam, F. W.: Science, $163: 75,1969$ ) showed the similarity of $\mathrm{N}$-terminal, and identity of $\mathrm{C}$-terminal portions of the H-chain. The chain was found in the

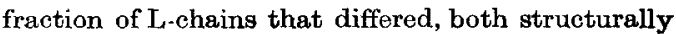
and by localisation in the molecule, from $\mathbf{H}$ - and L-chains. It was shown that this chain is identical with the chrin found in human colostral IgA (Merstecký, J., Zikán, J., Butler, W. T.: Science, 1971, in press).

The Role of Protein Carrier in the Formation of Antihapten Antibodies. B. ŔfHová, I. Kf́fA, Institute of Microbiology, Czechoslovak Academy of Sciences, Prague. 
No secondary reaction could be elicited after the immunisation of rabbits with two different small haptenic groups ( $p$-arsanilic and $p$-aminobenzoic acid) bound to different protein carriers (human serum albumin, bovine gamma globulin) provided antigen was used for secondary stimulation, com. posed of both haptenic groups but with different protein carrier (ovalbumin). The secondary response could be obtained only when an identical carrier was used for both primary and secondary stimula. tion. The secondary reaction could be elicited with heterologous carrier only if the haptenic group used was large enough (fluorescein isothiocyanate). This indicates that the antigenic determinant required for the induction of antibody response in small haptens ( $p$-arsanilic and $p$-aminobenzoic acid) includes even some part of the carrier, that is then neccessary for the secondary stimulation. If a large haptenic group was used (fluorescein isothiocyanate) the participation of the carrier in the formation of the antigenic determinant decreased. In spite of this, however, the secondary reaction to large hapten, elicited by means of heterologous carrier, did not reach the extent of the secondary reaction induced by means of homologous carrier.

Studies on the Antigen Elimination from the Blood Circulation in Chickens and Piglets During the Postnatal Period. Z. Procházxa, J. HampL, Veterinary Faculty and Research Institute of Veterinary Medicine, Brno.

The rate of elimination of ${ }^{131}$ I labelled albumin was studied in chickens and piglets after an intraperitoneal administration within the first 6 weeks of postnatal development. The rate of elimination of 131I HSA from the blood stream of chickens varied in this period within the range of values of $T_{2}=0.8-1.1$ days. The rate of elimination of 131I CSA from the blood stream of piglets was given by the range of values $T_{2}=2.4-3.6$ days; however, the $\mathbf{T}_{3}$ value gradually shortened with the increasing age of piglets. $T_{3}$ was not found in oneweek-old piglets.

The Formation of Cytophilic Antibodies During Specific Immunosuppression. J. LoKAJ, Institute of Microbiology, Medical Faculty, J. E. Purkynø University, Brno.

Guinea pigs were immunised subplantary, using the mixture of chicken erythrocytes in complete Freund adjuvant. For the suppression of the immune response, an intravenous injection of sheep erythrocytes and passive immunisation by homologous antibodies directed against sheep erythrocytes, were used. It was found that the method used for immunosuppression appeared to be immunologically specific: only the inhibition of response to sheep erythrocytes took place, whereas the reaction to chicken red blood cells remained unchanged. This suppression applied to the skin reaction of the delayed type and to the formation of cytophilic antibodies. The inhibition of the formation of haemolysin was apparent only early after immunisation (i.e. within 7 days). The levels of serum haemagglutinins in the experimental and control groups were of the same value. However, there remained an open question concerning the immunochemical characteristics of inhibited cytophilic antibodies, and furthermore, the question of the relationship between the induction (specific inhibition) of delayed hypersensitivity and formation of cytophilic antibodies.

The Influence of Ionizing Radiation on the Primary and Secondary Response in Chickens. J. KREJð', Z. Procházka, Research Institute of Veterinary Medicine, Brno.

The influence of ionizing radiation $(1,200 \mathrm{R}$, $\mathrm{LD}_{50}, 3_{0}$ ) on the primary and secondary immune response was studied in chickens. The intensity of the antibody response was studied on the basis of human serum albumin (HSA I'131) elimination from the blood circulation. The formation of antigen. antibody complexes, and the occurrence of serum antibody detected by passive haemagglutination assay. The relationship between the time of irradiation and antigen injection played an important role with respect to the primiary response whereas it did not influence the secondary injection of antigen. The ability to take up HSA I ${ }^{131}$ specifically from the blood circulation of chickens, was found to be radioresistant in both the primary and secondary reaction. The radiation damage of the secondary reaction in chickens was of the same magnitude as the suppression of the primary response.

The Dynamics of the Number of Plaque-Forming Lymphocytes in the Peripheral Blood of Pig Foetuses and Weaned Piglets. A. SokoL, M. Novík, School of Microbiology and Zoohygiene, Veterinary Faculty, Košice.

In 1967 , we reported a study dealing with the dynamics of thymus and haematologic criteria in pig foetuses during the second half of intrauterine life. In the present study, peripheral blood of 60 , 70, 100 and 111-day-old pig foetuses was examined for the presence of plaque-forming lymphocytes, using the chamber method (see Kunay \& Sokol). No plaque-forming lymphocytes were found in 60 and 70-day-old pig foetuses; in 100-day-old foetuses, plaque-forming lymphocytes were found sporadically and, finally, in 111 day old foetuses plaque-forming lymphocytes comprised already $1-5 \%$ of the total circulating lymphocyte pool. The question of the thymus origin of the majority of primarily circulating small lymphocytes in peripheral blood 
during the second half of the intrauterine develop. ment, is discussed. Furthermore, special attention was given to the partial correlation between the occurrence of secondarily circulating large lymphocytes in the blood, and to the presence of plaque. forming lymphocytes in vitro, and finally, to the cause of the blast transformation of lymphocytes at this developmental stage of pigs. The concentration of weaned piglets from different microectotypes in sties, represents a critical period in the life of pigs. Weaned piglets, besides being exposed to both psychological and physical stress, must cope immunologically with different microbial, viral and protozoal microinfections. Using the chamber method, we examined blood samples of weaned piglets on the 1st, 4th, 7th, 10th and 14th day after concentration in the sty, and the following observations were made: (1) the number of plaques sharply increased from the lst-7th day, then kept increasing at a slow rate until the 10th day, and by day 10 it reached double the starting value. From day 10-14 the number of plaques started to decrease very sharply back to the original value. (2) On the first day, $10-15 \%$ of circulating lymphocytes belonged to the "soluble factor" releasing cells. On the 10th day, the number of these cells doubled so that about $37 \%$ of circulatina lymphocytes possessed this "soluble factor" - releasing ability. On the 14th day, the number of these cells decreased to $12 \%$ of the total lymphocyte pool.

The Dynamics of the Number of Plaque Frorming Lymphocytes in Patients Undergoing Serious Operations. M. Kunay, A. Sokol, Department of Mierobiology, Faculty Hospital, Košice and School of Microbiology and Zoohygiene, Veterinary' Faculty, Košice.

One of the possible consequence of blast transormation of thymus-dependent lymphocytes under the influence of antigens and non-specific mitogens, appears to be the release of "soluble factors" into the microenvironment. The ratio of these potentially "soluble factor" releasing lymphocytes, transitorily circulating in peripheral blood, increases as soon as the number of disintegrating cells in the body increases. For example, their number increases after autohaemotherapy. This type of activated lymphocytes can be demonstrated by a simple method, originally proposed by Cunningham (1965) for the detection of plaque-forming B-lymphocytes, and further modified by Klemparskaja (1969) for examination of citrate blood in a microchamber in the cold. Using diluted blood, it was observed that in the vicinity of active, "soluble factor" releasing lymphocytes, a cell-free zone developed within 24-48 hours, the diameter of which being $2-4$ times wider than the size of the centrally located cell. The aim of our study was to follow the dynamics of the occurrence of plaque-forming lymphocytes in patients submitted to serious operations. It was found that in three samples obtained during the preoperation period, the number of plaque-forming cells varied within the range $1-15 \%$ of the total circulating lymphocyte count. The character and the specificity of the origin of this activity of lymphocytes in this particular model, is discussed.

The Differences in the Course of Postirradiation Gastrointestinal Syndrome in Newborn Conventional and Germ-free Piglets. I. MILER, I. MANDEL, F. MoRÁVEK, Institute of Microbiology, Czechoslovak Academy of Sciences, Prague and Department of Radiology, Military Medical Research and Training Institute, Hradec Králové.

The effect of the supralethal dose of ionizing radiation $\left(1,200 \mathrm{R}, \mathrm{Co}^{60}\right)$ was studied in newborn conventional, germ-free, and sterile, perorally monoassociated with Escherichia coli, piglets. It was found that this particular dose of radiation will elicit acute intestinal death within three days after irradiation in conventional piglets; the survival time in germ-free piglets however, was found to be three times as long. The artificial colonization of the intestinal tract of sterile piglets with a non-pathogenic strain of Escherichia coli prior to irradiation led to conventionalization of these animals and shortening of the postirradiation survival time closer to the level found in conventional animals. Moreover a correlation was found between the survival time and the onset of changes in the structure of the intestinal mucous membrane, particularly the damage of the intestinal epithelium (i.e. entero. cytes) in ileum and colon. Significant focal regressive changes of the epithelium and denudation of villi were found in conventional piglets $2-3$ days after irradiation. As regards germ-free piglets, however, the intestinal mucous membrane (epithelium), was found to be intact even $7-8$ days after irradiation with the same dose. The morphological characteristics of the intestinal mucous membrane of germ-free, monocontaminated piglets was comparable with that of conventional animals. The role of the presence or absence of the microbial factor for both lifespan and radiosensitivity of enterocytes, is discussed. Preliminary experiments did not confirm the significant participation of bacterial endotoxin present in the intestine, in the pathogenesis of the postirradiation gastrointestinal syndrome in new. born piglets.

Further Studies on the Purification of the Antibacterial Substances from Rabbit Leukocytes by Gel Filtration and Disc Electrophoresis. J. PRIXová, Department of Medical Microbiology, Medical School, Charles University, Hradec Králové.

An attempt to separate different cytoplasmic substances of rabbit polymorphonuclear leucocytes is described. Gel filtration on Sephadex G 100 
column and a control of the purification by disc electrophoresis on $5 \%$ polyacrylamide gel was performed. The separation of lysozyme from other substances with antibacterial activity against Escherichia coli was achieved. Disc electrophoresis has shown that the fractions are not homogeneous. The approximate molecular weight of antibacterial substances was estimated by gel filtration within the range of about 64,000 . The molecular weight found by disc electrophoresis was calculated within the range $28,000-35,000$. The difference is interpreted as the effect of splitting of the molecules by sodium dodecyl sulphate and 2-mercaptoethanol, which were used for disc electrophoresis. These results serve as preliminary information for further studies.

The Comparison of Mechanisms of Splitting Protein Antigen by Serum and Cellular Proteases. J. STEFANovIČ, M. FERENČík, Institute of Microbiology and Immunology, Medical Faculty, Comenius University, Bratislava.

It is assumed that prior to its contact with antigen-sensitive cells the intravenously injected antigen must be treated with enzymatic systems present in the circulation, and particularly within the cells. The proteolytic activity of rabbit, guinea pig and rat sera was therefore studied at $\mathrm{pH} 3.6$ (the cath. hepsin type of proteases) and at $\mathrm{pH} 7.5$ (the plasmin and trypsin type of proteases). The final proteolytic activity of sera was dependent on the $\mathrm{pH}$ value of the medium, length of incubation and animal species. At $\mathrm{pH} 3.6$, the proteolytic activity was significantly higher at all time intervals studied as compared with pH 7.5. Following the determination of the proteolytic activity of individual sera, various amounts of antigen (human serum albumin) were added, and using the Ouchterlony immuno. diffusion, radial diffusion and immunoelectrophoresis methods, immunochemical changes were studied at different time intervals. It was found that the antigen degradation was correlated with the time of incubation of antigen with serum. These results were then compared with data obtained in studies dealing with degradation of antigen by purified cathepsin D from cells.

\section{VIROLOGY SECTION}

Pathogenetic Studies with NWS Virus and Its Mutants. Z. JANDA, A. JIRÁNEK, Department of Experimental Virology, Institute of Sera and Vaccines, Prague.

The presence of virus in different organs and interferon and specific antibody production were determined after intracerebral inoculation with NWS virus and attenuated mutants. Special attention was paid to the development and character of pathological changes in the CNS.

Isolation of Conditionally Lethal Mutants of Influenza Virus. E. Tư̌rová, V. Vonka, Department of Experimental Virology, Institute of Sera and Vaccines, Prague.

Cold mutants of the influenza virus $A-2 / S-N$ (a recombinant of A-2/Singapore and A/NWS) were induced with 5-fluorouracil. Preliminary determination of their characteristics was done in hamster embryo fibroblest cultures.

Viral Envelope Proteins and Neurovirulence in Genetic Recombinants of $A_{0} / N W S$ and $A_{2}$ Influenza Viruses. V. MAYER, E. D. KILBOURNE, Institute of Virology, Slovak Academy of Sciences, Bratislava, and Department of Microbiology, Mount Sinai School of Medicine of the City University of New York, New York.

Genetic recombinants of neurotropic $\mathbf{A}_{0} / \mathrm{NWS}$ $\left(\mathbf{A}_{0} \mathrm{e}\right)$ and non-neurotropic strains of $\mathbf{A}_{2}\left(\mathbf{A}_{2} \mathbf{E}\right)$ influenza viruses in which haemagglutinin $\left(A_{0}\right.$ or $\mathbf{A}_{2}$ ) and neuraminidase (e or $\mathrm{E}$ ) viral envelope proteins were segregated $\left(A_{2} \Theta\right.$ and $\left.A_{0} E\right)$ were compared with the parental viruses for neurovirulence in intracerebrally inoculated mice. Neurovirulence was measured in terms of the capacity of the virus (1) to multiply in the brain and (2) to produce lethal disease. By these criteria $\mathbf{A}_{0} / \mathrm{NWS}$ was fully neurovirulent and the other parental viruses non-neurovirulent. The recombinants were of intermediate neurovirulence, but in each of them virulence was expressed differently. It is concluded from these preliminary data that influenza virus neurovirulence is polygenic and that it is not linked exclusively to either the haemagglutinin or neuraminidase of $\mathbf{A}_{0} / \mathrm{NWS}$ virus.

Early Phase of Development of Pathogenesis of Influenza A Inhalation Infection in Mice. V. Fră̌KOVÁ, J. Kolátorová, V. RychtERová, Military Institute of Hygiene, Epidemiology and Microbiology, Prague.

The data in the literature on the course of the pathogenesis of influenza in mice diverge on a number of points. The authors therefore particularly concentrated in their experiments on resolving questions associated with the early phase of the development of influenza in mice after the inhala. tion of infective aerosol under standard conditions, using: (a) different infection doses; (b) differently adapted virus; (c) experimental animals of different 
ages. The development of infectivity in the respiratory organs was studied from two to 120 hours after infection, with special reference to the site of primary multiplication of the virus and the presence of virus in the blood and various important organs. The production of different types of antibody was also studied.

Homologous and Heterologous Antibody Response after Administration of Influenza Virus $V$ Antigens. H. Závadová, Department of Experimental Virology, Institute of Sera and Vaccines, Prague.

Antibodies to viral structural antigens of homologous and heterologous influenza virus were determined after immunization with antigens isolated after ether scission of influenza virus.

Mouse Ascites Fluid as a Source of Antibodies to Arboviruses. V. HRonovsk Ý, R. BENDA, Military Institute of Hygiene, Epidemiology and Microbiology, Prague.

Mouse sarcoma 180 cells were used for the prepa. ration of monovalent immune ascitic fluids against Dengue-3 and Omsk haemorrhagic fever viruses. Suitable immunization methods and the technique for isolating ascitic fluids were tested and the fluids were compared with corresponding sera from the aspect of their protein content and ratio. The quantitative relationships and dynamics of the individual types of antibody activity studied in ascitic fluids by means of the NT, CFR and HIT and by indirect immunofluorescence were compar. able with the antibody levels in the corresponding mouse antisera. Repeated collection of ascites from the same animals after completing immunization was found to be unsatisfactory because of the relatively rapid decrease in the antibody concentration. Hyperimmune mouse ascitic fluids are particularly useful for the rapid demonstration of arboviruses by different immunofluorescence techniques.

Arborvirus Antzbodies in Experimentally Immunized Rabbits: Detection of Japanese Encephalitis Virus Neutralizing Antibodies by the Indirect Fluorescent Antibody Technique, B. Konych, Department of Medical Microbiology and Immunology, Faculty of Medicine, Charles University, Prague.

Rabbits weighing approximately $1.5 \mathrm{~kg}$ were immunized with two doses of either a $20 \%$ suspension of JEV-infected young Syrian hamster brains or infectious tissue culture medium, both in $10 \mathrm{ml}$ volumes and at 14-day intervals. Sera from blood samples obtained by cardiac puncture at $0,7,14$ and 21 days were examined in the plaque reduction (PR) test on continous PK cell cultures grown in Petri dishes (10² PFU JEV/0.I ml, with appropriate serum dilution) and in the neutralization test, evaluated by the indirect immunofiuorescent strining technique (IFT) on PK cell slide cultures, using $10^{4}$ PFU JEV $/ 0.1 \mathrm{ml}$ with equal volumes of doubling serum dilutions. In both instances the mixtures were incubated $60 \mathrm{~min}$ at $22 \mathrm{C}$ before adding to cultures. Cultivation was carried out 24 (IFT) and 72 (PR test) hours. In the case of the IFT, infection was terminated by $10 \mathrm{~min}$ fixation at $4 \mathrm{C}$ in pre-cooled acetone, after threefold wash. ing with distilled water; the PR test was fixed with $10 \%$ isotonic formalin and subsequently stained after Holland. (1) Both tests gave similar results. The IFT was somewhat more sensitive and yielded higher titres $(2,560$ IFT, $640-1,280 \mathrm{PR})$. (2). The administration of infectious brain suspension followed by tissue culture virus gave better antibody production results than any other combination of the two antigen source. (3). Besides saving timo and its high sensitivity, 24 hours' incubation in the IFT supported earlier results and reduced the difficulties occasionally encountered in the PT test to a minimum.

Induction of Antibodies to Early Antigens of Type 1, 2,5 and 6 Adenoviruses. L. KUTINová, D. REZÁCová, Department of Experimental Virology, Institute of Sera and Vaccines, Prague.

A defective SV 40 virtus genome was transcapsidated from an adeno 7 hybrid virus to adeno 1 and adeno 5 viruses. The hybrid adeno $1-S V 40$ and adeno 5-SV40 viruses were oncogenic for newborm hamsters. Cell lines which produced tumours in young adult hamsters were derived from the resultant tumours. The sera of these hamsters reacted in an immunofluorescence test with antigens induced by adeno $1,2,5$ and 6 prototype viruses in monkey kidney cells.

Experimental Coxsackie Group A Type 4 Virus Infection in Rhesus Monkeys. A. SIMková, A. Petrovičová, Research Institute of Epidemiology and Microbiology, Bratislava.

The experiments in question involved a controlled study of infection in young Indian rhesus monkeys following the subeutaneous, intravenous and oral administration of different amounts of Coxsackie A4 virus. The virus strain employed was originally isolated from the blood of a young man during the course, of severe herpangina followed by homotypical seroconversion. The infectivity titre of the viraemic patient's blood was $>10^{2.4}$ (intracerebral suckling mouse $L D_{50} / 0.015 \mathrm{ml}$ blood). Experimental infection of the monkeys was done with the first suckling mouse passege of the isolated virus. The results of quantitative virological tests and of clinical examination of the monkeys are degcribed, together with 
a number of observations on virus transmission. The findings are compared with those published in experimentel studies on the pathogenecity of CoxBackio A4 virus.

Raised Susceptibility of Immunosuppressed Mice to Sindbis Virus. E. GAJDošovÁ, Institute of Viro. logy, Slovak Academy of Sciences, Bratislava.

Mice naturally resistant to subcutaneous inocula. tion with Sindbis virus became susceptible after administration of the alkylating agent Cyclophosphamide, when subcutaneous injection of $10^{4} \mathrm{CPD}_{50}$ of the virus was followed by (I) pronounced viraemia; (2) relatively high infective virus titres in the brein and spleen and specifie death of the inoculated animals. Administration of the same dose of virus to untreated animals did not result in multiplication of the virus in their organs or in death. The formation of specific neutralizing antibodies and of interferon in the two experimental groups was compared.

Electron Microscopy Study of Development of Poxvirus officinale Infection in Alveolar Macrophages in vitro. A. JeufNková, R. Bmend, L. DANEŚ, Military Institute of Hygiene, Epidemiology and Microbiology, Prague.

Cell populations isolated by perfusion from rabbit lungs and suspended in Parker medium + 20\% calf serum were infected with high multiplicity doses of two different strains (dermolapina and neurolapina) of Poxvirus officinale. Non-absorbed virus was removed from the cultures by threefold gpinning and resuspension of the cells in fresh medium. Test samples, fixed in glutaraldehyde and $\mathrm{OsO}_{4}$ and embedded in durcupan, were collected 3 , $7,11,15,24,48$ and 72 hours after the final washing. Semi-thin and thin sections were prepared from the blocks and were examined in the light and electron microscope. All the known developmental particulate forms of the virus were found in infected cells (which were all of the macrophage type) in the 48- and 72-hour samples. Groups of immature bodies were found in the cytoplasm, while mature virions tended to occur more diffusely, in the vicinity of the cytoplasm membrane or extracellularly. The picture of infection with the two strains of the virus displayed no qualitative differences. The morphological findings were compared with the results of a parallel study of the infectivity of the cultures and of fluorescent intracellular antigen. The above method provides a basis for the evaluation of quantitative differences.
Pathogenesis of Inhalation Poxvirus Infection in Rabbits.*) R. BeNDA, V. RYchterová, Military Institute of Hygiene, Epidemiology and Microbiology, Prague.

Rabbits were infected with a rabbit neurovaccine virus aerosol formed by spraying directly in a steel through-flow chamber. The amount of virus administered was about 10 actual $\mathrm{ID}$. The rabbits were killed dynamically and their organs: were removed and treated for titration tests (rabbit. kidney cells), immunofluorescence tests (oryotome sections) and by histological techniques (paraffin sections). The titration results and morphological findings demonstrated the determinant significance of the lungs as the gateway of infection (as opposed to the nose, for example). In addition to the role of the lung macrophages. the bronchiolar passages and the alveoli, the significance of the efferent. lymph vessels and nodes for drainage was demonstrated; these afterwards also participated in the infiltration of the virus into the blood. The role of viraemia, which is very difficult to detect directly, was demonstrated indirectly from the findings in various target organs (particularly in the liver and later in the adrenals, kidneys and other organs). The very meagre findings in the CNS were confined chiefly to the olfactory area of the brain. The mode of neural transport of the virus from the olfactory mucosa was not determined, however. Some unresolved questions related to the spread of the virus in the organism can be supplemented in the discussion by information on results and experiences in experiments in which the virus was administered otherwise than by the inhalation route.

Influence of Infection with Attenuated Venezuelan Equine Encephalomyelitis (VEE) Virus on Antibody Response of Guinea Pigs and Mice to Sheep Red Blood Cells. J. Hzušková, V. Rychterová, V. Krmmant, Military Institute of Hygiene, Epidemiology and Microbiology, Prague.

Changes in the agglutinin and lysin titres were demonstrated in animals immunized with sheep red blood cells and infected with an attenuated strain of VEE virus. Whether the serum titres of these antibodies rose or fell depended on the time relationshipg between infection and immunization.

Utilization of Glucose by Human Diploid Cells as a Marker of Their Infection by a Wild or Attenuated Strain of Tick-borne Encephalitis Virus. M. STÁRER, H. Babrova, Tissue Culture Virology Department, Institute of Sera and Vaccines, Prague.

*. The histological findings are summed up by Dr. Rychterová in a separate paper. 
The authors studied glucose and protein meta. bolism and pyruvic and glutamic-oxalacetic transaminase levels in the cells and modium of human diploid cell cultures infected with the wild or the attenuated strain. Infection of the cells produced characteristic changos in their metabolism (chiefly in glucose consumption). Differences were demonstrated between cells propagating the wild and the attonuated strain as well as between infected and non-infected cultures. This significant difference for the two given strains can be evaluated as one of the markers differentiating wild and attenuated strains of Central European tick-borne encephalitis.

Changes in Glucose Metabolism in Human Diploid Cells after Infection with Certain Viruses. H. BABzová, M. Stárek, Tissue Culture Virology Depart. ment, Institute of Sera and Vaccines, Prague.

The authors studied glucose metabolism in diploid human embryonie lung cells infected with various viruses. Differenes charecteristic for the individual viruses were domonstrated within a short time, irrespective of the presence or absence of a CPE in the culture. Since these changes occur very early on, the course of infection of the culture can be studied by simple biochemical methods and some of the laboratory techniques commonly employed in virology can be greatly simplified. The use of human embryonic diploid cells for these studies was likewise found to be an advantage.

Enzyme Characteristics of Three Cell Systems after

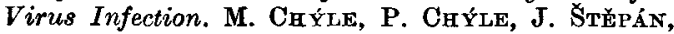
P. Schneiderka, F. Patočka, Department of Medical Microbiology and Immunology, Faculty of Medicine, Charles University, Institute of Experimental Biology and Genetics, Czechoslovak Academy of Sciences; Ist Department of Medical Chemistry, Faculty of Medicine, Charles University, Prague.

Total enzyme activities were determined and, employing a micromodification of quantitative electrophoresis in agar gel, isoenzymes were detected in stable-kine porcine (PK) and canine (Vlč 795) kidney epithelial cells and in a new cell model, Trichomonas vaginalis. The cells were infected with an avirulent clone and a virulent clone of Teschen disoase virus (TDV), with pseudorabies virus (PrV) and with murine leukaemia virus (MLV). The total enzyme activity values measured in cell homogenates before and after infection depended on the homog mnization technique employed. Compared with the control cultures, lactate, malate and isocitrate dehydrog snase (LDH, MDH, ICDH) values in PrV. infected Vlě 795 cells homog mnized by repeated freezing and thawing were markedly elevated; glucose-6-phosphate and glutamate dehydrogenase
(G6PDH, GIDH) values were lowered and gluta. mate oxalacetate transaminase (GOT) and nonspecific esterase (NE) values displayed no signifi. cant differences. In the same homogenates addi. tionelly extracted with sodium deoxycholate (DOC), $\mathrm{LDH}, \mathrm{MDH}, \mathrm{GIDH}, \mathrm{GOT}$ and NE values were lowered and ICDH and G6PDH values were raised. $\mathrm{LDH}, \mathrm{MDH}$, GOT and NE values in DOC-extracted Trichomonas vaginalis cell homogenates were higher than in cells homogenized by freezing and thawing only. In mechanically homogenized PrV-infected trichomonads, LDH, MDH, GIDH, GOT and NE values were much higher than in the control cultures. In DOC-extracted infected trichomonad homogenates, LDH, MDH, GOT and NE values were lower than in the control cultures and GIDH values were markedly higher. The use of various homogenization techniques thus allows partial characterization of the enzymes synthetized in virus-infected cells. After infection with $\operatorname{Pr} Y$ trichomonads grew at a higher rate during 72 hours' incubation. In further passages thus effect on the generation time was not apparent. PrV was completely inactivated within 48 hours during incubation with Trichomonas vaginalis. Total LDH and MDH activity in Trichomonas vaginalis cultures infectod twice with PrV and then simply passaged was higher than in the control cultures. The same activities in Trichomonas vaginalis infected once with MLV and then passaged were significantly lower than in the controls. These findings suggest that relationships in the pathology of human disease caused by this parasite may be far more intricate than was hitherto suspected. A comparison of PK cells infected with the avirulent clone and the virulent clone of TDV and with $\operatorname{PrV}$ showed no differences in the LDH, MDH, DIDH and NE zymograms compared with the controls. After infection with the virulent TDV clone and with $\mathrm{PrV}$ the mobility of the $\mathrm{MDH}_{1}$ fraction altered and its percentual proportion rose compared with the other two fractions. A change likewise occurred in the percentual proportion of the $\mathrm{NE}_{3}$ fraction, especially after infection with PrV. LDH, MDH and G1DH isoenzymes were detected in Trichomonas vaginalis. Acute PrV infection influenced the isoenzyme pattern of LDH only, by shifting the activity maximum from $\mathrm{LDH}_{2}$ to $\mathrm{LDH}_{4}$.

Observations on the Effectiveness of Alfalfa Mosaic Virus Transfer by Wasps in Relation to the Virus Level in the Source. J. MatisovA, Institute of Virology, Slovak Acadomy of Scienees, Bratislava.

The effeetiveness of alfalfa mosaic virus (AMV) transfer by the wasps Acyrthosiphon pisum and Myzus persicae was studied in relation to changes in the infective AMV level during infection of plants. Acquisitive sucking by the wasps on infected plants lasted 15,30 and 60 minutes and test sucking 24 hours. The testing plants were Faba vulgaris 
and Phaseolus vulgaris. The maximum AMV level in experimentally infected Nicotiana rustica plants was reached on the 9 th to 12 th day after inoculation; after that it steadily fell, but on the 31st day the final dilution point (FDP) of the virus was still $10^{-2}$. The effectiveness of transfer in experiments with Acyrthosiphon pisum was very low and displayed no discernible correlation to the $\mathrm{AMV}$ level in the source. In experiments with Myzus persicae, the maximum percentual transfer occurred from the source with the maximum virus concentration, but even in this case an increase in the virus concentration in the source was not accompanied by a marked increase in the effectiveness of transfer. The virus level in experimentally and naturally infected Medicago sativa plants ranged from $10^{-2}$ to $10^{-4}$. The results of experimental AMV transfer by Acyrthosiphon pisum and Myzus persicae showed signs of some correlation between the effectiveness of transfer and the virus level in the source, a ten. fold increase in the virus concentration (according to the FDP) being acoompanied by a roughly twofold increase in the effectiveness of transfer by both species of wasps.

Interferon Induction by Some Herpetic Viruses in Cell Cultures Infected under Various Conditions. H. LrBírová, Institute of Virology, Slovak Academy of Sciences, Bratislava.

Higher and earlier interferon formation (and diminished virus production) in old (6. to 7-day) cultures, as distinct from cultures infected after only one day in vitro cultivation, was demonstrated in previous studies using RIF-free chick embryo cells (RFCAC), tick-borne encephalitis and some other viruses. The present study describes similar experiments done with two herpetic (pseudorabies and herpex simplex) viruses in young and old RFCEC cultures. Both viruses were very poor (or negative) interferon inducers in 1-day-old cultures, but proved to be good or even excellent inducers when inoculated into old cultures under the same conditions. Surprisingly, low infection multiplicity $\left(10^{-4}\right.$ to $10^{-2}$ ID 50 per cell) was advantageous for abundant interferon formation in old cultures, while high infection multiplicity often failed to induce interferon formation. The resultant data are discussed in correlation to virus production and to the degree and rapidity of the cytopathic effect under the given experimental conditions.

Replication of Herpes Simplex Virus in Myxovirusinfected Cells. J. SzÁntó, J. LEššo, Institute of Virology, Slovak Academy of Sciences, Bratislava.

The synthesis of both infectious herpes simplex virus (HSV) and its antigen deteetable by immunofluorescence was depressed in ZP-1/58 cells (a cell line derived from rabbit lung) infected with New. castle disease virus (NDV) or influenza virus. In the case of $\mathrm{NDV}$, the decrease in HSV replication depended on the multiplicity of infection. Influenza virus inhibited HSV replication to a lesser extent and undiluted infuenza virus stocks had to be used for infection. In dually infected cultures, single cells contained only one virus antigen detectable by immunofluorescence. Interferon was determined in NDV-infected cultures. When tests for the presence of interferon were based on inhibition of the cytopathic effect of Sindbis virus, the results, with one exception, were negative, but when they were based on inhibition of Sindbis virus production, interferon was detected in most NDV-infected culture samples. Reduced HSV replication in myxovirus-infected cultures could be mediated by one of the following mechanisms: (1) altered metabolism of cells infected with myxoviruses; (2) intrinsic interference and (3) interferon.

On the Properties of a Cloned Herpes Simplex Virus (HSV) in Different Tissue Culture Systems and in Mice. J. LEšš, Institute of Virology, Slovak Academy of Sciences, Bratislava.

The properties of a HSV clone (multiplication at $36 \mathrm{C}, 32 \mathrm{C}$ and $41 \mathrm{C}$, cytopathic effeet, fluorescent antigen) were investigated in HeLa, $\mathrm{L}$, chick embryo and rabbit lung cells and in mice. The HSV clone was obtained by plaque purification in chick embryo cells. The original strain was isolated from a patient with herpes labialis. The clone differed from the original virus in respect of the character of its cytopathic effect in HeLa and I. cells. Fluorescent antigen was clearly detectable in the cell nuclei. Rabbit lung cells were found to be the optimal cell substrate for multiplication of this virus clone. At $41 \mathrm{C}$ the virus did not multiply in any of the types of cells tested except chick embryo cells, where a certain degree of propagation was found. The cloned virus was less virulent for mice after intracerebral inoculation only.

Epidemiology of Cytomegalovirus among Mentally Retarded Patients in a State Institution. S. K. SINHA, M. C. Gordon, E. Kaveggra, Central Wisconsin Colony and Training School, Madison, Wisconsin, U.S.A.

The recovery of cytomegalovirus (CMV) from infants and children and its association in patients with evidence of cerebral defects, usually in the form of reduced head circumference and psychomotor retardation, was first reported by Weller and Hanshaw (1962). Since then, Medearis (1964), Carlstrom (1965), Stern and Elek (1965) and other investigators from various countries at the International Conference on eytomegalovirus held at St. Gall, Switzerland, in 1970, have further emphasized 
its importance in human populations. This report concerns the epidemiology of CMV infection in severely mentally retarded patients resident in a state institution. Serological studies were done with the complement-fixation test (microtechnique) and CF titres of $1: 8$ and over were considered positive for CMV infection. In this study, serum specimens were collected from the patients and their mothers. The CF antibody responses were positive in $5 \%$ of resident children and $48 \%$ of their mothers and in $9 \%$ of out-patient children and $41 \%$ of their mothers. In another study, $7 \%$ of severely retarded children aged 7 years and under were found to be CMV positive. The clinical diagnosis revealed that $50 \%$ of these seropositive children were also microcephalic. Attempts were made to isolate the virus in 16 microcephalic children under the age of five. Urine specimens were collected by sterile catheter, adjusted to the desired $\mathrm{pH}$ and inoculated into WI-38 cell cultures for virus isolation. CMV was recovered from two of the 16 microcephalic patients. In order to observe seroconversion in resident patients, blood specimens were collected from each subject. They were first collected in 1965 (after admission) and again in 1970. Study of these paired sera from 89 patients indicated that CMV infection had a low seroconversion rate.

Properties of Rabbit Interferons Induced by $I: C$ Copolymer and NDV. I. TÁBORSKÝ, H. KoHLAGE, R. SImGERT, Department of Epidemiology, Faculty of Medicine, Purkyn̊̌ University, Brno; Institute of Hygiene, Marburg University, Marburg a.d. Lahn, G.F.R..

Four hours after the intravenous administration of $I$ : $C$ copolymer to rabbits it was found that, as after NDV induction, a high molecular weight (HM) and a low molecular weight (LM) component could be identified in their serum. The molecular weights of the HM and LM component (determined by chromatography on a Sephadex G-100 column) were in a close relation, irrespective of whether I : C copolymer or NDV was used for induction (the m.w. of the HM component was over 100,000 and of the LM component 40,000-50,000). HM serum interferon is distinctly more thermolabile than LM interferon. The HM component produced by $\mathbf{I}$ : $\mathbf{C}$ copolymer is considerably more thermost. able than the corresponding virus-induced component. When investigating the type of blood cells by which the two different serum components are produced, I : C copolymer was incubated in vitro with morphologically highly homogenous blood granulocyte, lymphocyte, peritoneal granulocyte, monocyte and macrophage suspensions. In every case only HM interferon was released. After incubating NDV with blood granulocytes, only HM interferon was again demonstrated, while in blood lymphocyte suspension, under the same conditions, a small amount of LM interferon, in addition to the HM component, was identified.
Effect of Cyclophosphamide on Endotoxin-induced Protection of Mice Challenged with Virus. V. RA. THOVÁ, D. KoČı̌̌Ková, L. BoRECKÝ, Institute of Virology, Slovak Academy of Sciences, Bratislava.

The protective effect of Escherichia coli endotoxin and/or endotoxin-induced interferon was studied in mice infected with EMC virus. The toxic effect of endotoxin was reduced by pre-immunizing the mice. This did not diminish the interferon-stimulating and protective effect of the endotoxin in EMC. challenged mice if the animals were challenged after the hyporeactivity period. Cyclophosphamide enhanced mortality in andotoxin-treated mice challenged with virus, reduced the antiviral and antiendotoxic antibody titres, raised the virus titre in the brain and prolonged survival of the virus in the brain.

Cytotoxicity of Interferon Preparations. L. BoRECK Ý, N. Fuchsberger, J. Žmla, G. Russ, O. Oravec, Institute of Virology, Slovak Academy of Sciences, Bratislava.

In agreement with earlier observations, interferon preparations of mouse cell origin were found to contain eytotoxic components. One of these was regularly associated with the molecular type which displayed interferon activity after Sephadex G-100 column chromatography. Attempts were made to separate cytotoxic and interferon activity by agar gel electrophoresis. The cytotoxicity of the interferon preparation was estimated from the inhibition of ${ }^{14} \mathrm{C}$-amino acid incorporation into $\mathrm{L}$ cells, from ${ }^{51} \mathrm{Cr}$ release from labelled mouse lymphoma cells and by measuring the NA content of L cells treated with interferon preparation fractions. Interferon activity was measured by a CPE inhibition test in $L$ cells challenged with EMC virus.

Further Studies on Interferon Release from Sensitized Mouse Leucocytes after Interaction with Target Cells. N. Fuchsberger, L. BoreckÝ, V. LAckovic, V. Hajnická, Institute of Virology, Slovak Academy of Sciences, Bratislava.

The addition of sensitized mouse leucocytes to L cell monolayers led to protection of the $\mathrm{L}$ cells against EMC virus challenge. The permanent presence of leucocytes was not required for antiviral protection. As reported, an interferon-like virus inhibitor (ILVI) was released from the sensitized leucocytes during their contact with the target cells. The dynamics of ILVI release are similar to those of virus-induced interferon pro. duction. Physicochemically, ILVI resembles other interferons of mouse leucoeyte origin. Sixty minutes' contact of ILVI with L cells proved-sufficient to induce resistance of the $\mathbf{L}$ cells to virus challenge. Maximum resistance was attained about six hours. 
after treatment of the L cells with ILVI. The development of resistance was inhibited by inhibitors of RNA and protein synthesis.

Distribution of Barth's Vaccine Strain of Aujeszky's Disease Virus in Pig Foetuses after Intraperitoneal Administration. A. Sokot, T. Gallo, Department of Microbiology and Zoohygiene, Veterinary College, Košice.

The virulence of Barth's attenuated vaccine strain $\mathrm{K} / 61-120^{\prime} 50 \mathrm{C}$ of Aujeszky's disease virus, its distribution in the organs and its transport from one foetus to another was tested in 88-day pig foetuses developing in utero. (A) All foetuses infected i.p. with a dose of $4 \times 10^{4}$ TCID $_{50}$ died and mummified within 14 days after infection. The adjacent foetuses also died. When the foetuses were removed 14 days after infection, two control foetuses infected by the contacttransplacental route survived. Apart from oedema of the placenta, lungs, intestine and spinal cord, no serious pathological anatomical lesions were found. The last foetus in the contralatiral control cornu was uninfected. No immunoglobulins were detected by immunoelectrophoresis in the serum of the contactinfected controls or of the uninfected control foetus. Low neutralizing antibody titres were demonstrated in the serum of the two contact-infected foetuses. On the 14th day after infection moderate virus titres were found in the foetal membranes, lungs, inteatine and all perts of the CNS, except the olfactory bulb, of the three control foetuses which died, as well as in the two contact-infected controls. When the foetuses were removed, neutralizing antibodies were already present in the serum of the clinically healthy foetus. (B) Another sow whose foetuses were also infected i.p. with a dose of $4 \times 10^{2}$ TCID $_{50}$, with a planned observation time of 21 days, did not last the full term of tho experiment and miscarried. (C) Comparison of the virulenee of the two Czechoslovak vaceine strains BUK 624 and TK 900 and Barth's Hungarian vaccine strain $K / 61-120^{\prime} 50 \mathrm{C}$ in pig foetuses showed Barth's strain to be the least attenuated of the three.

Persistence of Virulent Pseudorabies Virus in Herds of Vaccinated and Non-vaccinated Pigs. S. SABó, Z. Grunert, Institute of Virology, Slovak Academy of Sciences, Bratislava; State Veterinary Institute, Bratislava.

Two herds of pigs, one untreated and the other avceinated with an attenuated pseudorabies virus (PRV) strain, were observed 10-11 months for the occurrence of Aujeszky's disease (AuD) and PRV. Two outbreaks of AuD were observed among the unvaccinated pigs. During the first, PRV was recovered from 26 sows $(92.8 \%)$ and 42 sucklings $(75 \%)$, whereas humoral neutralizing antibodies (NA) were formed in six mothers only $(21.4 \%)$. Noither PRV nor NA were detected in weanlings at this interval. The number of seropositive animals later increased, but never reached $100 \%$. PRV was isolated at every interval tested, except in August and September, when no virus was recovered. The proportion of positive isolations ranged from $9.7 \%$ to $40.5 \%$ and of seropositive cases from $4.1 \%$ to $94.2 \%$. In the second herd, despite vac. cination in the first and ninth month, PRV was recoverable throughout the whole observation period (11 months); the proportion of positive isolations varied from $1.9 \%$ to $23.8 \%$, while $62.2 \%$ to $94.1 \%$ of the animals were seropositive. It was thus confirmed that PRV circulates en demically in herds, despite the presence of NA in the animals' sera.

Morphological Study of the Virus of a Cytomegalic Inclusion Diseare of Pigs. L. VAxf́cke, B. SMto, V. Pleva, Research Institute of Veterinary Medi. cine, Brno; Czechoslovak Collection of Microorganiams, Purkyné University, Brno.

An incidence of a cytomegalic inclusion disease of pigs was demonstrated in animals aged 10 to 31 days. Histologically, it was characterized by the presence of basophilic intranuclear inclusions in the cells of the tubuloalveolar glands of the nasal mucose and in the epithelial cells of the renal tubules. An electron microscopy study of the nasal mucosa showed the presence of virus particles resembling other cytomegaloviruses in their struc. ture and intracellular morphogenesis. The cell nucleus contained medulla-free capsids, nucleocapsids with medulla of varying shape and density and virus particles with an envelope. The virus particles usually acquired an envelope during passaga across the inner lamella of the nuclear merabrane and less frequently inside the nuclear matrix during reduplication of thé nuclear membrane, or in the cytoplasm, by impaction into the cytoplasm vacuoles. Acquisition of an envelope from the cell wall was not demonstrated. Two forms of virus particles were found in the cytoplasm. Particles with an envelope, measuring $120-150 \mathrm{~nm}$, occurred in the vacuoles, while nucleocapsids measuring 90-110 nm lay freely in the cytoplasm, often in surprisingly larg $\curvearrowright$ numbers and organized in crystal formation.

Demonstration of Certain Pig Enteroviruses in the Organs of Experimentally Infected Piglets by the Immunofluorescence Method. Z. Posptsin, H. WA. tanabe, J. Menštk, J. Sttěpánek, M. Goř̌, Research Institute of Veterinary Medicine, Brno. 
After pre-testing in tissue cultures, the indirect immunofluoreseence method was used to study the pathogenesis of experimental enterovirus infections in pigs. The virzs of infectious swine paralysis (strain KNM) and an enterovirus isolated from the respiratory tract of pigs (strain $\mathrm{Kr69TK}$ ) were employed. The main finding in conventionally bred piglets infected intracerebrally (IC), intra. nasally (IN) and by contact (C) with infectious swine paralysis was fluorescence in the Purkinje cells of the cerebellum and in the neurones of the brain and spinal cord. The maximum number of positive cells was observed on the 7th day after IC infection; on the 9 th and loth day the intensity of fluorescence and the number of positive cells abruptly diminished. After IN and $\mathrm{C}$ infection, fluorescence appeared $1-4$ days later and its intensity was Iower. Specific fluorescence of the endothelium of the CNS capillaries was also observed. In colostrum-deprived piglets infected by the IN route with enterovirus Kr69TK, specific fluorescence was found only in the lungs, where it was observed in the epithelial cells of the bronchi and occasionally of the alveoli also.

A Viral Gastroenteritis of Pigs: Isolation and Identification of the Virus. J. STẗ́ANEK, E. ME. SÁroš, Z. PospíšIL, Research Institute of Veterinary Medicine, Brno.

During a field outbreak of a viral gastroenteritis of pigs first described in Czechoslovakia in 1966, we isolated five virus strains in primary pig kidney tissue cultures. Their identity with the agent of viral gastroenteritis was demonstrated by a biological test in piglets, in which peroral infection was followed by development of the typical viral gastroenteritis syndrome. When the clinical signs reached the maximum, the experimentally infected pigs were killed and the presence of virus in their organism was demonstrated by reisolation in tissue cultures and by the immunofluorescence method. The virus strains isolated were sensitive to ether, chloroform and sodium deoxycholate and resistant to trypsin and survived the action of a wide $\mathrm{pH}$ range. Their growth activity in primary pig kidney and salivary gland tissue cultures was studied by titration and immunofluorescence.

Localization, Multiplication and Persistence of Infectious Bovine Rhinotracheitis Virus on Mucous Membranes of Experimentally Infected Calves. V. Rozkošný, J. Menštik, Z. PospfštL, Research Institute of Veterinary Medicine, Brno.

Six 14-day-old calves were infected intravenously, intranasally, intratracheally, intravaginally, in the conjunctival sac and on the preputial mucosa with the R-6 strain of infectious bovine rhinotracheitis (IBR), isolated in Czechoslovakia.
In every case the virus multiplied at the site of inoculation and, seconderily, on the other visible mucous membranes. In some cases, pathomorphological lesions were found at sites of secondary multiplication. The virus growth curves at the sites of primary and secondary multiplication were determined by titrating free virus in mucosal smears and at the same time the detection of virus antigen in the epithelial cells was attempted by the direct immunofluorescence method. The results confirmed that IBR virus (herpes virus bovis 1), like other members of the herpes group (herpes simplex in man or pseudorabies virus in pigs), produces diverse clinical syndromes and that the diagnosis of infectious bovine rhino. tracheitis, under the complicated epizootological conditions of cattle-breeding existing in Czechoslovakia, will often be diffieult.

Incidence of Antibodies to Infectious Bov ine Rhino tracheitis (IBR), Parainfuenza $\left(P I_{3}\right)$ and VDV among Young Cattle in Large-scale Breeding Stations in South-west Slovakia. A. Zuffa, J. SalaJ, Bioveta Research Centre, Nitra.

Blood samples were taken from calves aged from two we 3 ks to six months in 14 large kreeding stations in South-west Slovakia where mass respiratory infections had occurred in the past. Among the 440 serum samples tested, significant antibody titres to IBR virus were demonstrated in 13 $(2.95 \%)$, to $\mathrm{PI}_{3}$ virus in $334(75.8 \%)$ and to VDV virus in $309(70.2 \%)$. The serological results showed that there was a high incidence of $\mathrm{PI}_{3}$ and $\mathrm{VDV}$ viruses in cattle breeding stations in the area in question and provided evidence of the participation of these viruses in the incidence of mass diseases of the respiratory organs.

Australia Antigen in Tissue Culture. E. D. SHAw, Virology Division, Ortho Research Foundation, Raritan, New Jersey, U.S.A.

Investigations of the etiologic agent for the disease of viral hepatitis have indicated that theprototype Australia (Au) antigen, or the HepatitisAssociated-Antigen (HAA), has become increasingly associated with the type B, or serum hepatitis. Its relationship to type $A$, or infectious hepatitis, has not been clearly established. A summary of studies made with possible propagation of the HAA in tissue culture without overt cytopatchi effect (CPF) were presented, but the major portion of this paper described results from methods made to hybridize the HAA with (a) the trivalent polio. viruses in Sabin's vaccine and with (b) a type 11 echovirus, which yielded an overt CPE. Plaque. reduction techniques with the hybrid of trivalent poliovirus - Au antigen-HAA (Tri + P - AU-HAA) have demonstrated an immune reaction in con- 
valessent sera from patients with type A hepatitis, and specific AU antibody has inhibited the CPE of the hybrid of type 11 echovirus - AU.HAA (E.11 - AU.HAA).

Induction of Complementary Strand by RNA Isolated from Newcastle Disease Virus (NDV). M. Rosenbergová, Institute of Virology, Slovak Academy of Sciences, Bratislava.

RNA isolated from NDV is not infectious, but we were able to demonstrate its activity in cell cultures, virus specific RNA synthesis being detected in cells treated with actinomycin $\mathrm{D}$ and inoculated with viral RNA. Hybridization with viral RNA in vitro showed that the new RNA displayed approximately $50 \%$ annealing. This shows that part of this RNA is complementary to the RNA contained in virions. The incorporation of ${ }^{3} \mathrm{H}$-uridine into the RNA of cells inoculated with viral RNA was 20 times lower than in cells infected with whole virus. This RNA was separated by velocity gradient centrifugation into two fractions (18 S and $5 \mathrm{~S})$. In contrast to cells infected with whole virus, no radioactivity was incorporated into the higher molecular weight RNA. These experiments indicate that RNA isolated from NDV is, in cells, at least partly transcribed to a complementary strand of sufficient size to code for a few protein chains. It is not yet known whether this complementary strand possesses messenger ectivity.

Endonuclease Activity in Myxo-and Paramyxovirus Preparations. S. Pristašová, M. Rosenbergová, Institute of Virology, Slovak Academy of Sciences, Bratislava.

Enzymatic (endonuclease) activity was demonstrated in concentrated myxo- and para. myxovirus preparations. These preparations contained an enzyme which at temperatures below $40 \mathrm{C}$ hydrolysed only 5-10\% of the ribosomal RNA to fractions with a sedimentation constant of $4-5 \mathrm{~S}$. When the temperature was raised, the percentage of oligonucleotides in the acid-soluble fraction also rose. Under optimum reaction con. ditions, myxovirus preparations hydrolysed RNA, poly $A$, poly $I$, poly $C$ and poly $U$ and paramyxovirus preparations only RNA, poly $C$ and poly $U$. The thermostability of the enzyme and the correlation of the enzymatic reaction to the substrate concentration and the virus preparation concentration were studied. DN-ase activity was demonstrated in concentrated myxovirus preparations, but not in paramyxovirus preparations. The results showed that two enzymatic activities were present in the given preparations and that the enzymes were probably of cellular origin.
6-Azauridine Virus-inhibitory Activity Dependen on Cell-free Extracts Containing Uridine Kinase. B. Rada, T. HanušovskA, Institute of Virology, Slovak Academy of Sciences, Bratislava.

Newcastle disease virus (NDV), which is primarily resistant to inhibition by 6 -azauridine (AzUR) can be inhibited by this antimetabolite in combination with the action of cell-free extracts with a high uridine kinase level. This inhibitory effect was tested with two other viruses also primarily resistant to AzUR. Pseudorabies virus was less sensitive to the combined action of AzUR and cell-free extract and the multiplication of western equine encephalomyelitis (WEE) virus was not inhibited. At $80 \mathrm{C}$ the cell-free extract lost its AzUR-dependent inhibitory activity. This phenomenon could not be extended to other virus inhibitors. Twenty antimetabolites and virus inhibitors were tested with vaccinia, NDV and WEE viruses in the presence of cell-free extracts of Ehrlich ascitic carcinoma cells and of Rous sarcoma.

A Change in the Physicochemical Properties of $T M V$ Protein Caused by Substitution of One Amino Acid in the Structural Subunit. B. BEzúch, G. RuTTKAYNEDeckx́, Institute of Virology, Slovak Academy of Sciences, Bratislava.

Differences were found in the kinetics of depolymerization of the virus protein of the vulgare strain of tobacco mosaic virus (TMV) and its artificial Ni-2068 mutant, which differs from the vulgare strain by the substitution of cysteine for tyrosine 139 in the polypeptide chain of the virus protein. The kinetics of depolymerization of the virus protein were studied at $\mathrm{pH} 10.5$ by moving boundary electrophoresis (Tiselius) and when a steady state was attained the fractions were isolated by preparative electrophoresis in an agarose suspension and were analysed by spectro. photometry and electron microscopy.

Preparation of Influenza Virus Subunits by New Methods. G. Russ, G. RutTkay-NedeckY, V. Mucha, Institute of Virology, Slovak Academy of Sciences, Bratislava.

Influenza virus fractionated with ether can be broken down to a haemagglutinin-neuraminidase complex (HNC) and ribonucleoprotein. Ether scission of influenza virus is regarded as relatively ineffective and tedious and does not allow the separation of haemagclutinin and neuraminidase. The fractionation of influenza virus by Triton-X-100, Nonidet $\mathrm{P} 40$, sodium dodecyl sarcosinate and sodium dodecyl sulphate was therefore investigated. The split products were separated by electrophoresis in agarose suspension and were characterized by haemagglutination, determination of neura- 
minidase activity, the UV spectrum, electro. phoresis of the polypeptide chains in polyacrylamide gel and electron microscopy. The different methods of fractionating influenza virus were compared on the basis of their effectiveness (the amount of residual virus) and of the virus subunit yield. Attempts were made in preliminary experiments to separate haemagglutinin and neuraminidase from the HNC obtained by splitting influenza virus with Triton- $\mathrm{X}-100$ and sodium dodecyl sarcosinate.

Characteristics of the Induction of Thymidine Kincse by Polyoma Virus. J. ZEMLA, Institute of Virology, Slovak Academy of Sciences, Bratislava.

The author studied the influence of various experimental conditions and of certain, nucleic acid base derivatives and their analogues on the rate and kinetics of thymidine kinase induction in mouse embryo cell primocultures by polyoma virus. In non-infected cells the enzyme activity diminished with aging of the culture, the decrease being more rapid in low-serum modia. The level of relative induction of the enzyme activity was lower in old cultures and was markedly raised by thymidine. 5-fluorouracil partly inhibited induction of the enzyme, while 5-bromo-2'deoxyuridine stimulated it and caused a shift in its kinetics under certain conditions.

Genomic Masking and Phenotypic Mixing between Different Groups of RNA Viruses. J. ZAVADA, L. Hána, M. Rosenbergova, Institute of Virology, Slovak Academy of Sciences, Bratislava.

The progeny resulting from dual infection of cells with fowl plague virus (FPV) and vesicular otomatitis virus (VSV) was analysed. Selective plating of VSV plaques was achieved at $31.5 \mathrm{C}$ and of FPV plaques at $40.5 \mathrm{C}$. Complete polarity of the interaction was demonstrated, all FPV genomes from the progeny of dual infection being neutralized by anti-FPV serum and not by anti-VSV serum. VSV genomes were distributed in three classes of envelopes: (a) a pure VSV coat neutralized by antiVSV serum only; (b) phenotypically mixed particles displaying dual neutralization by both anti-VSV and anti-PFV serum; (c) a VSV(FPV) pseudotype resistant to anti-VSV, but neutralized by anti-FPV serum. Classes (a) and (b) each accounted for approximately $50 \%$ of the VSV genomes and class (c) for $1-5 \%$ tof the set containing VSV information. Phenotypic mixing, but no genomic masking, was also demonstrated in FPV produced by cells pre-infected with avian myeloblastosis virus. Experiments employing other virus com. binations and experiments attempting physical separation of the above pseudotypes are now in progregs.
Host-cell Repair of Animal Viruses. Z. ZAvadová, Institute of Virology, Slovak Academy of Sciences“ Bratislava.

Host-cell repair was demonstrated in animal viruses containing DNA (pseudorabies and vac. cinia) and in the replicative form of encephalomyocarditis (EMC) virus after irradiation with ultraviolet light. The pseudorabies virus $U V$ in. activation curve had two components, resistance of the second being manifestly soveral times greater than that of the first. The proportion of the "re. sistant" component fell considerably when ir. radiated virus was plated in the presence of caffeine, a known inhibitor of the repair system. Conversely, deplayed virus replication in the presence of puromycin significantly increased repair. Pseudorabies virus with incorporated 5-bromodeoxyuridine had a single-component inactivation curve with the same inactivation constant as the "sensitive" component of the control virus curve, thus showing that thymine photoproducts are involved in repair. The UV-irrediated replicative form of EMC virus RNA also showed lower-survival in the presence of caffeine, which did not affect irradiated virus or single-stranded virus RNA, however. The effect of caffeine on the virus yield from cells irradiated during the eclipse phase was even more pronounced. In some experiments the cell line XP-4, derived from $a^{-}$patient with Xeroderms pigmentosum (a hereditary defect of the repair system), was employed. Survival of vaccinia virus plated in XP.4 cells was significantly lower than in normal human fibroblasts. Experiments verifying the repair of replicative virus RNA are now being conducted with this cell line.

Morphological and Ultrastructural Characteristies of Some Phages of Mycobacteria. H. MoHeLská, H. KölBEL, Institute of Hygiene and Epidemiology, Prague, and Borstel Research Institute, Institute for Experimental Biology and Medicine, Borstel, GFR.

Electron microseopy was used to examine phages used in the study of the World Health Organization to differentiate between mycobacteria. The AGl and GS4E types were isolated by Redmond, D29 by Froman and BKl by Baess. The findings were compared with data on the better known phage groups. All the four types possess a head visible as a hexagon, and a noncontractile flagellum attached through a wider neck and terminated by a special structure. They belong to the morphological group B (Bradley) the D29 phage containing the previously demonstrated double-stranded DNA (Tokunaga). They differ little in size but the differences are characteristic and, as found by Bradley for staphylococeal phages, they may signal different immunological properties. The head is probably a bipyramidal pentagonal antiprism which is frequent in the phages (Moody, Boy de la Tour). 
Combined staining revealed a concentric circle structure, probably the DNA molecule (Bradley). The head probably also contains an auxiliary structure (Margaretten, Kellenberger). The flagellum protrudes from the apex of the pentagonal pyramid of the head through the neck and has no differentiated cortex and medulla. It may show a central channel. This is terminated also by a pentagonal pyramidal structure from the base of which a ter. minal filament described in the lambda phage (Eiserling) shoots out. The filament may be composed of several fibres cemented together, being seen individually only rarely and observed with other phages of the $\mathbf{B}$ group (Bradley). The particles maintain a five-fold symmetry.

Isolation of a Bacteriophage Propagating in Bdellovibrio bacteriovorus. J. SCHINDLER, J. LUDVfK, Department of Medical Microbiology and Immunology, Faculty of Medicine, Charles University, Prague, and Institute of Microbiology, Czechoslovak Academy of Sciences, Prague.

The phage was isolated from Prague sewage water. Its heretofore only host is the saprophytic mutant of the parasitic predatory Bdellovibrio bacteriovorus. It does not inactivate the plaqueforming ability of parasitic bdellovibrio. The phage, $\mathrm{Mp} \cdot 6$, has a hexagonal head about $40 \mathrm{~nm}$ in diameter and a tail $20 \times 14 \mathrm{~nm}$ with a coiled structure. Staining with acridine orange suggests that the phage contains double-stranded DNA.

Prophage Mutants Unable to Kill the Host upan Induction. Z. NEUBAder, Faculty of Natural Sciences, Charles University, Prague.

Exposure of Escherichia coli $\mathrm{Kl2}\left(\lambda\right.$ int $_{6} \mathrm{CI}_{857}$ ) lysogen carrying a heat-inducible prophage unable to excise from the host chromosome, to $42 \mathrm{C}$, results in extensive cell killing. Only about $10^{-8}$ cells form colonies at $42 \mathrm{C}$. Three types of survivors were found: (a) bacteria lysogenic for a defective prophage; (b) bacteria in which the prophage is entirely or partially deleted, (c) mutants called vir $\mathbf{r}$ in which no defect in prophage could be detected but which are refractory to $\lambda$, even $\lambda$-virulent. Analysis of the defective lysogens (a) revealed that the defect in the prophage is always due to two $\mathbf{m u}$ tations: one to the left of the CI region preventing the expression of the early genes at left (mutation of the positive regulatory gene $\mathrm{N}$ or a polar sex mutation); the other to the right of the CI region preventing $\lambda$-specific DNA synthesis (mutation in $O$ or $P$ or, a polar mutation in $x$ ). A wide range of prophage deletions was found in the second group of heat survivors (b). By this selection it was possible to obtain "cryptic" lysogens retaining e.g. one, two, three, etc. $\lambda$-specific genes. However, the CI region, with two early promotors on either side is always missing. The heat survivors represented by the third group (c), the vir mutants, are extremely low yielders of viable phage. In most cases, their inability to sustain $\lambda$ growth extends also to the heteroimmune phage $\lambda$ i434. In other cases, however, the refractivity is strictly immunityspecific. The early prophage functions are still heat-inducible in such strains. The vir character is related to the presence of the prophage.

Inactivation of Bacteriophages with cis-Platinum (II) diammo Dichloride. J. DroBnfk, A. KREKUlová, A. Kubelková, Division of Biophysics, Faculty of Natural Sciences, Charles University, Prague.

Inactivation of bacteriophages $\mathrm{T}_{2}, \mathrm{~T}_{4}, \mathrm{~T}_{4 \mathrm{~B} 01}, \mathrm{~T}_{3}$ and $\Phi \times 174$ by cis-platinum(II)diammino dichloride is not a simple exponential process. The survival curves show a shoulder at the beginning, followed by an exponential decrease with both the neutral complex and its hydrolysis product(s). The size of the shoulder is greater and the inactivation rate is smaller with $T_{2}$ and $T_{4}$ phages which are known as osmotic sensitive. This difference is less pronounced with the hydrolyzed complex which caused a greater inactivation effect. The inactivation by the complex is completely removed by AET. Some residual inactivation occurs after removal of the active platinum complex either by AET or by dilution; however, it is the same with $\mathrm{T}_{3}$ and with $\Phi \times 174$. Inactivation is not modified by the $\mathrm{Hcr}$ marker of the host bacterium. From the temperature dependence of inactivation constants, an energy of $17,100 \mathrm{cal} / \mathrm{mole}$ was calculated. It was concluded that permeability of the phage head plays a very important role in the inactivation process, and that the pattern of inactivation is different from that observed with alkylating agents and that it is not very much affected by the double-stranded or single-stranded (circular) form of the phage DNA.

Genetic "Amber" Map of the L Phage of Salmonella typhimurium. L. Sošková, J. SoškA, Department of General Biology, Faculty of Medicine, Brno, and Biophysical Institute, Czechoslovak Academy of Sciences, Brno.

The L phage of Salmonella typhimurium was subjected to mutagenesis by hydroxylamine and the suppressor-sensitive amber mutants formed were isolated and classified into complementation groups. Using two- and three-factor crosses the gene sequence was determined. The map is circular and genes for the early functions were found noar the "c" region. Representatives of the individual complementation groups were further complemented with conditionally lethal mutants of the related 
P22 phage. The results indicate that individual genes as well as a greater part of the chromosome are functionally homologous in both phages, with the exception of some genes in the control region.

Appearance of Deletions and of Nonhomologous Regions of the Lambda Phage in the Electron Micro. scope. Z. HradeČná, Biophysical Institute, Czechoslovak Academy of Sciences, Brno.

To map the deletions and substitutions of the lambda phage we used hybridization of comple. mentary DNA:DNA strands. The technique is based on a separation of complementary strands of phage DNA. Measurement of single-stranded and double-stranded regions of heteroduplex phage DNA in the electron microscope makes it possible to prepare an accurate map of the viral genome. The extent of deletions in different lambda $d g$ and lambda bio phages was examined. In the lambda $d g$ phages the genes of the host cell partly replace the left arm of the phag g gnome, in the lambda bio phages the right arm of the genome. The length of bacterial DNA incorporated into the phage genome of lambda bio phages was also examined.

Photodynamic Inactivation of $T 3$ Bacteriophage by $N$-substituted Derivatives of Acridine Orange. $\mathrm{E}$. Janovská, Z. Balcarová, Biophysical Institute, Czechoslovak Academy of Sciences, Brno.

In the presence of organic tricyclic dyes, visible light brings about photochemical changes and damage of different extent in biological objects. The basis of the photodynamic damage in vivo remains unclear. One of the approaches to studying the changes occurring after treatment with photodynamically active dyes is the examination of the extent of damage brought about by chemically related dyes or derivatives of the individual dyes, which should reveal the part of the molecule and the configuration which is most important for the biological effect. We investigated the photodynamic inactivation of the T3 phage by derivatives of acridine orange containing methyl, ethyl, propyl and benzyl at the ring nitrogen. These substituents altered the course of the photo-inactivation curves of the phage. The slope of the individual inactivation curves permitted the determination of the binding constants of these derivatives in vivo. The constants are in agreement with the data of Löber (Photochem. Photobiol. 8, 23, 1968) for complexes of these dyes with thymus DNA. The ability of the derivatives of acridine orange to form aggregates in the concentration rangs of $10^{-2}-10^{-6} \mathrm{M}$ was also examined. This ability was compared with results obtained during photodynamic inactivation in vivo.
Effect of UV Radiation on the Inactivation of Lambda Bacteriophage with Hydoxylamine. I. KORĆর KovÁ, Z. HradeČná, Biophysical Institute, Czechoslovak Academy of Sciences, Brno.

The inactivation of the lambda phag with hydroxylamine was followed in dependence on irradiation of the phage with small doses of UV light The bacteriophage was irradiated either before or after treatment with hydroxylamine. It was found that low doses of UV light may affect the sensitivity of the bacteriophage to hydroxylamine. If the phage is irradiated before applying hydroxylamine, the phage resistance to hydroxylamine is increased. If the phage is irradiated after treatment with hydroxylamine, a partial reparation of the damage caused by hydroxylamine takes place. Low doses of UV radiation have a protective effect and can actually repair the damage already caused. The mechanism of action of low doses of UV light on phage inactivation with hydroxylamine is now being studied.

Inactivating and Mutagenic Effect of Acridine Orange on sd Phage. J. Koudelika, A. S. KRIVISkII, V. V. Esfrova, Biophysical Institute, Czechoslovak Academy of Sciences, Brno, and Institute of Microbial Genetics, Moscow.

Both lethal and mutagenic effects of acridine orangs (AO) on free extracellular bacteriophage $s d$ were studied. It was found that the phage was strongly inactivated after treatment with $\mathrm{AO}$ at concentrations greater than $2 \cdot 10^{-5} \mathrm{M}$. At lower concentrations of $\mathrm{AO}$ no significant effect on the survival of the phage and on the mutation frequency was observed. The lethal effect of concentrated AO was accompanied by the mutagonic process: up to $15 \%$ mutants were formed under these conditions, most of them being apparently point mutations. The extent of inactivation and mutagenesis was dependent on the number of binding sites available for binding of $A O$ to DNA, temperature, and ionic strength. The activation energy for the lethal process calculated from the slopes of inactivation curves was $9.7 \mathrm{kcal} / \mathrm{mole}$ which is in agreement with the value obtained in vitro for strong binding of dye to DNA. Thus, the lethal process seems to be a consequence of strong $\mathrm{AO}$ binding (intercalation) to interphage DNA. The AO binding is also influenced by the conformation of DNA inside the phage particle which may thus modify both biological effects.

Effect of Streptomycin on the Reproduction and Phenotype Suppression of the T4 Bacteriophage. M. Pidra, Z. Hradečná, D. Toufarová, J. KouDékA, Biophysical Institute, Czechoslovak Academy of Sciences, Brno. 
The effect of streptomycin on the free phage was studied in the complex phage-host cell. All experiments were conducted with the host strain Escherichia coli BSTMr to exclude the lethal effect of streptomycin on the host cells. It was found that streptomycin does not affect the multiplication of $\mathrm{T}$ phages in host cells resistant to streptomycin and that it has no effect on phage adsorption to bacteria. The phenotype suppression caused by streptomycin in five amber mutants of $\mathrm{T4}$ was also investigated. The dependence between sup. pression and physiological function of the mutated gene was established. Application of the antibiotic did not affect the growth of amber mutants in a permissive strain CR63 which was sensitive to streptomycin. It was shown that the suppression proceeds under the same conditions evon in su-cells resistant to streptomycin.

Effect of Low Doses of UV Radiation on the Sensitivity of Bacteriophage to X-Irradiation. D. Tou, farová, Z. HradeĆná, Biophysical Institute Czechoslovak Academy of Sciences, Brno.

Low doses of UV light can affect the sensitivity of a bacteriophage to $\mathrm{X}$-irradiation. The effect of low doses of UV light was studied in the lambda phage and in the T-group phag 3 . It was shown that low doses of UV light to which the phage is exposed prior to $\mathrm{X}$-irradiation increase the resistance of the phage to $X$-rays. The increased resistance to $X$-irradiation was found in the lambda phage and in several phage mutants and in T3 and $\mathrm{T} 7$ phages. With $\mathrm{T} 2$ and $\mathrm{T} 4$ bacteriophages no increase in resistance was observed. Here, on the contrary, an increased sensitivity to the effect of $\mathrm{X}$-irradiation was observed after exposure to low doses of UV light. It follows from the results obtained that the sensitivity of the bacteriophage to X-irradiation depends on the composition of phage DNA.

Effect of the Alkylating Agent N,N-Dimethyl-2chloroethylamine on Escherichia coli Phages. M. Vizdalová, Biophysical Institute, Czechoslovak Academy of Sciences, Brno.

N,N-Dimethyl-2-chloroethylamine belongs to the alkylating agents which are known to have biological effects similar to those of ionizing radiation. We investigated here the effect of this agent on Escherichia coli phages. We used phages containing nucleic acids of different types, structure and composition: the double-stranded DNA phage T4 and lambda, the single-stranded DNA phage ФX174 and the single-stranded RNA phage fr. All the phages were clearly inactivated with $\mathbf{N}, \mathbf{N}$ dimethyl-2-chloroethylamine in spite of the fact that we were dealing here with a monofunctional alkylating agent. The higher sensitivity of doublestranded phages observed here as compared with the single-stranded ones is apparently associated with the differences in size of the phage particles and hence also in the nucleic acid content. The rate of inactivation of the phage by $\mathrm{N}, \mathrm{N}$-dimethyl2-chloroethylamine increases with increasing concentration of this agent up to a certain maximum and depends on the $\mathrm{pH}$ of the medium (it increases with decreasing acidity of the solution). Lethal damage to the phage-brought about by $\mathbf{N}, \mathbf{N}$. dimethyl-2-chloroethylamine cannot be repaired by ordinary repair processes. The result of reactivation by the host cells, reactivation multiplied by infection and reactivation by low doses of UV light was negative. The extent of lethal damage to the phage can be clearly decreased with the aid of protective substances. A high protective effect was found particularly with thiols. It is assumed that the protective effect of these compounds is due to a direct interaction of the free SH group of the thiol with the dimethylaminoethyl radical.

Possibility of Differentiation of Phage Strains with the Aid of Inactivation Effect of Some Physical and Chemical Agents. M. Vizdalova, E. JanovsKA, J. Pillich, M. Kř̀vánková, Biophysical Institute, Czechoslovak Academy of Sciences, Brno.

A great number of newly isolated bacteriophages requires a revision of the diagnostic tests used so far for the differentiation of phage strains. In phage diagnostics, morphological differences, differences in the effectivity spectrum and in immunological properties of phage strains are generally used. These criteria are in some cases unsatisfactory, e.g. for the differentiation of virulent polyvalent phages which are morphologically and serologically closely related and include the same range of hosts. In the present work we attempted to differentiate between 8 polyvalent staphylococcal phages (X, $\mathrm{PA}, 131,200, \AA / 5, \mathrm{~A} / 3,812$ and $\mathrm{PK}$ ) according to the inactivating effect of some physical and chemical agents: UV radiation, hydroxylamine and acridine orange. The results of the experiments show that. the phages examined differ mutually in their sensitivity to the agents used which could be made use of for classification and differentiation of phage atrains. 